\title{
Disaster management within the framework of a changing disaster landscape
}

Citation for published version (APA):

de Smet, H. (2017). Disaster management within the framework of a changing disaster landscape. [Doctoral Thesis, Maastricht University]. Datawyse / Universitaire Pers Maastricht. https://doi.org/10.26481/dis.20171116hds

Document status and date:

Published: 01/01/2017

DOI:

10.26481/dis.20171116hds

Document Version:

Publisher's PDF, also known as Version of record

\section{Please check the document version of this publication:}

- A submitted manuscript is the version of the article upon submission and before peer-review. There can be important differences between the submitted version and the official published version of record. People interested in the research are advised to contact the author for the final version of the publication, or visit the DOI to the publisher's website.

- The final author version and the galley proof are versions of the publication after peer review.

- The final published version features the final layout of the paper including the volume, issue and page numbers.

Link to publication

\footnotetext{
General rights rights.

- You may freely distribute the URL identifying the publication in the public portal. please follow below link for the End User Agreement:

www.umlib.nl/taverne-license

Take down policy

If you believe that this document breaches copyright please contact us at:

repository@maastrichtuniversity.nl

providing details and we will investigate your claim.
}

Copyright and moral rights for the publications made accessible in the public portal are retained by the authors and/or other copyright owners and it is a condition of accessing publications that users recognise and abide by the legal requirements associated with these

- Users may download and print one copy of any publication from the public portal for the purpose of private study or research.

- You may not further distribute the material or use it for any profit-making activity or commercial gain

If the publication is distributed under the terms of Article $25 \mathrm{fa}$ of the Dutch Copyright Act, indicated by the "Taverne" license above, 


\section{Disaster management within the framework of a changing disaster landscape}


(C) copyright Hans De Smet, 2017

Cover image: Hans De Smet (2016), Ilfracombe coast (UK)

Printing: Datawyse | Universitaire Pers Maastricht

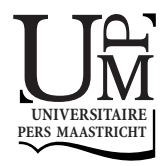

ISBN 9789461597656 


\title{
Disaster management within the framework of a changing disaster landscape
}

\begin{abstract}
PROEFSCHRIFT
ter verkrijging van de graad van doctor aan de Universiteit Maastricht, op gezag van de Rector Magnificus, Prof. dr. Rianne M. Letschert volgens het besluit van het College van Decanen, in het openbaar te verdedigen op donderdag 16 november 2017 om 10.00 uur door
\end{abstract}

Hans De Smet 


\section{Promotoren}

Prof. dr. M.G. Heijltjes

Prof. dr. Ir. J. Leysen (Royal Military Academy - Brussels, Belgium)

\section{Copromotor}

Dr. B. Schreurs

\section{Beoordelingscommissie}

Prof. dr. M.S.R. Segers (voorzitter)

Dr. P. Le Blanc (Technische Universiteit Eindhoven)

Prof. dr. A. Boin (Universiteit Leiden)

Dr. S. van der Haar 


\section{Proefschrift opgedragen aan}

Mieke, Arne \& Haakon, mijn gezin.

Als blijk van grote appreciatie voor jullie onverlaten steun tijdens de zeer intense periode oktober - november 2015.

Om het met een Nederlands spreekwoord samen te vatten:

'Eind goed, al goed'. 



\section{Contents}

List of Figures

List of Tables

Chapter 1 Disaster Research: Introduction, Literature Review and Overview of the Empirical Chapters

Framing the Issue

Disaster Research

Entering a New Area, a Major Challenge 18

Outline of the Dissertation $\quad 22$

Ongoing Disaster Research $\quad 27$

Chapter 2 Facing the Actual Disaster Landscape. A trend towards more Disasters out of the Box? 31

Abstract $\quad 32$

Introduction 33

The Shifting Nature of Hazards and Disasters

Towards Disasters of the $21^{\text {st }}$ Century 36

Disasters out of the Box and the Disaster Impact and Complexity Diagram 41

A Study of the Qualitative Shift in the Disaster Landscape 44

Discussion and Conclusion 48

Appendix A: The Disaster Impact and Complexity Diagram - Variables and Scales $\quad 50$

Appendix B: Generation of the Statistics, an Illustration 54

Appendix C: List of the Studied Disasters 56

Chapter 3 The Response Phase of the Disaster Management Life Cycle Revisited within the context of Disasters out of the Box 65

Abstract 66

Introduction 67

The Changing Disaster Landscape: More 'Disasters out of the Box' 68

Disaster Phase Research $\quad 69$

$\begin{array}{ll}\text { Method } & 71\end{array}$

$\begin{array}{ll}\text { Findings } & 77\end{array}$

Discussion $\quad 85$

Conclusion $\quad 89$

Note 90 
Chapter 4 Tightening the Reins or Letting Go: The Importance of Contingent Leadership when Dealing with Routine or Non-Routine Situations

Abstract

Introduction

Theory and Hypotheses Development

Method

Results

104

Discussion

Conclusion

Chapter 5 General Discussion and Conclusion

Concluding Remarks

Summary of the empirical findings

Theoretical Contributions

Practical Implications

Limitations and Areas for Further Research

Conclusion

References

Valorization Addendum

Nederlandse Samenvatting

Dankwoord

About the author 


\section{List of Figures}

Figure I-1: Dissertation research model 24

Figure II - 2: $\quad$ DI\&C-Diagram - Results for the individual disasters 45

Figure II - 3: $\quad$ DI\&C-Diagram - Results per time frame 46

Figure II - 4: $\quad$ Euclidian distance to absolute origin 47

Figure II - 5: $\quad$ Regression analysis of the Euclidian distance 48

Figure II - 6: Calculation of the score $\quad 55$

Figure II - 7: DI\&C position $\quad 55$

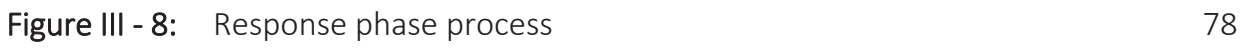

Figure III - 9: Event assessment process 83

Figure IV - 10: Contingency leadership model of multidisciplinary team decision quality 94

Figure IV - 11: Experimental sequence $\quad 101$

Figure IV - 12: Interaction of leadership style and environmental situation in $\begin{array}{ll}\text { predicting team decision accuracy } & 107\end{array}$

Figure IV - 13: Interaction of leadership style and environmental situation in predicting team decision speed 108

Figure IV - 14: Decision quality 111

\section{List of Tables}

Table I-1: Overview of the empirical studies 23

Table II - 2: $\quad$ Disaster Impact and Complexity Diagram variables and scales 50

Table III - 3: Interviewee sample selection $\quad 72$

Table III - 4: $\quad$ Responsive interviewing - Themes and concepts $\quad 74$

Table IV - 5: $\quad$ Descriptive Statistics and Correlations 105

Table IV - 6: $\quad$ Fixed Effects Estimates (Top) and Variance Estimates (Bottom) for Models Predicting Decision Accuracy 106

Table IV - 7: $\quad$ Fixed Effects Estimates (Top) and Variance Estimates (Bottom) for Models Predicting Decision Speed 108 

Chapter

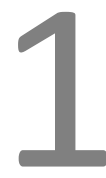

Disaster Research:

Introduction, Literature Review and Overview of the Empirical Chapters 

'Truth is eternal. Knowledge is changeable. It is disastrous to confuse them.'

M. L'Engle

\section{Framing the Issue}

Since the dawn of our existence, natural phenomena such as floods, storms, volcanic eruptions, earthquakes, landslides, etc. have affected our planet in an unpredictable way. However, these phenomena are merely classified as a hazard when they may affect people and the things they value (Cutter, 2005). These hazards are only one component of disaster. A disaster only occurs when a hazardous situation intersects with the human system (Perry, 1998). It is generally assumed that hazards and disasters originated when humans started to live in sedentary communities thousands of years ago, (see Balter, 2005; Lenski, Lenski, \& Nolan, 1991). Yet, the early inhabitants did not sit idly by to become easy victims. They started to take measures and developed means to reduce or mitigate the consequences of the disasters they faced (Coppola, 2011). Evidence of first hazard management practices date back to 3,500 BC. At that time, the Asipu, a group of consultants in ancient Mesopotamia, advised community decision makers about hazardous situations. They based their recommendations on a rudimentary process of decision analysis consisting of situational analysis and the proposal of alternatives including the possible outcomes (Covello \& Mumpower, 1985). The development of emergency management procedures to reduce the impact of disasters follows this ancient tradition. When necessary, the procedures were adapted, based on lessons learned from the past, and the modified ready-made response measures were implemented (Boin \& Lagadec, 2000; Kirschenbaum, 2004).

Applying emergency management procedures is part of what is generally referred to as the field of emergency management, which is defined as "the discipline and profession of applying science, technology, planning, and management to deal with extreme events [... which] are called disasters" (Drabek \& Hoetmer, 1991, p. xvii). The definition emphasizes that disaster research contributes to our understanding of emergency management by providing conceptual and practical tools for emergency managers. Consequently, the community of practitioners largely relies on established research findings, data that have to be collected with systematic methods, and academic recommendations to improve the means to cope with and survive disasters (Rossman, 1993).

This first chapter provides an introduction to the field of disaster research in order to give the reader a framework of understanding for the research setting and for the subsequent empirical chapters of this dissertation. First, a comprehensive literature review summarizes the core concepts of disaster research. Next, the actual situation, as 
well as the problems involved, is elucidated. Important mutations in the disaster landscape confront researchers, public authorities, disaster managers and emergency workers with major challenges, so further research is imperative. We have to rethink the issue if we want to stay well prepared to deal with future events and do not want to lose legitimacy (Ripley, 2008). This brings us to the core of the dissertation; the main research question, including the subsequent research objectives. Finally, the empirical studies of this dissertation are outlined.

The initial research of this dissertation, i.e. the literature research described in this chapter and the empirical studies presented in the Chapters 2 and 3, dates back to the years 2010-2011. However, since that period a lot of additional research on the subject of disasters of the $21^{\text {st }}$ century or mega-crises has been carried out. On that account, I added a final paragraph to this chapter, entitled 'Ongoing Disaster Research', in which I highlight some of the recent crisis and disaster related research orientations.

\section{Disaster Research}

Quarantelli, one of the most prominent scholars in disaster research, emphasizes that "[w]henever we want to research or discuss the consequences of any phenomenon, we need to have a clear idea of what that phenomenon is" (1985, p. 41). This implies that we need agreement about what a disaster is, and that we must create a clarifying definition that assists to distinguish disasters from other phenomena (Britton, 2005).

Laypeople usually associate the meaning of the word 'disaster' with how it is presented in the media (Couch, 2000). For the media, who essentially focus on dramatic visuals, a disaster assumes a symbolic value as a spectacle. However, the symbolic aspect can lead one away from real understanding (Alexander, 2005), or as Barkun stated (1974, p. 51), the term disaster is "easier to recognize than it is to define". Accordingly, Quarantelli admits that during his entire career, he has struggled to define and conceptualize the term 'disaster' (Quarantelli, 1995). He even realizes that we "should accept and recognize that there cannot be one all-purpose term with a single referent that can meet all the needs [...] and be useful for all users" (1987b, p. 22).

The notion disaster means many things to many people (Perry, 2007). The proposed definition depends on the purpose of interest of the definer (Kirschenbaum, 2004; Perry, 2007) and the scientific discipline using the term (Shaluf, Ahmadun, \& Said, 2003). Consequently, a universally accepted disaster definition doesn't exist, implying that there are many definitions available and that the concept remains rather vague (Britton, 2005; Eshghi \& Larson, 2008; Kreps, 1989; Perry, 2007). Over time, substantial change has taken place in defining disasters; changes which reflect the varying contexts in which disaster research has been done and which have impacted on research, knowledge accumulation and policy decisions (Peek \& Mileti, 2002; Perry, 2007). 


\section{Changing Definitions and Adapting Disaster Research Approaches}

In the introduction of his dissertation on the 1917 explosion in the Halifax harbor, Prince states (1920, p. 7): "[...] this work, which the author believes to be the first attempt to present a purely scientific and sociological treatment of any great disaster [...]". Ever since, it is commonly acknowledged that Prince's work was the first methodical disaster study (Scanlon, 1988). Though Prince defines the term disaster, it is not his first priority (Prince, 1920, p. 14): "To define the term catastrophe is scarcely necessary". Avoiding an explicit definition of the term disaster was rather common during the early decades of disaster research because of the supposition that anyone who conducts research for disasters must have at least an image or conception of the phenomenon (Quarantelli, 1985).

The earliest disaster research was based on the assumption that certain events (natural, man-made, etc.) generate significant negative effects on people, groups or societies (Perry, 2007). As such, a disaster has a discernible physical referent and is considered as 'something' from the outside which disrupts people's normality (Dombrowsky, 1981). That 'something' is called a disaster agent such as an earthquake, a flood, a chemical explosion, etc., and generates a disaster of the same name. A suchlike approach of defining disasters implies that different causal disaster agents engender different types of disasters with distinguishable characteristics (e.g. a flood is different from an explosion). Since knowledge of one agent tells nothing about another, early disaster research consisted of different studies which were often of a very diverse nature.

Dombrowski (1981) labeled the early disaster definitions and the related studies as un-sociological ones. However, a decade after the publication of Prince's dissertation, Carr already set disasters within the context of social life (1932, p. 211): "So long as the ship rides out the storm, so long as the city resists the earth-shocks, so long as the levees hold, there is no disaster. It is the collapse of the cultural protections that constitutes the disaster proper." As such, disasters were seen as manifestations of the vulnerabilities of social systems (Quarantelli, 1987b), or as events which are inherently rooted in social change (Perry, 2007). The growth of systematic disaster research in the social sciences started in the 1960s, with the publication of Fritz's disaster definition (1961, p. 655): "[A disaster] is an event, concentrated in time and space, in which a society, or a relatively self-sufficient subdivision of a society, undergoes severe danger and incurs such losses to its members and physical appurtenances that the social structure is disrupted and the fulfillment of all or some of the essential functions of the society is prevented." Social disaster studies emphasize the social disruption attendant to the cause and only use the disaster agent as a catalyst to the cause. As such, disasters are essentially seen as events that destabilize the social system (Porfiriev, 1998).

Over the years, the emphasis has shifted from disaster constructs focusing on a physical agent towards socially oriented constructs, which coincides with an evolution of a disaster agent-specific approach of studying disasters toward a generic approach 
(Quarantelli, 1985). The traditional agent-specific approach is generally used by researchers who are interested in hazards, such as geologists and meteorologists. They view a disaster as a severe event that occurs when a hazard intersects with a social system (Burton, Kates, \& White, 1978) so their focus is on the hazard and understanding it, not on the disaster caused by the event. However, since the end of the 1960s, hazard researchers put increasing focus on vulnerability and mitigation measures and consequently start to examine disasters in more social terms. Alexander (2005) for example states that disasters are not only the events but also the social consequences of the event, and Quarantelli (2005) argues that the focus of disaster research should be on the social nature of the events and not on the hazards causing them. Putting the emphasis on the hazards leads to treating disasters as epiphenomena (Quarantelli, 2005). After all, little can be done about hazards, while much can be done to the social systems which are the real sources of vulnerability.

This general point is consistent with the view of social science scholars who agree that disasters are inherently social phenomena (Dombrowsky, 1998; Gilbert, 1998; Rosenthal, 1998). If there are no negative social consequences, there is no disaster, or as Albala-Bertrand (1993, p. 10) observes: "without people there can be no disaster". As such, disasters are seen as stemming from human induced vulnerability (Gilbert, 1998). The social oriented disaster constructs impose to concentrate on the properties of the social occurrence of a disaster instead of the specific characteristics of its agents and physical impact. Consequently, the nature of the collective response becomes important, which entails a generic approach to disasters with a focus on disaster planning, response and preparedness (Peek \& Mileti, 2002; Quarantelli, 1985).

\section{Disaster and Related Constructs}

In their quest to find an acceptable definition of disaster, researchers normally try to find an overall construct, which actually captures too much (Quarantelli, 2005). In this paragraph, I briefly clarify the concepts which are generally related to disasters and subsequently present my working definition used within the framework of this research.

\section{Crisis and Disasters}

Though the notions crisis and disaster are often used synonymously, they are two theoretical different constructs (Boin, 2005). Crises can be defined as "transitional phases during which the normal ways of operating no longer work" (Boin et al., 2005, p. 2). The term refers to an unexpected and most unwanted situation, necessitating important decisions. The authors point out that this definition is rather subjective in nature, because it is an elite construction: we speak of a crisis when decision-making authorities experience the situation as such (Boin, 2005). In general terms, a crisis is seen as a disruption of normality (Boin, 2005), a decisive moment (Davies \& Walters, 1998), and a turning point between possible good and bad endings (Stallings, 2005). Crises thus are 
not necessarily bad as specified by Fink (Fink, 2002, p. 15): "a crisis is an unstable time of state of affairs in which a decisive change is impending-either one with the distinct possibility of a highly undesirable outcome or one with the distinct possibility of a highly desirable and extremely positive outcome." Disasters by contrast are negative events. A disaster can be seen as a "crisis with a bad ending" (Boin, 2005, p. 163). Therefore, many scholars argue that disasters are part of a 'larger class of events' (Perry, 2007; Quarantelli, 1998; Stallings, 2005).

\section{Hazards and Risks, Vulnerability and Resilience}

Two other terms which are related and often cause confusion are hazard and risk. The Federal Emergency Management Agency defines a hazard as (1997, p. xxv) "an event or physical condition that has the potential to cause fatalities, injuries, [...] damage". In the body of disaster literature the term hazard typically refers to anything (e.g. a condition, a situation, a practice, etc.) that has the potential to cause harm and thus constitutes a source of risk (Cohrssen \& Covello, 1989). Though in popular speech the concepts hazard and risk are often used interchangeably, risk is more than the mere existence of a hazard (Waring \& Glendon, 1998). One of the most widely used definitions of risk is that risk is the likelihood of an event occurring multiplied by the consequences of that event (Ansell \& Wharton, 1992, p. 100). The definition implies that by reducing either the likelihood of a hazard or the potential consequences that might result, the risk is reduced. For that reason, many researchers make a link to the notions vulnerability and resilience. Vulnerability can be defined as "being prone to or susceptible to damage or injury" (Wisner, Blaikie, \& Davis, 2004, p. 11), resilience as "a measure of propensity to avoid loss" (Coppola, 2011, p. 29). As such, both notions constitute a measure of how well a system (e.g. an infrastructure, a person, a society, etc.) can cope with or sustain a risk. For that reason, it is important to note that vulnerability and resilience have both temporal and spatial dimensions, are contextual and only have meaning with respect to hazard. Consequently, vulnerability and resilience vary by location and over time (Hill \& Cutter, 2001).

\section{A Plethora of Definitions}

Two decades ago, Kaplan declared (1997, p. 408): "50\% of the problems in the world result from people using the same words with different meanings. The other $50 \%$ comes from people using different words with the same meaning." To describe and classify disastrous events, researchers have proposed a hierarchy of terms generally taking into account organizational involvement (Quarantelli, 1987b). Unfortunately, the conundrum of definitions often creates disagreement and confusion (Perry, 1989). To avoid the Kaplan dilemma, I now briefly clarify the terms which are commonly used to describe events of various magnitudes.

At the lower side of the hierarchy of terms, common events such as accidents and emergencies are presented. Both types of events do not disrupt the social order and 
can be routinely handled with local resources. An accident is defined as "an unexpected or undesirable event, especially one causing injury to a small number of individuals and/or modest damage to physical structures" (Drabek, 1996, p. 3). An emergency is "an unexpected occurrence or sudden situation that requires immediate action" (Porfiriev, 1995, p. 291), "through the use of routine community resources and procedures" (Drabek, 1996, p. 3). At the upper side of the hierarchy, more severe types of events such as disasters and catastrophes are presented. Events of this nature disrupt the social order and require resources beyond the capability of the affected community (Kreps, 1995). The difference between the two types of events is the degree of severity. While a disaster is a "non-routine event that exceeds the capacity of the affected area to respond to it" (Pearce, 2000, p. 22), a catastrophe exceeds all ability to respond so that "new organizations must be created in order to deal with the situation" (Quarantelli, 1987b, p. 25).

\section{Disaster, a Working Definition}

After an extensive study of literature, I developed the following working definition of disaster within the framework of this dissertation: 'A disaster is an event, caused by a triggering agent (or triggering agents), which disrupts a social system or even an entire society in a way that the available local emergency capacities are overwhelmed so that an effective handling of the situation is impossible.'

\section{Entering a New Area, a Major Challenge}

\section{Are we Facing Mutations in the Disaster Landscape?}

Decades of research has established a rich knowledge of disasters and toolkits of best practices to deal with these events (Lagadec, 2009a). However, since the end of the last century, several researchers point out that the disaster landscape is fundamentally changing shape. One trend is that the frequency of disasters has significantly increased since the second half of the $20^{\text {th }}$ century and the total number of people affected each year is dramatically rising (Eshghi \& Larson, 2008; Granot, 1998; Kirschenbaum, 2004; Rasmussen \& Batstone, 1989). As well, academics warn that there is a strong notion that several kinds of disasters are evolving into what they name modern disasters or disasters of the $21^{\text {st }}$ century (Boin \& Lagadec, 2000; Rosenthal, 1998), crisis emergencies (Leonard \& Howitt, 2007), or mega-crises (Helsloot et al., 2012b; Rosenthal, 2009). They argue that modern disasters are not just about more of the same. They add to the historical ones that remain with us, but are also different in important ways (Quarantelli, Lagadec, \& Boin, 2006). A qualitative leap in the evolution of the disaster landscape is the essence of the challenges we face, as described by Lagadec: "[...] the 'good old' crises of the 1980s and 1990s, with their confined stage and still relatively simple rules, 
are undergoing mutations. That leap was in fact the crux of the Katrina challenge and fiasco" (Lagadec, 2009a, p. 476).

\section{Katrina, Just Another Hurricane ..., or Just Not.}

Hurricane Katrina came about in the typical way as the majority of the tropical hurricanes that strike the Caribbean and North America; a tropical disturbance that emerges off the west coast of Africa and then drifts west into the Atlantic Ocean (Cooper \& Block, 2006; Hyndman, Hyndman, \& Catto, 2008; Lin, Robertson, \& Hill, 2000). The $12^{\text {th }}$ tropical depression of the 2005 Atlantic hurricane season was first observed on August $23^{\text {th }}, 2005$ (National Hurricane Center, 2005c). At that time, the inhabitants of the Gulf Coast of the United States did not much worry about this meteorological phenomenon. However, several forecast models indicated that depression $\mathrm{N}^{\circ} 12$ would move along mainly western track direction Florida and the Gulf of Mexico, and they warned that it would soon strengthen into a tropical storm or even worse (Knabb, Rhone, \& Brown, 2005).

On the morning of August $24^{\text {th }}$, depression $N^{\circ} 12$ strengthened into the tropical storm Katrina. A few hours before it made landfall in South Florida the next morning, it became a Category-1 huricane on the Saffir_Simpson Huricane Scale (Hyndman et al., 2008). Since Katrina spent only about seven hours over land in crossing Florida, its strength did not significantly diminish (National Hurricane Center, 2005a). Moreover, once entering the warm waters of the Gulf of Mexico, the storm quickly began an impressive cycle of intensification that finally culminated in a category 5 hurricane on the morning of August $28^{\text {th }}$. At that time it became clear that the eye of the by then immense hurricane would head to the New Orleans Metropolitan area. Specialized services such as and the National Hurricane Center (2005b) and the National Weather Service (2005) warned of catastrophic damage that would be caused by the storm and in particular by the accompanying massive storm surge. As a consequence of these alarming reports, New Orleans Mayor Ray Nagin issued the first-ever mandatory evacuation of the city (Brinkley, 2006; Senauth, 2007).

On Monday morning August, 29 at 06.10 AM, Katrina made its second landfall as a fast moving Category 3 hurricane. Although the hurricane did not maintain its frightening Category 5 intensity, it still remained a storm of epic proportions and became one of the most devastating and deadliest natural disasters in United States history. The total number of fatalities reported to be either directly or indirectly related to the hurricane is over 1,800 (Knabb et al., 2005). Over 2 million people were displaced (O'Keefe, 2007) and over 300,000 homes were destroyed or made unlivable (Collins, 2006). The Federal Emergency Management Agency (FEMA) declared that the area affected by Katrina was 233,000 square kilometers, an area almost the size of the United Kingdom and covering the states of Alabama, Mississippi, Louisiana and Texas (Kromm \& Sturgis, 2008; Steiger, 2008). Although Katrina caused widespread devastation all along the central Gulf Coast, 
the city of New Orleans suffered utmost. By August 31, over $80 \%$ of the Greater New Orleans area flooded due to a failure of the city's hurricane protection system (Van Heerden, 2007).

Along with this destructive natural disaster, Americans were confronted with major failures of government performance at all levels of the federal system. While local authorities were already completely overwhelmed from the first moments Katrina came ashore in the New Orleans area, the Secretary of Homeland Security declared the event to be an Incident of National Significance the next day, the first ever formal declaration of this designation (Townsend, 2006). The announcement triggered the recently developed National Response Plan (NRP), which was mandated by President Bush in the aftermath of 9/11, and which granted the Department of Homeland Security (DHS) the right to provide coordination for federal support to on-scene incident command structures (Brinkley, 2006). While NRP looked good on paper and in training exercises, DHS was an untested organization, unsure of how to deploy its authority and resources. A key failing of DHS leadership was the inability to understand Katrina as an incident of national significance on par with 9/11 (Moynihan, 2009). Local, State and Federal responses were uncoordinated and repeatedly late (Senauth, 2007). Many issues of coordination, jurisdictional authority and resource allocation still had to be worked out while the disaster was unfolding (Lester \& Krejci, 2007). American authorities demonstrated that they were incapable of managing a predicted disaster in an efficient and effective way (Friedling, 2005). Accordingly, the event became a symbol of the omnipresent ineffectiveness of the existing emergency management systems in the case of a major disaster. This lead to three major investigations executed by the White House (Townsend, 2006), the House of Representatives (Davis, 2006) and the Senate (Collins, 2006).

The general connotation of the three reports is resumed in some striking quotations: "Hurricane Katrina found us -still- a nation unprepared for catastrophe" (Collins, 2006, p. iii); "Our current system for homeland security does not provide the necessary framework to manage the challenges posed by $21^{\text {st }}$ Century catastrophic threats" (Townsend, 2006, p. 52); "We must expect more catastrophes like Hurricane Katrinaand possibly even worse. In fact, we will have compounded the tragedy if we fail to learn the lessons-good and bad-it has taught us and strengthen our system of preparedness and response. We cannot undo the mistakes of the past, but there is much we can do to learn from them and to be better prepared for the future. This is our duty." (Townsend, 2006, p. 65); "Avoiding past mistakes will not suffice. Our leadership and systems must be prepared for catastrophes we know will be unlike Katrina, whether due to natural causes or terrorism" (Collins, 2006, p. 19), and "With Katrina, there was no shortage of plans, but there was not enough plan-ning. [...] If 9/11 was a failure of imagination, then Katrina was a failure of initiative. It was a failure of leadership." (Davis, 2006, p. xi). 


\section{Demanding Challenges - Research Question and Objectives}

Hurricane Katrina is but one example that demonstrates that several modern disasters take on new dimensions. Since the beginning of the third millennium, we have witnessed similar major events such as the 9/11 attack (2001), the SARS outbreak (2003), the widespread Northeast blackout (2003), the Southeast Asia Tsunami (2005), the Kashmir earthquake (2005), the Haitian earthquake (2010) the Deepwater Horizon oil spill (2010), etc. If a general trend toward more disasters of the $21^{\text {st }}$ century is a fact, it means that the traditional emergency management skills and capacities are challenged to a large extent. In such a context where "[d]isasters create difficulties, even for those who study disasters" (Rodríguez, Quarantelli, \& Dynes, 2006, p. xiii), simply extending existing methods and practices to the challenges of modern disasters may be suboptimal (Miller, 2001) or even counterproductive (Boin \& Lagadec, 2000). A "more of the same" logic thus becomes outdated to a large extent (Lagadec, 2009a, p. 473). Consequently, disasters of the $21^{\text {st }}$ century confront researchers, public authorities, disaster managers and emergency workers with major challenges. If we want to avoid to be continually one disaster behind (Davis, 2006), we have to rethink the issue. Consequently, further research is imperative.

The key objective of this dissertation is to facilitate a better understanding of the main consequences of a mutating disaster landscape and to provide scholars and practitioners with a more comprehensive view of modern disaster management. Therefore, the general research question was defined as following: 'Are modern disasters marked by important mutations, and if this is the case, what are the major consequences for the intervening emergency management organizations and for the people leading those organizations?' In pursuing the main objective and in order to contribute to the literature, partial research questions and related objectives were investigated in the three empirical chapters of the dissertation.

The first gauntlet to take up was to investigate whether or not there is a mutation of the disaster landscape towards more disasters of the $21^{\text {st }}$ century which are qualitatively different. Though the trend is credible, no academic study has been found in the existing disaster literature confirming such a qualitative evolution. Hence, the first specific research question was: 'How much evidence is there to support the hypothesis that there is a trend towards more disasters of the $21^{\text {st }}$ century which are qualitatively different from historical ones? (Q1)'. The related objectives were:

- Based on a study of literature, to identify the main characteristics of disasters of the $21^{\text {st }}$ century and lay bare the consequences for the responding units of emergency management organizations;

- To develop a tool permitting to study the qualitative aspects of disasters;

- To use the newly developed tool, carry out a longitudinal study of a set of randomly selected disasters in order to determine trends over the years. 
The results of the first study confirmed the trend towards more disasters of the $21^{\text {st }}$ century. This implies that societies will be more greatly affected in the future, but also that the work of the responding units of emergency management organizations will be more heavily challenged. The second partial research question then is defined as: 'How can we re-conceptualize the response activities of intervening units of emergency management organizations within the context of disasters of the $21^{\text {st }}$ century? (Q2)'. The related research objectives are:

- To study the existing disaster phase research, with a special attention to the response phase of the disaster management life cycle;

- To expose the weaknesses of the response phase within the context of disasters of the $21^{\text {st }}$ century;

- To carry out an in-depth study of the response phase of the disaster management life cycle in order to remodel the phase, focusing on a new and fresh approach.

Quarantelli et al. (2006) emphasize that disasters of the $21^{\text {st }}$ century do not replace the kind of disasters we have always known. They add to the historical ones that remain with us, which implies that emergency management decision-making teams have to make fast and accurate decisions for events which vary widely in complexity. For that reason, we formulated the third partial research questions as: 'Which leadership style yields the best performance when an emergency management decision-making team is confronted with real world situations that vary in complexity? (Q3)'. The associated objectives are:

- To advance a contingency leadership model of multidisciplinary team decision quality;

- To investigate whether the effect of leadership style on team decision quality depends on the environmental situation (routine vs non-routine situations) wherein multidisciplinary teams are operating.

\section{Outline of the Dissertation}

In pursuing the main objective and in order find answers to the formulated research questions, I conducted three empirical studies, which are outlined in detail in the following paragraph. Each of these studies has been published (Chapters 2 and 3) or is under consideration (Chapter 3) and was co-authored by others, the reason for which these chapters are written from a first person plural point of view. In Table I - 1 each study is presented with its core research question, the methodology used, and the main 
findings. In addition, and for illustrative purpose, the overall research model is presented in Figure I - 1.

Each chapter represents a self-contained empirical study which can be read independently. Consequently, some parts of the dissertation will be redundant to the reader, especially the literature review and the related theoretical background. As I used three different methodologies to study the research questions, the redundancy is mostly limited to the introduction parts of the manuscript.

Table I - 1: Overview of the empirical studies

\begin{tabular}{|c|c|c|c|c|}
\hline $\begin{array}{l}\text { Research } \\
\text { Question }\end{array}$ & Study & Sub-questions & Methodology & Main findings \\
\hline \multirow{3}{*}{$\begin{array}{l}\text { Are modern } \\
\text { disasters marked } \\
\text { by important } \\
\text { mutations, and if } \\
\text { this is the case, } \\
\text { what are the } \\
\text { consequences for } \\
\text { the intervening } \\
\text { emergency } \\
\text { management } \\
\text { organizations and } \\
\text { for the people } \\
\text { leading those } \\
\text { organizations. }\end{array}$} & Study 1 & $\begin{array}{l}\text { Q1: How much } \\
\text { evidence is there to } \\
\text { support the } \\
\text { hypotheses that } \\
\text { there is a trend } \\
\text { towards more } \\
\text { disasters of the } 21^{\text {st }} \\
\text { century which are } \\
\text { qualitatively different } \\
\text { from historical ones? }\end{array}$ & $\begin{array}{l}\text { Conceptual } \\
\text { research } \\
\text { Brainstorming } \\
\text { (Osborn, 1963) } \\
\text { Estimate- } \\
\text { feedback-talk- } \\
\text { estimate (EFTE) } \\
\text { method (Nelms } \\
\text { \& Porter, 1985) }\end{array}$ & $\begin{array}{l}\text { The study of a randomly selected set of } \\
\text { disasters from } 1900 \text { until } 2010 \\
\text { demonstrates that we are facing a trend } \\
\text { towards more disasters of the } 21^{\text {st }} \\
\text { century }\end{array}$ \\
\hline & Study 2 & $\begin{array}{l}\text { Q2: How can we re- } \\
\text { conceptualize the } \\
\text { response activities of } \\
\text { intervening units of } \\
\text { emergency } \\
\text { management } \\
\text { organizations within } \\
\text { the context of } \\
\text { disasters of the } 21^{\text {st }} \\
\text { century? }\end{array}$ & $\begin{array}{l}\text { Qualitative } \\
\text { research } \\
\text { Responsive } \\
\text { interviewing } \\
\text { approach (Rubin } \\
\text { \& Rubin, 2005) }\end{array}$ & $\begin{array}{l}\text { The response phase evolves as a } \\
\text { comprehensive process through three } \\
\text { succeeding stages (paralysis, operational } \\
\text { response, and strategic response) } \\
\text { including some importing sub-processes } \\
\text { such as the gradual buildup of capacities, } \\
\text { the coordination process and the event } \\
\text { assessment process }\end{array}$ \\
\hline & Study 3 & $\begin{array}{l}\text { Q3: Which leadership } \\
\text { behaviors yield the } \\
\text { best performance } \\
\text { when an emergency } \\
\text { management } \\
\text { decision-making } \\
\text { team is confronted } \\
\text { with real-world } \\
\text { situations that vary in } \\
\text { complexity? }\end{array}$ & $\begin{array}{l}\text { Quantitative } \\
\text { research } \\
\text { (experimental } \\
\text { study) } \\
\text { Multilevel } \\
\text { modelling } \\
\text { (Bliese, 2013) }\end{array}$ & $\begin{array}{l}\text { Directive leadership style results in } \\
\text { better team decision accuracy when } \\
\text { dealing with routine situations, whilst in } \\
\text { the context of non-routine situations, } \\
\text { empowering leadership behaviors have } \\
\text { stronger effects. } \\
\text { Teams lead by a directive leader make } \\
\text { faster decisions in both routine and non- } \\
\text { routine situations. }\end{array}$ \\
\hline
\end{tabular}



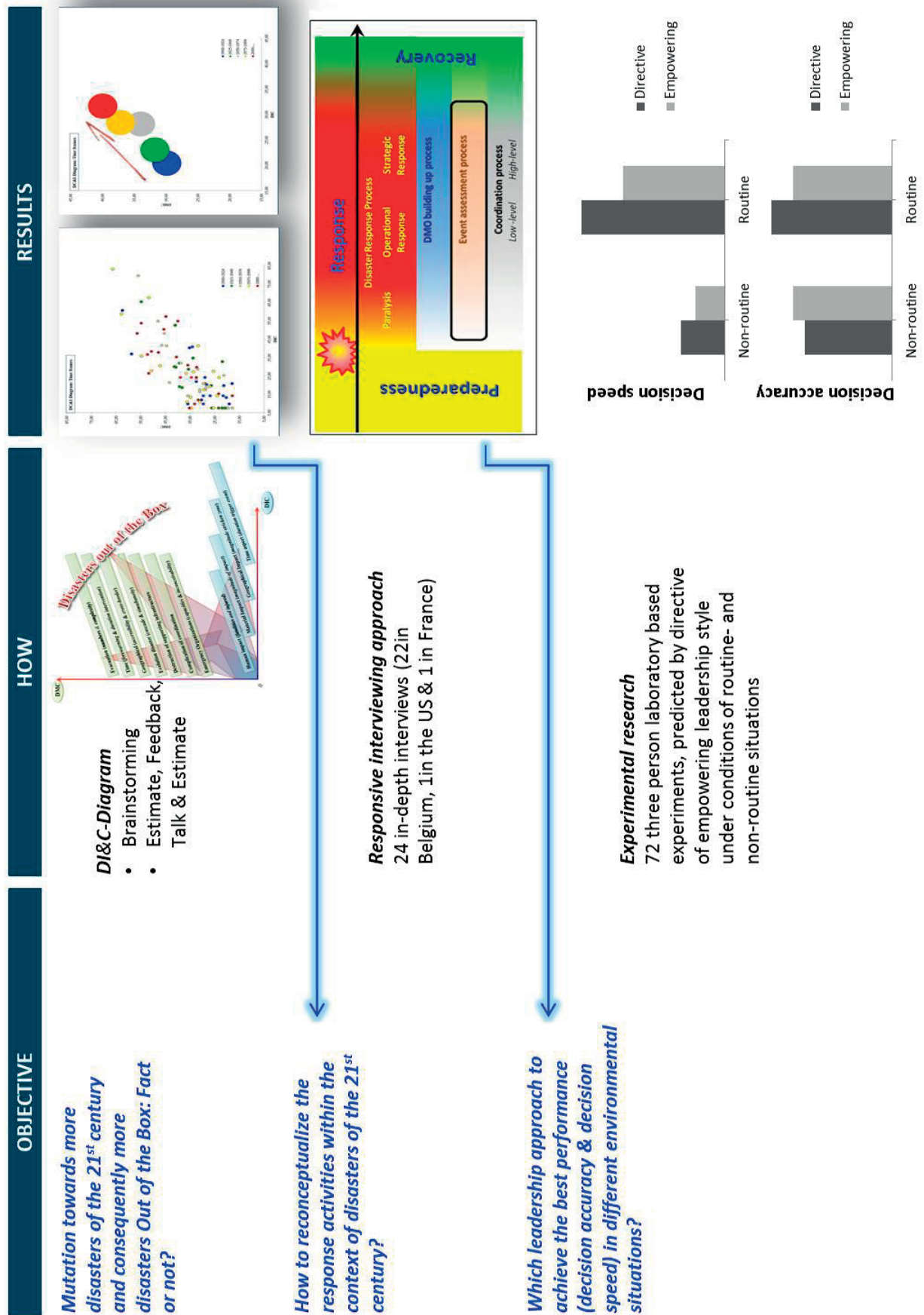

Figure I - 1: Dissertation research model 


\section{Overview Chapter 2}

Chapter 2 titled 'Facing the Actual Disaster Landscape. A trend towards more Disasters out of the Box?' focuses on the changing nature of modern disasters. Based on an extensive literature review, I identified the main features of disasters of the $21^{\text {st }}$ century impact and complexity- and then defined the notion 'disaster out of the box'. A disaster becomes 'out of the box' when it causes an organizational crisis to the intervening units of emergency management units and as a consequence disrupts their performance. In the analytical part of the conceptual research, I first developed the 'Disaster Impact and Complexity Diagram' (DI\&C-Diagram), a tool which allows the study disasters over time in order to determine qualitative trends. During a brainstorm session, academics having experience with risk, crisis and disaster management were asked to identify potential variables which can be related to the main features of disasters of the $21^{\text {st }}$ century. Next, they were requested to refine the identified variables applying the 'estimatefeedback-talk-estimate' (EFTE) method (Nelms \& Porter, 1985), which were then used to develop the DI\&C-Diagram. Subsequently, I used the DI\&C-Diagram to investigate 100 disasters that occurred between 1900 and 2010. The used dataset was randomly selected from the Disaster Database Project, developed by Green (2011).

The study contributes to the existing body of literature in the following key aspects. Firstly, by methodologically analyzing disasters from a qualitative point of view, the research provides evidence for the assumed qualitative shift in the disaster landscape. Findings confirm a trend towards more disasters of the $21^{\text {st }}$ century which have an increasing potential to become 'disasters out of the box'. It therefore sets the scene for a new understanding of modern disasters, not by finding ideal scripts to deal with the events, but by highlighting important points of interest.

\section{Overview Chapter 3}

Recent disaster studies essentially pay attention to reinforcing mitigation efforts and establishing resilient societies (McBean, 2012). Nevertheless, disasters continue to strike and disrupt entire societies (Coppola, 2011). Therefore, disaster response remains crucial in managing disasters, and it will even become more important, taking into account the results of the first empirical study which confirms the changing disaster context. Albeit researchers underline that we have to reassess our understanding of responding to disasters (Lagadec, 2009a; OECD, 2003; Robert \& Lajtha, 2002), the response phase of the disaster management life cycle has not been reevaluated. Therefore, the study in Chapter 3, entitled 'The Response Phase of the Disaster Management Life Cycle Revisited within the context of disasters out of the box', aims to remodel the response phase of the disaster management life cycle, focusing on an alternative and fresh approach. To get a deeper understanding of the impact of dealing with disasters of the $21^{\text {st }}$ century on the response activities, I relied on the knowledge of people hav- 
ing a considerable experience with emergency planning and disaster management. Data was collected and analyzed using the 'responsive interviewing approach' (Rubin \& Rubin, 2005).

The study reveals that the response phase is more than just a set of activities which aim at limiting injuries, loss of life, and damage to property and the environment. The data demonstrate that the response phase evolves as a comprehensive process through succeeding stages (paralysis, operational response and strategic response), encompassing important sub-processes such as the gradual buildup of capacities, the coordination process and the event assessment process. It therefore provides a key contribution to disaster scholarship and the existing disaster and emergency management literature.

\section{Overview Chapter 4}

Over the years, people have succeeded in developing means to cope with and survive disasters based on lessons learned (Kirschenbaum, 2004). Knowledge gained through experience allows disaster managers and emergency workers to respond to events which are understandable in terms of past disasters (Gundel, 2005; Hills, 1998). However, this is not the case in the event of disasters out of the box (Lagadec, 2009a). Therefore, in Chapter 4, titled 'Tightening the Reins or Letting Go: The Importance of Contingent Leadership when Dealing with Routine or Ron-Routine Situations.' I investigate whether the effect of leadership style on team decision quality as a measurement of team performance depends on the environmental situation wherein decision-making teams are operating.

In my study, I focused on two distinct leadership styles which have assumed special attention in leadership research, directive and empowering leadership (Lorinkova, Pearsall, \& Sims Jr., 2013; Sims Jr., Faraj, \& Yun, 2009; Srivastava, Bartol, \& Locke, 2006; Yun, Faraj, \& Sims Jr., 2005). With respect to environmental situations I considered routine and non-routine decision-making problems. Where existing literature demonstrates that the relative benefits of both styles of leadership on team performance remain unclear, I assumed that the directive leadership style will be more beneficial in routine situations whereas the empowering leadership style is better suited in nonroutine situations. Therefore, I first advanced a contingency leadership model of multidisciplinary team decision quality. Next I tested my hypotheses regarding the relationship between leadership style and team decision quality, including the moderating role of the environmental situation by relying on an experimental setting. In doing so, I hope to contribute to the existing leadership and team literature by introducing the possibility that the effect of leadership style on team decision quality depends largely on the context (i.e. the environmental situation). 


\section{Ongoing Disaster Research}

In 2009, an international working conference on Mega-crises was held in The Hague (Helsloot \& Rosenthal, 2009). The meeting was an excellent opportunity for the authors of an at that time upcoming book to discuss the concepts of their individual chapters (Helsloot et al., 2012a). In the book, different topics related to the new concept of mega-crises are elucidated: leadership (Leonard \& Howitt, 2012), case studies of several recent natural and man-made mega-crises (e.g.: Comfort, Siciliano, \& Okada, 2012; Harrald, 2012; Hellberg \& Muller, 2012), and insights on topics such as the early discovery of and preparation for mega-crises to happen (e.g.: Endter-Wada \& Ingram, 2012; Jacobs, 2012).

Scientists emphasize that a mixture of new threats and accruing vulnerabilities undermine the stability and prosperity of modern societies to a high extent (Boin \& Lodge, 2016; Kuipers et al., 2015). Unseen complexity and tight coupling of critical infrastructures are considered the main drivers of unanticipated events which can hardly been controlled (OECD, 2011; Perrow C., 1984). In that context, mega-disasters may gradually become "the new normal" (Tierney, 2014, p. 238). Governments usually focus much of their disaster management efforts on routine emergencies, i.e. those that have occurred many times before and will periodically reoccur ('t Hart, 2013). The impacts of these emergencies can straightforwardly be managed within the existing institutions and organizations, and societies resist by slightly adapting when sufficient pressure is brought to bear (Handmer \& Dovers, 1996). Hence, routine events do not lead to significant changes in societies (Birkmann et al., 2010). This applies much less strongly to mega-crises. To avert mega-crises, existing disaster management tools and resilience practices are insufficient and more fundamental changes are imperative (Birkmann et al., 2010; Tierney, 2014). Consequently, mega-crises can represent threshold events leading to more fundamental changes where dominant ways of thinking and acting are subject to critical review and revision (Birkmann et al., 2010).

A first evolution worth mentioning in academic thinking is related to the recent convergence between two traditional strands of research: the study of risk and crisis 'management' (safety-oriented) and the study of risk and crisis 'politics' (security-oriented) ('t Hart \& Sundelius, 2013). The actual research focus has shifted towards generic societal vulnerabilities regardless of the source of the threat. Integrated approaches to studying crisis and disaster management have become the norm ('t Hart \& Sundelius, 2013; e.g.: Alpaslan \& Mitroff, 2011; OECD, 2011). The central concern of both practitioners and academics is to enhance organizational, governmental and societal resilience ('t Hart \& Sundelius, 2013; Stark, 2014). However, in the face of an ever-expanding risk catalogue, containing many unknowns, stakes are extremely high. Consequently, the assessment of potential mega-disasters demands a sophisticated mix of expertise and thus requires a multidisciplinary approach (OECD, 2011). 
Boin and Lodge highlight that the political-administrative systems in place are "easily outmatched by new and unforeseen threats" (Boin \& Lodge, 2016, p. 290). The study of several modern disasters (e.g.: 't Hart, 2013; Harrald, 2012; Roberts, 2013) have made clear that administrative personnel and political leaders usually find it hard to deal with the dynamics of disasters. The academics also found that the public administration community has been very absent up to now in the debates about designing institutions that protect against mega-crises. Therefore, they argue that the time has come for public administration researchers to incorporate disaster management into their research agenda (Boin \& Lodge, 2016).

A third point of particular interest in the current crisis and disaster literature is related to transboundary crises within the European Union. European integration has made the EU member states very vulnerable to transboundary crises, which stretch across geographical borders and national systems (OECD, 2003; OECD, 2011). National governments cannot deal with these crises unilaterally. Managing them effectively requires joint response and good cooperation with the international partners (Rhinard, 2009), which creates serious political and administrative challenges (Ansell, Boin, \& Keller, 2010; Nohrstedt, 2013). Since the beginning of the $21^{\text {st }}$ century, the EU has developed several joint crisis management capacities and sense-making tools (i.e. tools that aim at the collection, analysis, and sharing of information), which are clearly explored and analysed by Boin, Rhinard and Ekengren (Boin, Ekengren, \& Rhinard, 2014; Boin, Rhinard, \& Ekengren, 2014). The researchers conclude that efforts to enhance transboundary coordination and information sharing is a work in progress which moves slowly, and that the EU is still far removed from acting in an autonomous fashion since capacities have barely been institutionalized: "member states maintain full authority and choose which tasks to delegate to the EU" (Boin et al., 2014, p. 140). This implies that any joint response to a transboundary crisis requires the cooperation and the resources of one or more member states (Kuipers et al., 2015). As the existing civil protection systems of the EU member states still constitute the core elements of any European transboundary response system, Kuipers et al (2015) carried out a comparative study of these systems in 22 European states. The researchers found that the national civil protection systems differ markedly, but underline that the diversity does not inherently need be seen as an obstacle to good crisis management as long as there is no lack of trust in national crisis management systems. Based on their findings, the researchers plead for a nuanced approach with regard to the future EU roles in transboundary crisis management. In their opinion, the EU should rather expand its role a 'promotor', a 'facilitator' and a 'connector' for member state cooperation (Kuipers et al., 2015).

Since the publication of Prince's dissertation on the 1917 Halifax harbor explosion (Prince, 1920), research on disasters has proliferated. In the course of a century, an innumerable amount of studies has generated a wealth of observations, lessons and generalizations. Such forms of knowledge transfer are indispensable to understand the conception of the phenomenon 'disaster', and are particularly essential to facilitate the 
work of disaster practitioners and emergency workers who are responsible of managing these events in an effective way. However, modern societies advance and change at an incredible speed and therefore face daunting new and unforeseen security challenges (Kuipers et al., 2015). The threats we face today are more numerous, more substantial and more complex than ever before. As a consequence, the work of disaster researchers and emergency practitioners is never done, it is a never ending story (NYC Emergency Management, 2014). 



\section{Chapter}

\section{Facing the Actual Disaster Landscape. A trend towards more Disasters out of the Box?}

This chapter sets out the manuscript: De Smet, H., Schreurs, B., \& Leysen, J. (2014b). Facing the actual disaster landscape. A trend towards more Disasters out of the Box? In Etkin D. \& Murphy B.L. (Eds.), Disaster and Emergency Management in Canada (pp. 131). Vancouver, CA: CRHNET.

Earlier versions of the text were published as a magazine article and presented at a conference in 2012 as:

De Smet, H., Lagadec, P., \& Leysen, J. (2012). Disasters out of the Box: A a New Ballgame? Journal of Contingencies and Crisis Management, 20, 138-148.

De Smet, H., Leysen, J., \& Lagadec, P. (2011). De Smet H. \& Leysen J., A Significant Evolution of the Disaster Landscape. In Lim G. \& Herrmann J.W. (Eds.), Proceedings of the 2012 Industrial and Systems Engineering Research Conference; Orlando, FL, May 1923, 2012. 


\section{Abstract}

Given recent disaster research, it seems that our planet has become a more dangerous place to live than ever before. Despite the rapid progress of knowledge and technology, millions of people have been killed, seriously injured or materially afflicted by some kind of disaster, which is the consequence of important changes in the current disaster landscape. On the one hand, disaster statistics indicate that there has been a general increase in the quantity of disasters since the second half of the last century. On the other hand, disaster researchers also mention a qualitative shift in the disaster landscape, challenging the existing emergency management skills and capacities. Unfortunately, no academic study has been found in disaster literature proving such an evolution. In order to be better prepared for future disasters, it is indispensable to study the qualitative change in the disaster landscape further in depth. In this chapter, we first discuss the changing nature of hazards and the ensuing disasters, as well as the driving forces behind this evolution. Then we concentrate on the existing theoretical approach regarding the evolution of the disaster landscape and essentially focus on the main characteristics of modern disasters as described in literature. These characteristics are then used for the development of the 'Disaster Impact and Complexity Diagram', a tool which examines disasters from the perspective of impact and complexity in order to determine trends over the years. The last section of the chapter deals with a study of a set of randomly selected disasters from 1900 until 2010, using the DI\&C-Diagram. Findings are discussed and important points of interest in dealing with modern disasters are highlighted. 


\section{Introduction}

On Friday March 11, 2011, at 02:46 p.m. JST (00:46 a.m. EST), a 6-minute undersea megathrust earthquake occurred in the western Pacific Ocean. The epicentre of the earthquake was situated at approximately $70 \mathrm{~km}$ east of the Pacific coast of the Tohoku region (north-eastern portion of Honshu, the largest island of Japan) and its hypocenter at an underwater depth of circa $30 \mathrm{~km}$. This Great East Japan Earthquake is the most powerful known earthquake in recent history of Japan and one of the five largest earthquakes of the modern era (Ammon et al., 2011). The tremor triggered a 'merging tsunami' (Song et al., 2012), i.e. a tsunami where two or more wave fronts join to form a single wave capable of traveling long distances without losing power and amplifying its destructive power at landfall. The tsunami, characterized by double high waves up to 40 meters traveling up to $10 \mathrm{~km}$ inland, impacted approximately $350 \mathrm{~km}$ of the Japanese coastline and caused exceptional and dramatic consequences. By May 2011, the Japanese National Police Agency confirmed 13,013 fatalities, 4,711 injured and 14,921 missing persons, as well as major devastation in several areas (Sakai, 2011). Many electrical generators were taken down leaving around 4.4 million households without electricity. Important failures at three nuclear power plants were reported. The most important one happened at the Fukushima Daiichi Nuclear Power Station, resulting in public concern over long-lasting environmental contamination and human injury from radioactivity.

The Great East Japan Earthquake is considered as one of the worst disasters ever. Unfortunately, it is not an isolated event. Since the beginning of the $21^{\text {st }}$ century, we have witnessed similar major disasters such as the Haitian earthquake (2010), the Deepwater Horizon oil spill (2010), Hurricane Katrina (2005), the Southeast Asia Tsunami (2004), the 9/11 disaster (2001), etc. Since the second half of the last century, the disaster landscape has experienced important changes. So, despite the rapid progress of knowledge and technology, millions of people are still killed, seriously injured or materially afflicted by some kind of disaster. On the one hand, disaster research shows that there has been a general increase in the quantity of disasters since the second half of the last century. On the other hand, several academics also mention a qualitative shift in the disaster landscape. They state that there is a strong notion that several modern disasters, which they define as 'disasters of the $21^{\text {st }}$ century' (Boin \& Lagadec, 2000; Lagadec, 2009a; Rosenthal, 1998) or 'mega-crises' (Helsloot et al., 2012b; Rosenthal, 2009), are structurally different from those we had to deal with in the past. According to the same authors, the qualitative change in the disaster landscape challenges the existing emergency management skills and capacities, or as Rosenthal states: "[These events are] not just more of the same - they are also about something else. 'Something [that] may very well be among the many unknown's" (2009, p. 4). Unfortunately, no academic study has been found in disaster literature supporting such an evolution. In order to be better prepared for future disasters, it is necessary to study the qualitative change in the disaster landscape further in depth. 
In this chapter, we first discuss the changing nature of hazards and the ensuing disasters, as well as the driving forces behind this evolution. Next, we concentrate on the existing theoretical approach regarding the evolution of the disaster landscape. We essentially focus on the main characteristics of modern disasters as described in literature, and then use these characteristics as a basis for the development of the 'Disaster Impact and Complexity Diagram' (DI\&C-Diagram), a tool permitting to study disasters from the perspective of impact and complexity in order to determine trends over the years. The last section of the chapter deals with a study of a set of randomly selected disasters from 1900 until 2010, using the DI\&C-Diagram. Findings are discussed and important points of interest in dealing with modern disasters are highlighted.

\section{The Shifting Nature of Hazards and Disasters}

Paraphrasing Guiberson, there is no denying that natural phenomena are in fact magnificent events; although to a certain extent (2010, p. 1): "Drops of water glistening on a spider web are a delight. A stream of water gushing through a forest is a wonder. But a 40-foot surge of water created by a colossal earthquake [can be the cause of an enormous] disaster." As a matter of fact, natural phenomena such as volcanic eruptions, earthquakes, tsunamis, storms, floods, etc. have always made our planet a hazardous place to live on. Yet, such occurrences only become potentially dangerous to humanity once they threaten people and the things they value. Normal natural events then become hazards (Cutter, 2005). Still, not every hazard evolves into a disaster. Disasters only occur when the human system intersects with a hazardous situation (Perry, 1998). If no humans had been around, the eruption of Mount Vesuvius on August 25, AD 79, would just have been another volcanic eruption. Unfortunately, at the time of the outburst, people had settled in stable communities near the supposedly inactive volcano. Even though the exact population in Pompeii in AD 79 is not known, it is certain that thousands died almost instantly just after the eruption occurred (Genzmer, Kershner, \& Schütz, 2007; Gunn, 2008).

When people got organized in sedentary communities, villages and cities, a social shift providing them an important degree of safety and resilience, they became at the same time more vulnerable to natural phenomena because a lot of the societies were located in hazard-prone regions such as coastlines and deltas (Lagadec, 2009a; Mileti, 1999). Due to this societal evolution and the ensuing process of expanding urbanization, there has been a constant and considerable increase of areas that are particularly vulnerable to hazards (Quarantelli, 1996). Natural events such as earthquakes, heavy storms or hurricanes then often evolve into devastating disasters causing heavy loss of life and property.

As human societies progressively evolved, additional types of hazards emerged (Quarantelli et al., 2006). From the beginning of the industrial revolution at the end of 
the $18^{\text {th }}$ century, humans maintain a sustained strive for modernity which is characterized by new industries (e.g. nuclear and chemical plants), revolutionary scientific technologies (e.g. genetic engineering, robotics, Artificial Intelligence, etc.), modern infrastructure (e.g. giant dams, skyscrapers, etc.) and mass transportation means (e.g. highspeed trains, huge tankers, giant cruise ships and airplanes such as the Airbus A-380, etc.). At the same time, the new systems increase the risk for users, operators, bystanders and even future generations and become high-risk technologies, having a potential for disaster not present in the past (Perrow, 1999a). According to Beck, development and modernization not only have to be understood in a positive way, there is a dark dimension too. He states that "the consequences of scientific and industrial development are a set of risks and hazards, the likes of which we have never previously faced" (1986, p. 2). Some researchers even argue that the attempt to cope with the increasing risks indirectly generates new hazards. Tenner (1996) concludes that the law of unintended consequences can be a brutal tyrant. The solution to one problem often turns out to be the cause of another (e.g. the use of agricultural pesticides enhances crop production but also causes harmful effects to humans and the environment if not properly used).

According to the Organisation for Economic Co-operation and Development (OECD) important changes to major risks and hazards are expected to take place in the coming decades. Based on the findings of 'The Futures Project on Emerging Systemic Risks', a two year project (2000-2002) conducted within the framework of the OECD International Futures Programme (IFP) ${ }^{1}$, the authors classify the driving forces behind the evolution into four major categories (OECD, 2003).

- Demographics

The constant growth of the world population, particularly in the developing regions such as Africa, Asia and South-America, results in more urbanization and the ensuing emergence of a growing number of mega-cities. The UN estimates that by 2025 there will be over 8 billion people on earth and that over $60 \%$ of them will be living in cities (Britton, 1998). Due to this concentration of population, a growing number of people becomes vulnerable to hazards at the same time and at the same place (Hunter, 2004; Mileti, 1999; Quarantelli, 1993).

- The environment

The environment undergoes major changes which can in part be related to natural evolution (natural climate variability). Nevertheless, there is an increasing concern about the impacts of socio-economic development (e.g. worldwide

1 The IFP is the OECD's forward studies group that has provided strategic, long-term thinking and horizon scanning for the organization since 1990. IFP events offer a platform where policy makers can freely confront their visions and concerns about the future, seek the views of others, and engage in a stimulating dialogue. 
population and economic growth, consumption patterns, etc.), as well as about the irresponsible use of natural resources (e.g. massive deforestation) on environmental change and especially on global warming. It has become evident that the global climate is changing and will continue to change over the coming decades and centuries, and that anthropogenic greenhouse gas emissions and increased pollution are largely to blame (Raggatt, Butterworth, \& Morrissey, 1993; van Aalst, 2006). Recent research demonstrates that climate change will not express itself primarily through slow shifts in average conditions over a long period, but that it is extreme events (e.g. storms, floods, heat waves etc.) that we should focus on (Helmer \& Hilhorst, 2006; IPCC, 2013).

- Technology

Technological progress makes modern societies and their interconnected infrastructures very complex and interdependent. Consequently they become subject to rapid and cascading failures with devastating consequences (Castells, 1996; Perrow, 1999a).

- Socio-economic structures

Globalization considered in all its dimensions integrates regional economies, societies and cultures into a global network through communication, transportation and trade. Globalization not only enhances coping capacities (e.g. international aid), it also puts societies at a higher level of risk (Rosenthal, 2009).

The driving forces, which are numerous and diverse, reshape conventional hazards and often create new ones. As a consequence, societies face important challenges with regard to future risk and hazard management and with regard to the management of the ensuing emergencies and disasters.

\section{Towards Disasters of the $21^{\text {st }}$ Century}

Reliable knowledge and research about what happened in past disasters may help disaster policy makers, disaster managers and emergency workers in planning for future events (Kar-Purkayastha, Clarke, \& Murray, 2011). As a consequence, the need for systematic disaster data has been a growing concern for disaster researchers (Guha-Sapir, Hargitt, \& Hoyois, 2004). However, disaster data should be handled with care for multiple reasons (Guha-Sapir et al., 2004). Before discussing disaster data and statistics, we first draw attention to the most important pitfalls related to the use of disaster figures.

\section{Disaster Data and Statistics}

Initially, the general approach to disaster management remained reactive in nature and data were collected on an ad hoc basis, mainly at the time of a new event. Consequent- 
ly, the information was far from complete, mostly outdated and for the greater part unusable (Guha-Sapir \& Below, 2002).

In the 1970s, a shift in disaster management emerged and the concept of comprehensive emergency management was developed by the National Governors Association (1978). The new approach implies that a state has the responsibility and must have the capacity to manage all types of emergencies and disasters considering the four phases of contemporary disaster management: mitigation, preparedness, response and recovery. Due to this holistic disaster management approach, the demand for statistics on disasters was augmented considerably. In such a context, policy makers, disaster managers and academics need accurate data, commensurable across countries and consistent over time in order to develop efficient and effective disaster mitigation and prevention plans. Accordingly, the first efforts of systematic data gathering by means of disaster databases emerged and the continuous improvement of modern information systems, even in developing countries, has greatly facilitated access to disaster data.

In spite of this favorable evolution, the quality of the disaster databases remains a major weakness. According to disaster researchers the main causes are the lack of standardized methodologies for data gathering and the nonexistence of an unambiguous definition of the concept disaster (Perry \& Quarantelli, 2005; Quarantelli, 1998). Besides, until present day, no single institution has taken on the role of prime provider of verified data and no internationally standardized method for assessing disaster damage has been put forward for global use. As a consequence, data on disaster outcomes remain rather patchy (Guha-Sapir \& Below, 2002).

The original data used by the different disaster databases are collected from diverse sources such as newspapers, reports elaborated by governments or insurance companies, case studies, aid agencies and NGOs, etc. A lot of the information used is unreferenced and is not linked to any distinguishable document. Furthermore, most of the data are not gathered for any statistical or academic purpose. There often is another rationale behind the data gathering which may bias the information available. As a consequence disaster statistics should always be looked at with some restraint as specified by Quarantelli (2001):

- Figures concerning the number of fatalities after a disaster are in general trustworthy. However, it is not always clear where to draw the line on when a fatality can be directly attributed to the disaster.

- Fatality counts are often affected by deliberate distortions. Authorities of developing countries may exaggerate casualty rates in order to increase the level of relief or they may reduce or deny casualty rates when the truth may be embarrassing (OECD, 1994). Such socially constructed data (Mileti, 1999) are thus very imprecise. 
- Data on injured or affected people have to be interpreted with even greater caution. A key problem is the ambiguousness of concepts and variables. Pollander and Rand (1989) pointed out that even in the medical disaster literature there is no generally accepted definition of what exactly constitutes an injury (e.g. heavily or lightly wounded, need to be hospitalized or not, etc.).

- Generally, the most unreliable data are the estimates of property damage and economic losses. We must recognize that the information is collected by various organizations and agencies each having their own specific motive (e.g. insurance companies, interest groups, governments, etc.). Additionally, there is no universally agreed economic currency standard with regard to disaster losses. Making reliable comparisons between suchlike datasets is thus almost impossible.

Due to the dubiousness of many data and figures, disaster statistics must be used with great caution. As a consequence, they should be regarded as indicative. Relative changes and general trends are by and large more useful to look at than absolute and isolated numbers.

\section{More Disasters per Time Frame, a Known Evolution}

Different scholars (Eshghi \& Larson, 2008; Granot, 1998; Rasmussen \& Batstone, 1989) and studies (International Federation of Red Cross and Red Crescent Societies, 2007) report a steady increase in the quantity and frequency of disasters since the second half of the last century, a trend which is validated by the statistics of three major disaster databases. To record

- EM-DAT: The Emergency Events Database was created in 1988 at the Centre for Research on the Epidemiology of Disasters at the University of Louvain in Belgium, and contains core-data on the occurrence and effects of over 18,000 mass disasters in the world from 1900 to present.

- NatCad: A private international level disaster database, maintained by the Munich Reinsurance Company. It collects information on natural disasters and covers a period from AD 79 to the present and contains over 20,000 entries.

- Sigma: The Sigma database is maintained by the Swiss Reinsurance Company. It gathers figures on global natural and man-made events from 1970 to the present with more than 7,000 entries.

Disaster statistics indicate that there has been a general increase in the quantity of disasters per time frame during the last decades. First, the number of disasters related to natural hazards has risen considerably since the second half of the last century. Second, from the beginning of the 1970s, societies have been stricken more frequently by technological disasters. This man-made form of disasters is even growing at a much 
greater rate than natural disasters (Coppola, 2011). Third, disasters related to health (e.g. infectious diseases and epidemics) and terrorism have gained ground in recent years. The statistics also indicate that, even if the number of disasters has tripled since the 1970s, disasters are becoming less deadly. But then again, the total number of people affected each year (people who lost their home, their crops, their animals or their livelihoods, at least temporarily) and the economic losses have increased significantly (UN/ISDR, 2002).

\section{Qualitative Different Disasters, an Underexplored Issue}

Since the end of last century, several academics mention a complementary shift in the disaster landscape. In addition to the quantitative upward trend, they refer to a qualitative change of disasters. They assume that there is a strong notion that several disasters we face today are structurally different from those we had to deal with in the past and define these modern disasters as 'disasters of the $21^{\text {st }}$ century' (Boin \& Lagadec, 2000; Rosenthal, 1998), crisis emergencies (Leonard \& Howitt, 2007) or 'mega-crises' (Helsloot et al., 2012b; Rosenthal, 2009).

Disasters of the $21^{\text {st }}$ century can no longer be considered as just more of the same. They add to the ancient ones, which have not disappeared, but they are intrinsically different. A new ball game (De Smet, Lagadec, \& Leysen, 2012) which, according to the disaster literature, is characterized by two general features: impact and complexity. In the following paragraphs, we clarify these general features by means of some typical cases.

First of all, disasters of the $21^{\text {st }}$ century demonstrate a qualitative jump in severity (Lagadec \& Carli, 2005). They are of an increasing magnitude and have a more devastating impact on societies, with more infrastructures destroyed and more people affected at the same time. The 2004 Indian Ocean undersea subduction earthquake with a magnitude of 9.1 on the Richter scale generated a series of devastating tsunamis, affecting many countries in Southeast Asia and causing serious damage and deaths as far as the east coast of Africa. More than 230,000 deaths as well as over 1.5 million people displaced were reported (Hyndman et al., 2008). Hardly eight months later, one of the five deadliest hurricanes that ever struck the United States seriously affected the Gulf region (Knabb et al., 2005). Although the eye of Hurricane Katrina passed east of the city of New Orleans, the enormous storm surge caused multiple levee breaches which led to the flooding of about $80 \%$ of the city to varying depths up to over 6 meter (Graumann et al., 2005). It is by and large accepted that the global region affected by the storm is approximately the size of England (more than 230,000 $\mathrm{km}^{2}$ ) and that the total damage cost amounts to \$125 billion (2005 USD). According to the White House report about the Federal Response to Hurricane Katrina - lessons learned (Townsend, 2006, p. 65) "[w]e must expect more catastrophes like Hurricane Katrina-and possibly even worse [...] We cannot undo the mistakes of the past, but there is much we can do to learn 
from them and to be better prepared for the future", a vision shared by several academics (Mileti, 1999; Quarantelli, 1993).

A second overall feature of disasters of the $21^{\text {st }}$ century is that they evolve towards very complex events which become extremely hard to manage in an effective way. Intervening emergency managers and responsible policy makers are pushed to the limits of their capacities, policies and even their imagination. According to the disaster literature, the complexity can be explained from three different angles:

- The changing limits of impact in space and/or in time (Beck, 1986).

On April 25, 1986, the explosion of the overheated reactor 4 of the Chernobyl Nuclear Power Plant in Ukraine blew off the lid of the reactor hall and started a giant graphite fire producing a protracted release of large quantities of radioactive substances into the air. The radioactive fall-out reached most of the European states. The Chernobyl disaster made researchers understand that there is something substantially new about modern disasters (Birkland, 1997). Their impact often generates cross-border spillover effects which reach far from the trigger event (Mongillo \& Zierdt-Warshaw, 2009; Perrow, 1999b)

Also, disasters of the $21^{\text {st }}$ century more often affect future generations. In 1984, the Bhopal gas tragedy caused death to approximately 2,000 people in the first few days. Many thousands more died later on from the consequences of intoxication due to the disaster. The exact number of the total death toll will never be known. According to Dinham and Sarangi (2002), over hundred thousand chronically ill survivors were still in desperate need of medical attention at the end of the $20^{\text {th }}$ century and an estimated 30 of them were dying every month from exposure-related illness.

- The possibility of multiple cascade effects.

The increasingly interconnected nature of current social infrastructures such as information systems, transportation networks, utility supply systems, etc., have an important impact on the effects of current disasters. Our growing dependence on technology and IT-networks makes our lives easier and more comfortable. Yet, at the same time this evolution enlarges the probability of fast spreading disasters and of multiple cascade effects occurring after the initial trigger event. In addition, such interconnected networks can amplify minor emergencies and transform them into major disasters in no time (Quarantelli, 1996; Smith, 2005). On August 14, 2003, a line failure in combination with human errors in a small power generating plant in Eastlake, Ohio caused an enormous power failure. The blackout affected an estimated 50 million people in parts of Ohio, Michigan, New York, Pennsylvania, New Jersey, Connecticut, Massachusetts, Vermont, and the Canadian provinces of Ontario and Québec. States did not have power for two days and parts of Ontario experienced rotating blackouts for up to two weeks (NERC Steering Group, 2004). 
- Unprecedented, unknown and unconceivable aspects of disasters.

Although each disaster is characterized by a high amount of uncertainty, more and more we find ourselves confronted with events for which we do not have readymade responses. In such circumstances, we cannot fall back on preestablished plans and procedures, making the third angle of complexity the most destabilizing one, or as stated by Lagadec (2009a, p. 478): "[w]hen the map is lost, the best specific solutions vanish". On September 10, 2001, few Americans would have believed that their economic and military hubs would be attacked by terrorists, merely armed with box cutters and using U.S. commercial airplanes, notwithstanding the fact that the best-selling author Tom Clancy used this scenario as a plot for his 1994 novel 'Debt of Honor'. The Americans were expecting missiles.

Even if we think that global epidemics were something of the past (e.g. smallpox, bubonic plague, etc.), the spectre of major outbreaks of infectious diseases (e.g. H5N1 outbreak) has returned. Such events greatly concern emergency workers because of the overwhelming demands it would make on health systems and especially because of the consequences to society as yet unknown.

The possibility of occurrence of unprecedented, unknown and even unthinkable (inconceivable) disasters is growing, mainly due to the complexity and interconnectivity of today's societies and the growing dependence on modern technology. In such a complex environment, the side effects of disasters will exceed the level of traditional chain reaction of second order effects (Perrow, 1999a; Quarantelli, 1993).

\section{Disasters out of the Box and the Disaster Impact and Complexity Diagram}

During history, humans have systematically developed means to cope with and survive disasters by putting in place specific "emergency management procedures". As the hazard and disaster landscape evolved, they have continually adapted their mitigation, preparedness and intervention measures based on successful and less successful experiences (Kirschenbaum, 2004), in order to be more resilient to the situation. Formal Emergency Management Organizations (EMOs) fitted out with specialized equipment and trained personnel have been installed gradually on and since World War II, there has been a professionalization of disaster planners and managers. Their main assignment is to establish and constantly maintain and improve procedures for emergency management organizations to deal with emergency situations and disasters (Quarantelli et al., 2006).

As demonstrated in the previous paragraph, the actual disaster landscape is subject to important changes. On the one hand, existing disaster statistics clearly demonstrate a significant quantitative shift, which in itself is a worrisome evolution. On the other hand, the assumed evolution towards more qualitatively different disasters of the $21^{\text {st }}$ century is far more alarming. If such a trend is real, we can expect that our societies will 
be more severely affected in the future, and more importantly, that the work of the intervening EMOs will be more challenged, notwithstanding the improved disaster and emergency management capacities and procedures.

Although a trend towards more disasters of the $21^{\text {st }}$ century is very credible (e.g. the media coverage on current major disasters, the cases described in the previous paragraph, etc.), no academic study has been found in the existing disaster literature substantiating such a general qualitative evolution. In order to be better prepared for future disasters, it is indispensable to address this gap in disaster research and to investigate the qualitative change in the disaster landscape in depth. To this purpose, we introduce the notion 'disasters out of the box' and subsequently develop the 'Disaster Impact and Complexity Diagram' (DI\&C-diagram), a tool which allows studying disasters over time in order to determine qualitative trends.

\section{Disasters out of the Box}

A well performing organization is an "organization that realises its present objectives (ongoing business) while at the same time preparing itself to realise its objectives of and in the future" (Leysen \& Van Nuffel, 2006). An organizational risk therefore, is a possible event which may compromise the realization of the organization's objectives and therefore its performance. When the organization's performance is compromised, the organization goes through an organizational crisis (Davies \& Walters, 1998).

The main objective of EMOs intervening during a disaster is to manage the event in the most efficient and effective way. Yet, the performance of the EMOs can be jeopardized in different ways. If an intervening EMO is hit and affected partly or even completely by a disaster itself, the EMO loses necessary capacities (i.e. resources, processes and/or knowledge). Also, the disruption of supporting infrastructures external to an EMO can compromise its work (e.g. the breakdown of a power station may disrupt the communications, destroyed bridges complicate the accessibility to the disaster zone, etc.). Finally, disasters may be of such complexity or that inconceivable, that the intervening emergency workers are confronted with an event for which they do not have readymade responses and cannot fall back on pre-established plans and procedures.

In each of the above-mentioned situations, the disaster jeopardizes the performance of the intervening EMO, which goes through an organizational crisis. In such case the disaster becomes 'out of the box' to the considered EMO. The notion 'disasters out of the box' is thus related to intervening EMOs during disasters.

\section{DI\&C-Diagram}

The major goal of the current research consists in determining whether the disaster landscape is characterized by a trend towards more disasters of the $21^{\text {st }}$ century and consequently more 'disasters out of the box'. Therefore, it was decided to develop the 
DI\&C-Diagram as a tool to study disasters over the years in order to determine a qualitative trend. The following method, consisting of three steps, was used.

During the first step, six academics working at the Risk, Crisis and Disaster Management research pool of the Faculty of Social and Military Sciences at the Belgian Royal Military Academy were gathered in a meeting room and received an explanatory briefing about disasters of the $21^{\text {st }}$ century, the two main features of such events as described in literature (impact and complexity) and the concept of 'disasters out of the box'. Following the briefing, the researchers were asked to determine different variables which can be related to the main features of disasters of the $21^{\text {st }}$ century during a 30-minute brainstorm session. The technique, developed by Osborn (1963), permits the use of the full experience and creativity of all participants in a free and open environment. Each person was asked in an alternate way to note a potential variable on a postit, which was then put on a white-board. After the brain storm session, a total of 80 potential variables were identified.

In the second step, the 80 potential variables were further discussed and specified by the six researchers applying the 'estimate-feedback-talk-estimate method' (EFTE method), which is a variant of the Delphi technique. The method, also referred to as the Interactive or Mini Delphi procedure (Nelms \& Porter, 1985; Puglisi, 2001), includes open debate phases (Talk) between the different rounds. In this research, we essentially concentrate on the emergency phase of the disaster management life cycle (National Governor's Association, 1979), the phase during which the EMOs intervene. The Emergency Phase begins at the moment the event leading to a possible disaster is detected and usually ends when the situation has stabilized (De Smet, Leysen, \& Lagadec, 2011). Consequently, the participants were asked to:

- Find a consensus about relevant variables applicable to the Response phase (e.g.: the potential variable 'cost of the catastrophe' is largely related to the reconstruction phase of the disaster management life cycle and therefore was not taken into further consideration).

- Cluster similar items into unambiguous variables (e.g.: the identified potential variables 'probability of the event', 'ignorance', 'without precedent' and 'recurrence' were grouped in the variable 'inconceivability').

- Relate the remaining variables to one of the two general features of disasters of the $21^{\text {st }}$ century, representing the two dimensions of the DI\&C-Diagram: Disaster Impact Consequences (DIC) and Disaster Management Complexity (DMC).

After an EFTE-process of three rounds, a consensus was reached about seventeen appropriate and unambiguous variables; five related to DIC and twelve to DMC (appendix A, Table II - 2).

The last step consisted in the development of the DI\&C-Diagram, in which studied disasters can be positioned as a function of impact and complexity. The position should 
be interpreted as following: the further the disaster is positioned away from the origin, the more severe (impact) and/or complex it is, and the bigger the probability that it becomes 'out of the box' to the intervening EMOs. During a final EFTE-process, the six researchers were asked to further analyse the variables in order to develop an appropriate scale for each of them and to determine a way to calculate the position of a studied disaster into the DI\&C-Diagram. Agreement was found on the following:

- For each of the 17 variables, an appropriate scale was defined (for details, see appendix A, Table II-2).

- To present a studied disaster in the two-dimensional DI\&C-Diagram as a function of impact and severity, the subsequent procedure is followed:

First, a score is calculated using formula 1. The score represents the position of the center of the allocated category on a scale between 0 and 100.

Next, when all the scores for the studied disaster are computed, the arithmetic mean is calculated for both the scores related to DIC and DMC. The obtained values represent the coordinates of the position of the studied disaster in the DI\&C-Diagram (an example of the calculations is represented in appendix B).

$$
\text { Score }=\frac{100}{n}\left(a-\frac{1}{2}\right)
$$

$\mathrm{n}$ : number of categories for the considered scale

a: allocated category for the considered variable

\section{A Study of the Qualitative Shift in the Disaster Landscape}

\section{Method}

In order to examine the qualitative evolution of the disaster landscape throughout time, we decided to study 100 disasters between 1900 and 2010 considering the following five time frames: 1900-1924, 1925-1949, 1950-1974, 1975-1999, and 2000-2010. As reference we used the Disaster Database Project, developed by Green III (Green III, 2011). In addition to quantitative data (e.g. number of fatalities, people injured, buildings destroyed, etc.), the database disaggregates each disaster into phases as defined by Fink (2002): the prodromal stage, development, impact, response and recovery. The user obtains a detailed description of the factors involved in each stage, as well as a narrative of the event during each particular phase. At the time of consultation, the database was still $^{2}$ a living information source containing data of more than 2,500 disasters and covered natural disasters, human system failures and conflict based disasters. For inclusion into the database, events are considered disasters if "(1) they represent a threat to life,

2 Through lack of funding, professor Green was compelled to close the database at the end of 2011. 
property, or the environment, (2) they would have required the use of emergency procedures for the limitation of their impact, (3) they reasonably could have caused a responsible jurisdiction, agency, or organization to invoke or declare the existence of an emergency situation or to mobilize its resources in response, and (4) some significant degree of community or organizational impact was present" (Green III, 2011).

For each of the considered time frames, we randomly selected twenty disasters out of the Disaster Database Project which were studied using the DI\&C-Diagram. Indispensable information necessary for the study of the 17 parameters, which was not available within the database, was collected using different types of complementary data sources (online sources, articles, reports, etc.). The studied disasters are represented in appendix C.

\section{Results}

The results of the study are represented in the Figures II - 2 and II - 3. Figure II - 2 gives a representation of the individual positions of the 100 studied disasters within the DI\&CDiagram. Figure II - 3 depicts the positions of the means of the different scores DIC and DMC (coordinates) per time frame, while the radius of the bubbles is proportional to the overall standard deviation of the considered scores DIC and DMC.

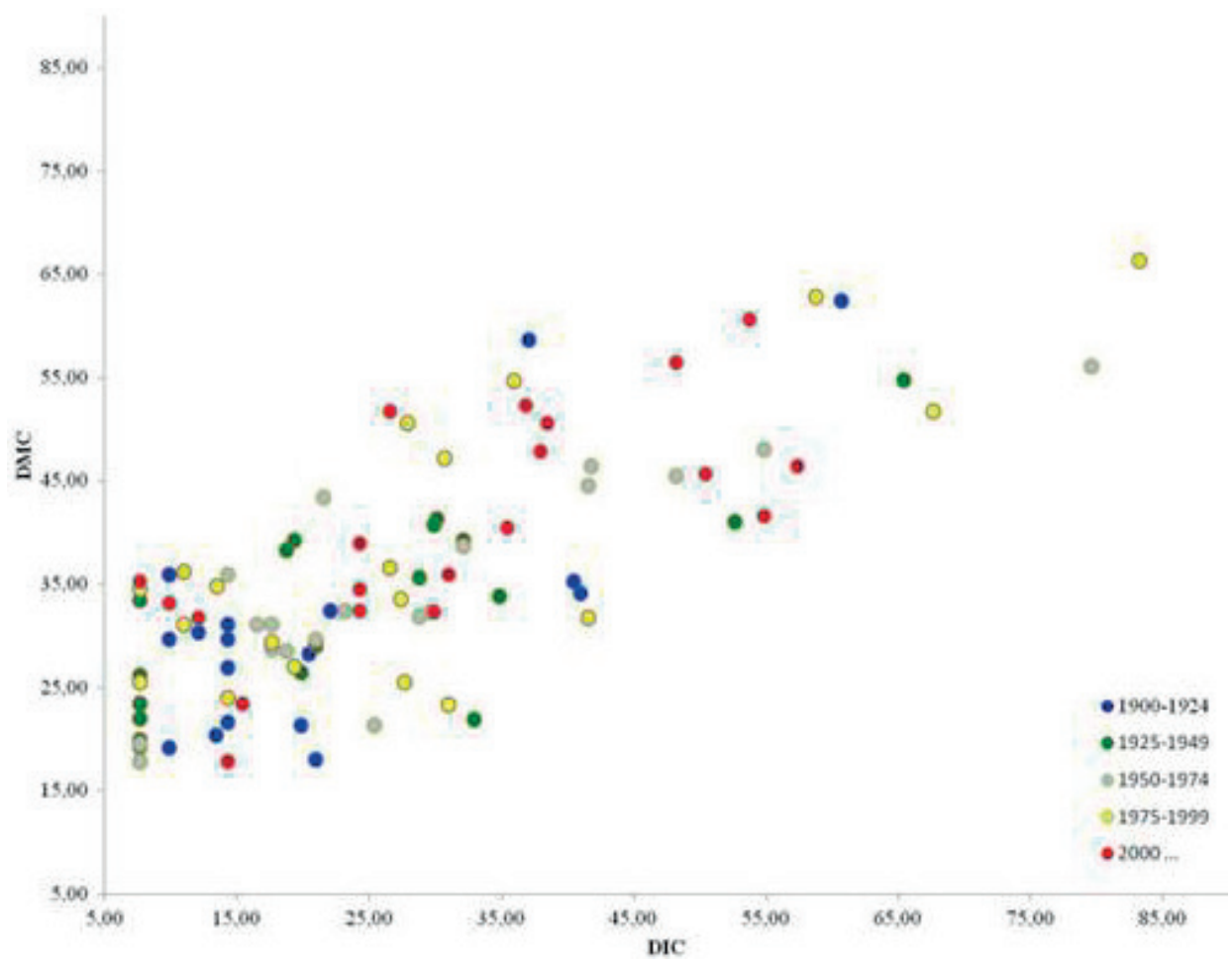

Figure II - 2: DI\&C-Diagram - Results for the individual disasters 
Figure II - 2 clearly indicates that the majority of the studied disasters between 1900 and 1949 (blue and green dots) are essentially centered in the lower left side of the DI\&C-Diagram, whereas those from 2000 on (red dots) are spread from the lower left side to the upper right side. This conclusion is confirmed in figure II - 3. We observe a jump in severity and magnitude (DIC) since the 1950s, whereas from the mid-seventies disasters obviously become more complex to manage (DMC). Figures II - 2 and II - 3 give a qualitative, visual indication that disasters evolve towards more disasters of the $21^{\text {st }}$ century and consequently become more 'out of the box'.

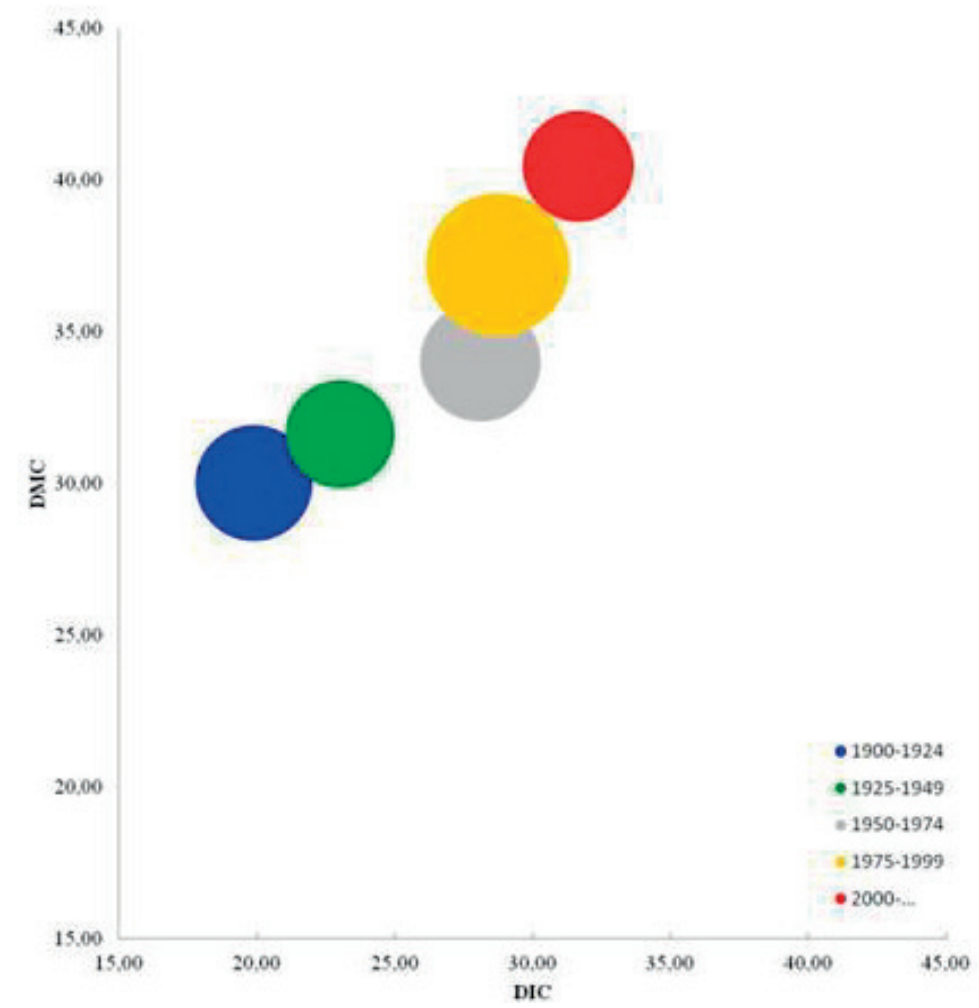

Figure II - 3: DI\&C-Diagram - Results per time frame

To confirm the previous conclusion, we further analysed the obtained results in a statistical way. First, we calculated the values of the absolute origin of the DI\&C-Diagram. By applying formula (1), a score of zero can never be obtained. To illustrate this, we use the scales with the highest number of categories (human impact - see Table II - 2, appendix A) and calculate the smallest possible score (i.e. for category 1), which is 5.56. By extension we then determined the absolute origin of the DI\&C-Diagram. The absolute origin is the smallest coordinate possible by considering category 1 for each of the 17 scales. As absolute origin, we obtain 7.64 (DIC) and 11.18 (DMC). 
DI\&C-Diagram

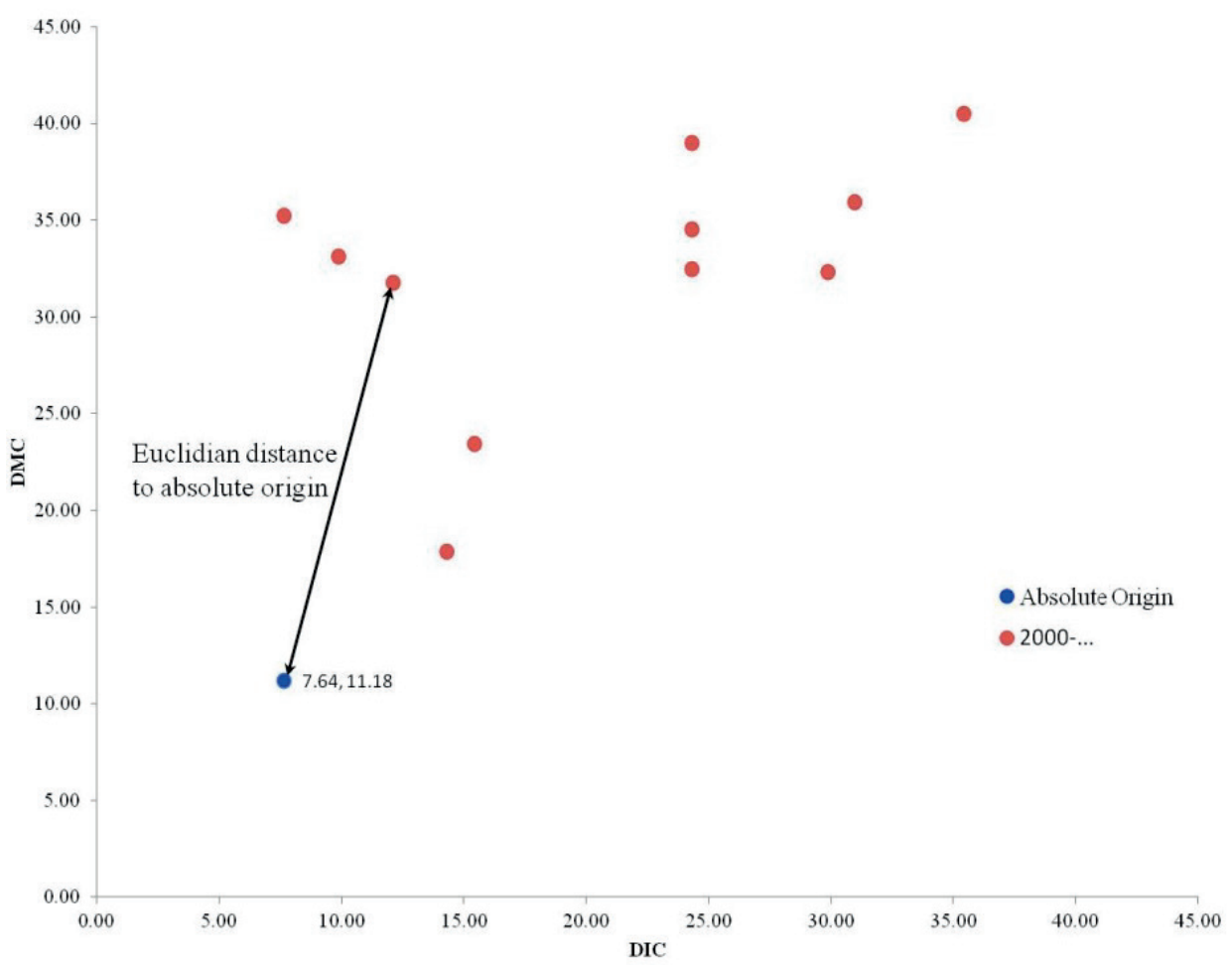

Figure II - 4: Euclidian distance to absolute origin

Next, we classified the studied disasters in a chronological way by considering the year in which the disaster happened, and then calculated the Euclidian distance of each pair of values (DIC and DMC) of the studied disasters to the absolute origin of the DI\&CDiagram (Figure II - 4). The Euclidian distance is the measure of a disaster being 'out of the box'. A simple linear regression was calculated to predict the Euclidian distance over time. A significant regression equation was found $(F(1,98)=7.99, p<.01)$, with an $R^{2}$ of .08. The results, represented in Figure II - 5, clearly demonstrate that there is a significant annual increase of the Euclidian distance per year, $b=.14, t(98)=2.38, p<.01$. The small value of $R^{2}=.08$ can be explained considering the following remarks:

- Extreme events have always existed even in ancient times: the eruption of super volcano Toba 74,000 years ago, the tsunami generated by an earthquake in Greece which destroyed Alexandria in AD 365, the Shaani earthquake which killed over 800,000 people in 1556 , etc. 


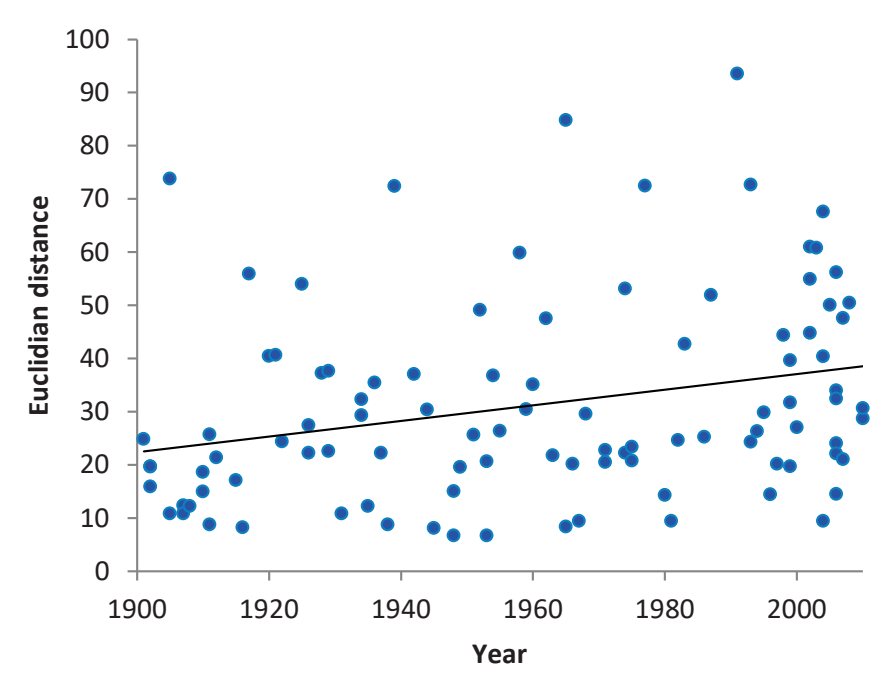

Figure II - 5: Regression analysis of the Euclidian distance

- Not all disasters we face today are extreme in nature and can be considered as 'disasters out of the box'. We still are and will always be confronted with the more traditional disasters for which we can easily fall back on pre-established plans and procedures, even if we take into account that there is no such thing as a routine disaster (Boin \& Lagadec, 2000).

Based on the results of the study, we can conclude that there is an obvious trend towards disasters of the $21^{\text {st }}$ century, entailing the possibility that more disasters will evolve into 'disasters out of the box'.

An additional important finding concerns the correlation between DIC and DMC values. Looking at the data in Figure II - 2 already gives a good indication of the correlation between the two variables. Calculation of the Pearson correlation coefficient and $\mathrm{R}^{2}$ confirms this indication: DIC and MMC are strongly positively correlated, $r(98)=.79, p<$ $.01\left(R^{2}=0.62\right)$. Given this high correlation between 'impact' and 'complexity', we can assume that the larger the impacts are, the more complex the disasters.

\section{Discussion and Conclusion}

Even though, from time to time, societies have been confronted with disasters of extreme magnitude and complexity throughout history, it appears that suchlike events occur much more frequently during the last decades. The issue that actual disasters are changing shape has been discussed by several scholars (e.g.: Boin \& Lagadec, 2000; Helsloot et al., 2012b; Leonard \& Howitt, 2007; Rosenthal, 1998), but no academic study has been found providing empirical evidence for such an evolution. For that rea- 
son, we developed the 'Disaster Impact and Complexity Diagram' as a tool to examine trends in the qualitative evolution of disasters over the years, and then studied a randomly choses set of disasters between 1900 and 2010, considering five time frames: 1900-1924, 1925-1949, 1950-1974, 1975-1999, and 2000-2010. The results of our study prove that in recent time, there is a trend towards more disasters of the $21^{\text {st }}$ century, which have an increasing potential to become 'disasters out of the box'.

The management of disasters has always been a very challenging task for policy makers, disaster managers and emergency workers. In the context of a continuously changing hazard and disaster landscape, people have always been forced to adapt their capacities and policies to deal with emergencies and disasters in an efficient and effective way. When dealing with traditional disasters, the policy of adjusting the existing and known procedures and textbooks in accordance with lessons learned appears to be rather effective. However, the results of our study provide empirical evidence for the assumption that we are not only confronted with just more of the same, but that in addition we have to deal with disasters that are obviously more complex and therefore present a "new class of adversity with many unknowns" (Helsloot et al., 2012b, p. 5). Recent events such as the Southeast Asian Tsunami (2004), Hurricane Katrina, the catastrophic Haitian earthquake (2010) and the Great East Japan Earthquake (2011) have shown that ruling practices are no longer that efficient and effective. Traditional policy assumptions of disaster and emergency management become outdated when confronted with disasters of the $21^{\text {st }}$ century, which are characterized by an increasing impact and complexity. The results of our study therefore confirm the necessity to rethink the issue of the mutating disaster landscape thoroughly if we want to avoid being continually one disaster behind (Davis, 2006). As such the conventional military wisdom to 'never prepare for the last war' (Granatt, 2014) holds all the more.

Accordingly, the identified trend towards more disasters of the $21^{\text {st }}$ century involves important challenges to disaster managers at the policy level as well as to emergency workers at the operational level. Many of the disasters we face today have evolved past the bounds of traditional disaster and emergency management which is basically embedded in a Cartesian philosophy (Lagadec, 2009a). However, the relationships between cause and effect in complex phenomena such as disasters of the $21^{\text {st }}$ century are seldom linear in nature, so making relevant prognoses about what will happen after the trigger event becomes very difficult. Therefore, we should pay more attention to thinking creatively about the unprecedented, the unknown and the inconceivable aspects of modern disasters if we want to stay well prepared for future events and do not want to lose legitimacy (Ripley, 2008). New phenomena, for which we have no readymade answers, demand innovative thinking and reasoning out of the box. Creativity will become crucial if we want to be prepared to manage today's and future disasters. As a consequence, the acquisition of these competences must be stimulated during training sessions, or as LaPorte states (2007, p. 62): "Leaders must prepare to be very surprised and no longer rely exclusively on existing plans which aim mainly at avoiding surprise". 
Chapter 2

\section{Appendix A: The Disaster Impact and Complexity Diagram - Variables and Scales}

Table II - 2: Disaster Impact and Complexity Diagram variables and scales

\begin{tabular}{|c|c|c|}
\hline \multicolumn{3}{|c|}{ Disaster Impact Consequences (DIC) } \\
\hline Human impact & $\begin{array}{l}\text { 1. Number of fatalities } \\
\text { Only the immediate death toll is } \\
\text { taken into consideration. } \\
\text { 2. Number of injured people } \\
\text { Only the immediate number of } \\
\text { injured people is taken into } \\
\text { consideration. }\end{array}$ & $\begin{array}{lc}\text { 9 } & \text { categories } \\
\text { 1. } & x \leq 50 \\
\text { 2. } & 50<x \leq 100 \\
\text { 3. } & 100<x \leq 200 \\
\text { 4. } & 200<x \leq 500 \\
\text { 5. } & 500<x \leq 1,000 \\
\text { 6. } & 1,000<x \leq 5,000 \\
\text { 7. } & 5,000<x \leq 10,000 \\
\text { 8. } & 10,000<x \leq 100,000 \\
\text { 9. } & 100,000<x\end{array}$ \\
\hline Material impact & $\begin{array}{l}\text { 3. Material destruction } \\
\text { Magnitude of the material } \\
\text { destruction and/or } \\
\text { contamination after the impact } \\
\text { of the event }\end{array}$ & $\begin{array}{l}\text { 4 categories } \\
\text { 1. Small: one destructed or contaminated site } \\
\text { (plant, building, ...) } \\
\text { 2. Medium: more than one destructed or } \\
\text { contaminated site, partial destruction of a } \\
\text { village, small town or small region ( }<50 \\
\mathrm{~km}^{2} \text { ) } \\
\text { 3. Big: partly destruction or contamination of } \\
\text { more than one town } \\
\text { 4. Very big: destruction or contamination of a } \\
\text { large region (several towns are heavily } \\
\text { disrupted or affected) }\end{array}$ \\
\hline Geographical impact & $\begin{array}{l}\text { 4. Area of the stricken zone } \\
\left(\text { in } \mathrm{km}^{2}\right)\end{array}$ & 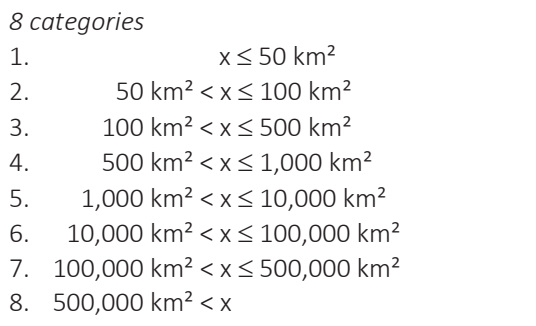 \\
\hline Time impact & $\begin{array}{l}\text { 5. Duration of the (trigger)event } \\
\text { A long-lasting trigger event } \\
\text { generally causes a more } \\
\text { devastating disaster. }\end{array}$ & $\begin{array}{l}\text { 6 categories } \\
\text { 1. } \quad x \leq 1 \mathrm{Min} \\
\text { 2. } 1 \mathrm{Min}<\mathrm{x} \leq 5 \mathrm{Min} \\
\text { 3. } 5 \mathrm{Min}<\mathrm{x} \leq 1 \mathrm{Hr} \\
\text { 4. } 1 \mathrm{Hr}<\mathrm{x} \leq 1 \text { day } \\
\text { 5. } 1 \text { day }<x \leq 1 \text { week } \\
\text { 6. } \\
1 \text { week }<\mathrm{x}\end{array}$ \\
\hline
\end{tabular}


Disaster Management Complexity (DMC)

Aspects related to evacuation of victims

Time aspects

Geographical aspects
1. Number of victims to evacuate 6 categories

$\begin{array}{llc}\text { A larger number of people to } & 1 . & x \leq 100 \\ \text { evacuate complicates } & \text { 2. } & 100<x \leq 1,000 \\ \text { emergency operations. } & \text { 3. } & 1,000<x \leq 5,000 \\ & \text { 4. } 5,000<x \leq 10,000 \\ & \text { 5. } 10,000<x \leq 100,000 \\ & \text { 6. } 100,000<x\end{array}$

2. Complexity of evacuation Besides the number of victims to evacuate, other aspects complicate evacuation and consequently emergency operations (e.g. contamination of the disaster zone, the willingness of people to evacuate, etc.).

3. Length of forewarning 4 categories

1. Fluent: no difficulties

2. Minor: minor difficulties

3. Complicated: hindered evacuation causing important difficulties

4. Difficult: very difficult evacuation

5 categories
1. 1 week $<\mathrm{x}$

2. 1 day $<x \leq 1$ week

3. $6 \mathrm{Hr}<\mathrm{x} \leq 1$ day

4. $1 \mathrm{Hr}<x \leq 6 \mathrm{Hr}$ $\mathrm{x} \leq 1 \mathrm{Hr}$

\section{6 categories}

1. $\quad \mathrm{x} \leq 12 \mathrm{Hr}$

2. $12 \mathrm{Hr}<x \leq 1$ day

3. 1 day $<x \leq 3$ day

4. 3 day $<x \leq 1$ week

5. 1 week $<x \leq 2$ weeks

6. 2 weeks $<x$ working in shifts, etc.).

4 categories

1. Easy: no hinder

2. Medium: hindered accessibility

3. Difficult: accessibility is hindered in a major way

4. Very difficult: accessibility is hindered in a major way during a long period

6. Cross-border event Cross-border events involve emergency management organizations belonging to different jurisdictions complicate emergency operations.
5 Categories

1. not a cross-border event

2. cross-border event (more than one state/province)

3. more than one country on the same continent affected

4. more than one country on different continents affected

5. worldwide event 
Disaster Management Complexity (DMC)

7. Cascade effects

Cascade or domino effects

complicate emergency

operations.

\section{5 categories}

1. No cascade effects

2. Minor cascade effects (limited in time and space) not hampering the work of the emergency management organizations

3. Cascade effects (limited in time and space) hampering the work of the emergency management organizations in a considerable way

4. Multiple cascade effects hampering the work of emergency management organizations in a considerable way

5. Important cascade effects spread in time and space

8. Simultaneous events

4 categories

Simultaneous events complicate emergency operations.

1. No simultaneous events

2. Limited simultaneous effects within the intervention zone of the emergency management organizations, not hampering their work

3. Simultaneous events within a limited zone (operational zone), hampering the work of the emergency management organizations

4. Very important simultaneous events on a strategic level

Aspects related to supporting infrastructure

Coordination aspects
9. Impact on supporting infrastructure and/or services Destruction or disruption (even if minor) of supporting infrastructure (e.g. roads, bridges, energy supply facilities, telecommunications, etc.) complicates emergency operations.

10. Impact of legal, procedural and/or political features Features such as legal and/or procedural aspects, political regimes, language barriers etc., generally have a negative impact on emergency operations.

\section{4 categories}

1. Insignificant: no impact on emergency operations

2. Medium: destruction of supporting infrastructure and/or services hampering the intervening emergency management organizations

3. Important: destruction of supporting infrastructure and/or services causing important difficulties to emergency operations

4. Massive: major destruction/affection of supporting infrastructure and/or services causing massive complications tot emergency operations

4 categories

1. Insignificant: no impact on coordination

2. Medium: minor impact on coordination

3. Important: coordination is hampered in a considerable way

4. Massive: coordination is very much complicated or even hindered 
Facing the Actual Disaster Landscape. A trend towards more Disasters out of the Box?

Disaster Management Complexity (DMC)

Emergency organization 11. Capacities of the intervening aspects emergency management organizations

The more levels of authority involved, the more complicated the emergency operations will be.

12. Inconceivability Unprecedented and thus unknown events negatively influence emergency operations.

\section{4 categories}

1. Local capacities

2. Regional reinforcement

3. National reinforcement

4. International reinforcement

4 categories

1. Low: rather normal events, normal consequences

2. Medium: rather normal events, big consequences

3. High: seldom happening events

4. Very high: exceptional events 


\section{Appendix B: Generation of the Statistics, an Illustration}

To illustrate the calculations and the generation of the statistics, we randomly selected a disaster out of the list of studied disasters: The Knickerbocker Theatre Collapse ( $N b 20$ - see appendix C).

\section{Determination of the Values of the Variables}

The table below reports the values of the 17 variables as well as the corresponding categories, the calculated scores and the arithmetic means for both DIC and DMC (representing the coordinates of the position of the studied disaster in the DI\&C-Diagram). The calculation of the score of variable 1 is illustrated in Figure II - 6. Figure II - 7 depicts the position of the studied disaster in the DI\&C-Diagram.

\begin{tabular}{|c|c|c|c|}
\hline Variables & Values and categories & $\begin{array}{l}\text { Calculated } \\
\text { scores }\end{array}$ & Means \\
\hline \multicolumn{4}{|l|}{ DIC } \\
\hline \multirow[t]{2}{*}{ Human impact } & 1. Number of fatalities: 98 - Cat 2 & 16.67 & \multirow[t]{5}{*}{24.31} \\
\hline & 2. Number of injured people: 133 - Cat 3 & 27.78 & \\
\hline Material impact & $\begin{array}{l}\text { 3. Material destruction: The theatre was destroyed (one building) } \\
\text { - Cat } 1\end{array}$ & 12.5 & \\
\hline Geographical impact & 4. Area of the stricken zone: The area of the building - Cat 1 & 6.25 & \\
\hline Time impact & $\begin{array}{l}\text { 5. Duration of the (trigger)event: Witnesses have reported that } \\
\text { there was no hint of danger such as cracking or loud noises } \\
\text { beforehand (sudden collapse) - Cat } 1\end{array}$ & 58.33 & \\
\hline \multicolumn{4}{|l|}{ DMC } \\
\hline \multirow[t]{2}{*}{$\begin{array}{l}\text { Aspects related to } \\
\text { evacuation of victims }\end{array}$} & $\begin{array}{l}\text { 1. Number of victims to evacuate: The roof collapsed on the } \\
\text { concrete balcony, which in turn collapsed onto the orchestra } \\
\text { seating section, - Cat } 2\end{array}$ & 25.00 & \multirow[t]{10}{*}{28.96} \\
\hline & $\begin{array}{l}\text { 2. Complexity of evacuation: A blizzard lasting for } 28 \text { hours } \\
\text { resulted in significant accumulation of snow and ice throughout } \\
\text { the Washington, DC area, paralysing much of the city - Cat } 3\end{array}$ & 62.50 & \\
\hline \multirow[t]{2}{*}{ Time aspects } & $\begin{array}{l}\text { 3. Length of forewarning: There was no hint of danger such as } \\
\text { cracking or loud noises beforehand (sudden collapse) - Cat } 5\end{array}$ & 90.00 & \\
\hline & $\begin{array}{l}\text { 4. Duration of the emergency operations: No information of exact } \\
\text { duration, but estimated less than a day - Cat } 2\end{array}$ & 25.00 & \\
\hline \multirow[t]{2}{*}{ Geographical aspects } & $\begin{array}{l}\text { 5. Geographical aspect: Due to accumulation of snow and ice a lot } \\
\text { of streets were nearly impassable, paralysing much of the city - } \\
\text { Cat } 1\end{array}$ & 32.50 & \\
\hline & 6. Cross-border event: No-Cat 1 & 10.00 & \\
\hline \multirow{2}{*}{$\begin{array}{l}\text { Evolution of the } \\
\text { disaster }\end{array}$} & 7. Cascade effects: No - Cat 1 & 10.00 & \\
\hline & 8. Simultaneous events: No - Cat 1 & 12.50 & \\
\hline $\begin{array}{l}\text { Aspects related to } \\
\text { supporting } \\
\text { infrastructure }\end{array}$ & $\begin{array}{l}\text { 9. Impact on supporting infrastructure and/or services: Due to } \\
\text { accumulation of snow and ice a lot of streets were nearly } \\
\text { impassable, paralysing much of the city - Cat } 3\end{array}$ & 12.50 & \\
\hline Coordination aspects & 10. Impact of legal, procedural and/or political features: No - Cat 1 & 12.50 & \\
\hline
\end{tabular}


Facing the Actual Disaster Landscape. A trend towards more Disasters out of the Box?

\begin{tabular}{lll}
\hline Variables & Values and categories & $\begin{array}{l}\text { Calculated Means } \\
\text { scores }\end{array}$ \\
\hline $\begin{array}{l}\text { Emergency } \\
\text { organization aspects }\end{array}$ & $\begin{array}{r}\text { 11. Capacities of the intervening emergency management } \\
\text { organizations: Local capacities (police, firemen, and military } \\
\text { personnel) - Cat 1 } \\
\text { 12. Inconceivability: Rather normal disaster, but with big } \\
\text { consequences - Cat 2 }\end{array}$ & $\mathbf{3} 2.50$ \\
&
\end{tabular}

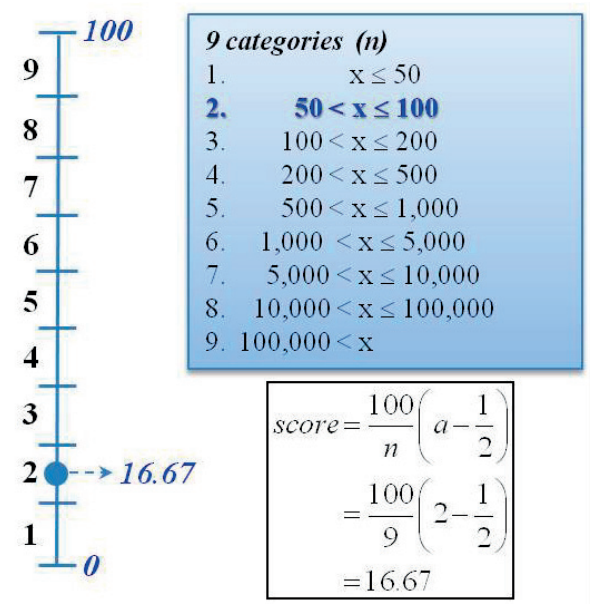

Figure II - 6: Calculation of the score

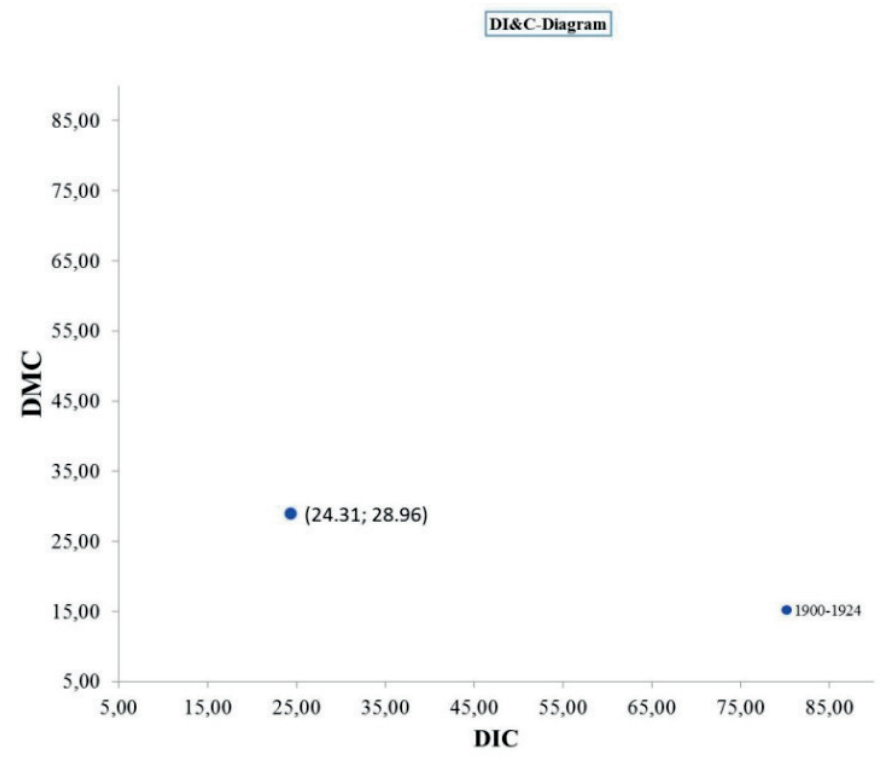

Figure II - 7: DI\&C position 


\section{Appendix C: List of the Studied Disasters}

$\mathrm{N}^{\circ}$ Description of the disaster Dat

1 Senghenydd Coal Mine explosion May 24,

Underground mine explosion in the town of Senghenydd (Wales, UK), killing 82 miners. 1901

2 Ibrox Stadium collapse April, 5

A partial stadium collapse that caused 25 deaths and 517 injuries among the supporters 1902

watching the 1902 British Home Championship match between Scotland and England

(Glasgow, Scotland).

3 Fraterville Mine disaster May 19,

Underground mine explosion near the community of Fraterville (Tennessee, USA) killing 1902

216 miners. The explosion was caused by a buildup of methane gas which had leaked from an adjacent unventilated mine.

4 Coal Creek Number 2 And 3 Mine explosions May 22,

Explosion in the Coal Creek Mines (British Columbia, Canada) killing 128 miners. The 1902

mines were reported to have been very gassy with significant quantities of fine coal dust.

5 Towboat Defender explosion January 3,

Sudden explosion of the boilers of the steamboat on the frozen Ohio River (West Virginia, 1905

USA) causing 9 fatalities and 6 badly injured people.

6 Kangra earthquake April 4,

A major earthquake (magnitude 7.8) in the Kangra Valley (Himachal Pradesh region, 1905

India) killing almost 20,000 people and causing widespread destruction.

7 Steamboat City of Troy fire April 5,

Shortly after departure from New York, a fire started in the galley of the steamboat 1907

which became quickly out of control. The captain landed the ship at the Gould Dock in

Ardsley (Westchester County, New York, USA). The passengers were safely evacuated but the ship burned to the waterline and ignited the dock.

$8 \quad$ SS Cyprus sinking

October 11,

The lake freighter SS Cyprus sank during a gale storm on Lake Superior about 8 miles

1907

north of Deer Park (Luce County, Michigan, USA). All but one of the 23 members of the crew perished.

9 Coal Creek Number 2 Mine bump

July 31 ,

Sudden mine bump (a seismic jolt occurring within a mine, often due to the explosive 1908

collapse of a wall or one or more support pillars) near the town of Fernie (British

Columbia, Canada). 20 miners were trapped for 8 hours and 3 were killed.

10 Wellington avalanche

March 1,

An enormous avalanche engulfed the railroad depot of Wellington (Washington, USA) and swept a stranded passenger train with 100 persons aboard into a 150-foot-deep gorge. Only 26 survived.

11 Loss of Airship America

October 20,

Due to an engine failure, the airship was no longer manoeuvrable and drifted for more

than 2,200 km over the Indian Ocean. All 6 crew members could be rescued in the vicinity of Bermuda (USA).

12 Taff Vale Railway accident

January 23,

A signalling failure caused a collision between a passenger train and coal train on the Taff 1911

Vale Railway line at the town of Hopkinstown, near Porth (Wales, UK) and resulted in the loss of 11 lives. 


$\mathrm{N}^{\circ}$ Description of the disaster
13 Sinking of the SS Yongala
The passenger ship sank nearby Cape Bowling Green (Queensland, Australia) on its way
from Melbourne to Cairns when steaming into a severe cyclone. The ship couldn't be
warned in time because it was not yet equipped with a wireless communication system.
All 122 people on board perished.

14 Regina tornado

A violent tornado of $400 \mathrm{~m}$ wide and an estimated wind velocity of $500 \mathrm{~km}$ per hour devastated huge parts of the city of Regina (Saskatchewan, Canada). 28 persons were killed.

15 Explosion of the HMS Princess Irene

Being loaded with mines in preparation for a minelaying mission during the war, the ocean liner exploded (Medway Estuary, Kent, UK). 377 people died.

16 Quebec Bridge collapse

Date

March 23,

1911

During the construction of the second Quebec bridge (Canada), the prefabricated center

June 30 ,

1912 span dropped into the Saint Lawrence River at the moment it was being hoisted into place.

17 Halifax explosion

Due to the explosion of the SS Montblanc (a French cargo ship fully charged with

December 6, wartime explosives) much of the city of Halifax (Nova Scotia, Canada) was devastated. About 2,000 people were killed and it is estimated that nearly 9,000 others were injured.

18 Mendoza earthquake

The earthquake (magnitude 6.0) affected the provincial capital Mendoza (Argentina). It caused huge material damages and about 400 fatalities.

19 Oppau explosion

Workers attempting to break-up solidified ammonium nitrate in silos using permissible dynamite, triggered two blasts. The explosion excavated an enormous crater and damaged most of the buildings in the town of Appau (Germany).

20 Knickerbocker collapse During a severe northeastern storm in the District of Columbia (USA), snowfall reached up to 26 inches causing the roof of the Knickerbocker Theater to collapse onto the balcony which failed and fell onto the spectators seated on the floor.

21 Tri State tornado

May 27,

1915

September 11 1916

1917

The tornado is considered as one of the deadliest tornados in U.S. history. Its continuous

December 17, 1920

September 21 1921 track of more than $350 \mathrm{~km}$ was the longest ever recorded and crossed from southeastern Missouri through southern Illinois into southwestern Indiana. About 700 people were killed.

22 Eastern Storm of 1926

April 5,

A violent storm, lasting for four days, hit the San Diego region (USA), destroyed several 1926 buildings and caused considerable human distress.

23 San Luis Obispo Oil Refinery fire

April 7,

A stroke of lightning started a fire at the Union Oil tank farm. The oil overtopped dikes and ignited most of the facility. The ensuing firestorm generated multiple small tornados, complicating the work of the fire fighters.

24 St. Francis Dam collapse

March 12,

The St. Francis dam (California, USA), designed between 1924 and 1926, would provide water to the city of Los Angeles. During the filling of the reservoir, the dam collapsed and the resulting flood killed up to 600 people.

25 Coal Creek Number 1 East Mine fire

March 25 After the collapse of a roadway, signs of fire were detected in the mine nearby the town of Fernie (British Columbia, Canada). The effort to remove the burning coal started immediately, but lasted for three weeks. 


\begin{tabular}{lll}
\hline$N^{\circ}$ Description of the disaster & Date \\
\hline 26 & Placentia Bay tsunami & November 18, \\
A 7.2 earthquake in the Atlantic Ocean triggered a large submarine landslide and led to a & 1929 \\
tsunami that struck the coast of the Burin Peninsula (Newfoundland, Canada). & June 9, \\
27 & HMS Poseidon sinking & 1931 \\
Despite good visibility, the Poseidon collided with the Chinese merchant steamer SS Yuta & 19 after a series of misjudgements whilst exercising in the Bohai Sea (China). The vessel sank \\
immediately causing 22 fatalities.
\end{tabular}

28 SS Moro Castle event

September 8,

During a storm the luxury cruise ship, en route from Havana to New York, caught fire and 1934

burned. 137 passengers and crew members were killed.

29 Gresford Colliery event

September 22,

A series of major explosions caused by ignition of methane gas by a shot at the coalface produced a fire which ruptured the Dennis Main Deep nearby the town of Gresford (Wales, UK). Over 250 people were killed.

30 Grobheringen collision

December 24, As a local Erfurt to Leipzig train crossed the main line on the bridge over the River Saale nearby the town of Großherringen (Germany), it collided with the Berlin to Basel express as a result of human error.

31 Tupelo tornado

April 5,

The Tupelo (Mississippi, USA) tornado was one of several from a severe thunderstorm. 1936

The tornado, with a total ground track of approximately 15 miles destroyed the major part of the city. Over 200 people were killed.

32 New London School explosion

March 18,

The New London School (Texas, USA) was destroyed by a gas explosion. Over 450 people 1937 were killed. The school had illicitly tapped wet gas from a drilling site to save costs of heating, a practice not explicitly authorized by local oil companies, but widespread in the area.

33 Natal Number 3 Mine explosion

July 15,

During a thunderstorm, lightning struck the rails used by mining cars and ignited an

1938 explosion within the mine nearby the town of Natal (British Columbia, Canada).

34 Erzincan earthquake

December 27, A severe earthquake of seven violent shocks (the biggest one measuring magnitude 8.0) 1939 hit the province of Erzincan (Turkey), killing over 30,000 people.

35 Honkeiko Colliery explosion

April 26,

A huge explosion in the coal mine at Benxi (Liaoning province, China) killed over 1,500

1942

Chinese miners.

36 East Ohio Gas Company event

One of the three 240-million-cubic-foot liquefied natural gas tanks of the Cleveland

October 20 company (Ohio, USA) started to leak. During reparation, the leak ignited and caused a series of explosions.

37 SS Harmonic event 1944

The Canadian steam ship was completely destroyed by a fire at the dock of Point Edward (Ontario, Canada).

38 Eastern Airlines flight 572

The DC-3 departed from Winston-Salem (North Carolina, United States) for a flight to January 13 Washington. The plane crashed after having struck the top of a tree. The probable cause of the accident was the failure of the flight crew to follow the prescribed instrument procedure during the course of an instrument approach.

39 BSAA Star Tiger disappearance January 30 The passenger aircraft disappeared without trace over the Atlantic Ocean while on a 1948 flight between Santa Mari (Azores) and Bermuda. The loss remains unsolved to this day. 


\begin{tabular}{lll}
\hline$N^{\circ}$ & Description of the disaster & Date \\
\hline 40 & Holland Tunnel fire & May 13, \\
The fire in the tunnel under the Hudson River between New York and New Jearsey (USA) & 1949 \\
started after a truck lost one of its eighty 55-gallon drums of carbon disulfide. At the & \\
moment of the fire, approximately 125 vehicles were in the tunnel. &
\end{tabular}

41 New Orient Number 2 Mine explosion

December 21, A methane gas explosion devastated the New Orient Mine Number 2 near the town of West Frankfort (Illinois, USA). At the moment of the explosion 218 miners were down. Almost all of them were killed.

42 Kern County earthquake 1951

The magnitude 7.5 earthquake which was felt in Reno, Nevada, and in the upper floors of buildings in San Francisco, caused major devastation in the city of Kern County (California, USA).

43 Nutts Corner Crash January 5 A Vickers Viking flying from London to Dunrod (Ireland), with 31 passengers and 4 crew, 1953 crashed at the airport of Nutts Corner at night. 7 people died.

44 Conneaut collision A freight train, fully loaded with pipes of $30 \mathrm{~cm}$ in diameter, lost its cargo nearby the town of Conneaut (Ohio, USA). One of the pipes shifted an adjacent track out of position. A passenger train derailed and collided with the freight train. Later, a second passenger train collided with the resulting wreckage. There is evidence that the pipes were incorrectly secured.

45 Kumbh Mela stampede

The stampede occurred in Allahabad in Uttar Pradesh (India) during the main bathing day of Mauni Amavasya (New Moon). During a failure of crowd control (over 4 million pilgrims were in the city) over 800 people were killed.

46 Novorossiysk explosion July 21, 1952 In the harbor of Sevastopol (USSR), the Soviet battleship exploded and capsized less than 3 hours after the explosion. A large number of crew members were entombed in the capsized hull. More than 600 sailors drowned (only 9 were rescued after 36 hours).

47 Ida (Kanagawa) typhoon

The typhoon made landfall in Kanagawa Prefecture, 15 miles south of Tokyo (japan). It February 3, 1954

27 March 27 1953 deposited 15 inches of rain which caused the Kano, Meguro, and Arakawa rivers to flood. 1958 Flooding and landslides damaged or destroyed over 2,000 buildings and 244 bridges. Over 1,200 people were killed.

48 Roseburg explosion

August 7,

A truck loaded with 4.5 tons of ammonium nitrate and 2 tons of dynamite was parked 1959 overnight behind a hardware store in the center of the town of Roseburg (Oregon, USA). Apparently, a trash can fire ignited the truck, causing the load to explode. 7 city blocks were destroyed and buildings in another 28 were damaged.

49 La Coubre explosion

March 4,

The French freighter, loaded with over 70 tons of grenades and ammunition, exploded 1960 when being unloaded at a pier in Havana harbor (Cuba). During the initial emergency operations, 3 warehouses stored with munitions also detonated. The entire waterfront district sustained severe damage. The probable cause for the explosion was poor ammunition handling.

50 Huascarán avalanche October 29, 1955 September 2627, 958 


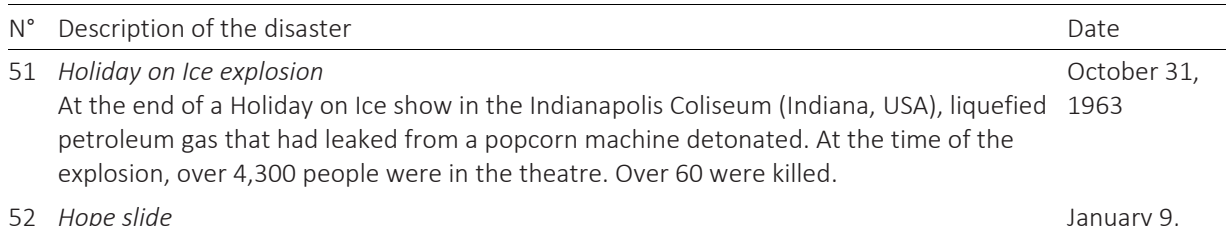

52 Hope slide

January 9

The collapse of the south-western slope of Johnson Peak nearby the town of Hope (British 1965

Columbia, Canada), covered a 3-km section of the Hope-Princeton highway with

$47,000,000$ cubic meters of debris up to a depth of 85 meters. Four drivers were crushed in their vehicle.

53 Barisal cyclone

May 11

A tropical cyclone with maximum winds of over $16 \mathrm{~km}$ per hour and a $3.7 \mathrm{~m}$ storm surge 1965

killed almost 20,000 people in the Barisal Division (People's Republic of Bangladesh).

54 SS Daniel J. Morrell event

The Great Lakes freighter SS Daniel J. Morrell en route from Buffalo, New York to

November 29 Taconite, Minnesota (USA) broke apart and sank in a Lake gale during a severe storm.

55 Le K3

A fire broke out on board of the nuclear submarine K3 which was on its way on the Norwegian Sea. Almost 40 of the crew members were killed.

56 Ferry Wahine sinking

Approaching Wellington Harbor (New Zealand) in reduced visibility and with the radar inoperable, the steamer Wahine was hit by a very large wave. The ship was blown off course and grounded on Barrett Reef. Wave action freed the damaged Wahine from the reef and started to carry her into the harbor. During the evacuation, over 50 people were killed

57 Ibrox stadium disaster

January 2,

The disaster occurred when crush barriers collapsed at the moment thousands of fans

1971 made their way out of the Ibrox Park Stadium in Glasgow (Scotland) during a match between the Celtic Football Club and the Rangers Football Club.

58 Salvador stadium stampede Fans stampeded as a fight erupted in the grandstand of the Salvador stadium (Brazil) during a football match.

59 Quebrada Blanca Canyon landslide 1966

September 8 1967

April 10,

1968

A massive landslide of rock and mud in the Quebrada Blanca Canyon (Colombia) buried 61974 buses and 20 other vehicles.

60 Cyclone Tracy

The tropical cyclone with hurricane wind force caused major damage to the village of

March 4,

Darwin (Australia). Although Tracy was very compact (the eye of the storm was 4 miles in diameter), it lasted for 6 days. Over 70 people were killed and more than 160 were reported missing.

61 SS Edmund Fitzgerald event

The Fitzgerald sunk in Lake Superior (USA) during a severe storm. No survivors were

November 10, reported

62 MV Berge Istra explosion

The modern bulk carrier loaded with 188,000 tons of iron ore, was on its way from

Tubarão (Brazil) to Kimitsu (Japan) when a series of 3 massive explosions caused the Berge Istra to rapidly sink in the Molucca Sea (Indonesia).

63 Vrancea earthquake

March 4,

The 7.2 magnitude Vrancea (Romania) earthquake was felt throughout the Balkans. Over 1977 1,500 people were killed and more than 11,000 were reported wounded. About 35,000 buildings were damaged. 


\begin{tabular}{|c|c|c|}
\hline $\mathrm{N}^{\circ}$ & Description of the disaster & Date \\
\hline 64 & $\begin{array}{l}\text { Ferrell Number } 17 \text { mine explosion } \\
\text { Inadequate ventilation controls in the Westmoreland Coal Company's mines nearby the } \\
\text { town of Uneeda (West Virginia, USA), allowed methane gas to accumulate and caused an } \\
\text { explosion. }\end{array}$ & $\begin{array}{l}\text { November } 7 \\
1980\end{array}$ \\
\hline
\end{tabular}

65 Winter Park sinkhole

May 8,

During a period of record-low water levels in Florida, a massive sinkhole opened up in 1981 Winter Park (Florida, USA). In a single day the hole widened to $98 \mathrm{~m}$ and to a depth of 27 $\mathrm{m}$. A two-story home and a number of vehicles disappeared into the sinkhole.

66 Luzhniki disaster

October 20

The deadly human crush took place at the Grand Sports Arena of the Luzhniki Stadium in 1982 Moscow (USSR) during a football match between Spartak Moscow and Haarlem (Netherlands). The number of fatalities was not officially revealed until seven years later.

67 Coalinga earthquake

May 2,

The magnitude 6.5 earthquake which struck the Coalinga region (California, USA) was 1983

caused by an unknown fault. More than 5,000 aftershocks were recorded of which almost 900 had a magnitude of 2.5 or larger.

68 K-219 event

The Soviet Navy Yankee class nuclear ballistic missile submarine K-219 suffered a missile fuel explosion and fire, causing damage to the nuclear reactor controls. Nitric acid fumes compromised compartment seals and the crew was unable to contain the fire. The vessel sank in 18,000 feet of water.

69 Goiânia radioactive contamination

The contamination occurred after an old radiotherapy source was stolen from an September 27, abandoned hospital site in the city of Goiânia (Brazil). It was subsequently handled by many people resulting in 4 deaths. About 112,000 people were examined for radioactive contamination and 249 were found to have significant levels of radioactive material in or on their body.

70 02B cyclone

October 3, 1986

The 1991 Bangladesh cyclone was among the deadliest tropical cyclones ever measured. It struck the Chittagong district in the southeastern part of the country. Winds of $250 \mathrm{~km}$ per hour forced a $6 \mathrm{~m}$ storm surge inland, killing over 150,000 people.

71 Latur earthquake

September 29, A 6.4 magnitude earthquake struck the Maharashtra state in the western region of India. 1993 Over 50 villages were demolished and more than 10,000 people were killed.

72 Collision between the Balsa 37, the B-155 and the Ocean 255

August 10, The Tank Barge Ocean 255 and the Tank Barge Bouchard B-155, two vessels carrying million liters of fuel oil, collided with the freighter Balsa 37 near the entrance of Tampa Bay (Florida, USA). Over 1.3 million liters of oil were spilled into the bay.

73 Maracaibo National Jail riot

April 29,

1991

During a riot, which lasted for six days, an estimated 100 people died in the vastly

January 3 , 1994 overcrowded Maracaibo National Jail (Venezuela). Inmates shot and stabbed each other and set fire to the prison.

74 Soufrière Hills volcano eruption

July 18 ,

After a long period of dormancy, the Soufrière Hills volcano on the Caribbean island of Montserrat became active in 1995 and has continued to erupt ever since. Its eruptions have rendered more than half of Montserrat uninhabitable and destroyed the capital city. About two thirds of the population left the island.

75 Khobar Towers bombing

A terrorist attack on a housing complex in the city of Khobar (Saudi Arabia). At that time the towers were being used as quarters for American military personnel. 


\begin{tabular}{|c|c|c|}
\hline $\mathrm{N}^{\circ}$ & Description of the disaster & Date \\
\hline 76 & $\begin{array}{l}\text { Anzob Pass avalanche } \\
\text { Over } 40 \text { people were killed when a sudden avalanche buried } 15 \text { trucks and cars under }\end{array}$ & $\begin{array}{l}\text { October 23, } \\
1997\end{array}$ \\
\hline
\end{tabular}

77 Jesse Oil Pipeline explosion

The sabotaged pipeline had been leaking fuel for three days at a steady rate. When hundreds of people were trying to scoop the leaking fuel for personal use at the community of Jesse (Nigeria), the oil pool suddenly ignited in an explosion and fire.

78 Oklahoma tornado outbreak

October 17, 1998

On May 3, a series of 66 tornados broke out in Oklahoma and Kansas (USA). The events of this day were the beginning of a vigorous severe weather event that lasted for three days and brought violent tornado storms to Oklahoma, Kansas, Arkansas, Texas, and Tennessee.

79 Whatcom Creek fire June 10 , A pipeline rupture in the city of Bellingham (Washington, USA) spilled 230,000 gallons of 1999 gasoline into Whatcom Creek and ignited.

80 Sinking of the MV Asia South Korea

May 3

1999 The ferry which was en route from Cebu City to Iolo City (Philippines) sank near Bantayan 1999 Island in rough seas. Over 50 people were killed.

81 Capsizing of the ferry Arlahada

The wooden hull cargo vessel Arlahada, en route to the Province of Tawi-Tawi

April 12, (Philippines), picked up approximately 200 passengers from small boats. The passengers boarded the Arlahada from one side which caused the capsizing of the vessel.

82 Igandu railway accident

A passenger train en route from Dar es Salaam to Mwanza (Tanzania) either went out of control or suffered a brake failure. It hit a freight train and 14 of the 15 coaches derailed and overturned.

83 Texas floods

A week of intense rainfall in the region of the watersheds of the Guadalupe, San Antonio and Neuces Rivers caused a major inundation in a larger part of Texas (USA).

84 South and North Carolina Winter Storm

A winter storm with ice, snow and freezing rain caused the loss of power to over 2000 $1,600,000$ residences and businesses in central North and South Carolina (USA). Some families were without power for 10 days or more.

85 Jiashi earthquake June 24 2002

Due to a 6.8 magnitude earthquake, with its epicenter in Jiashi county (Xinjiang Province, 2003 China), several thousands of houses and buildings collapsed. A huge number of people were killed and injured.

86 Cyclone Heta

The category 5 tropical cyclone caused major damage on the islands of Tonga, Niue and American Samoa (Polynesia).

87 Al Hoceima earthquake

A magnitude 6.4 earthquake at a depth of $13 \mathrm{~km}$ caused heavy casualties in the $\mathrm{Al}$ Hoceima region (Morocco). In no time over 2,000 buildings, mainly constructed on mud brick, were destroyed or severely damaged.

88 Interstate 75 pileup

A chain reaction accident involved approximately 50 vehicles on Interstate 75 in the January 7

2004

February 24, 2004 vicinity of Clarkston (Michigan, USA). Bright sunlight combined with icy road conditions resulted in multiple collisions when traffic stopped and automobiles collided at slow speed. 


\begin{tabular}{lll}
\hline $\mathrm{N}^{\circ}$ Description of the disaster & Date \\
\hline 89 & Moscow blackout & May 25, \\
A fire and explosion in one of the substations of the city's energetic company caused & 2005 \\
massive electric generating plant failures and created a widespread electric power &
\end{tabular}
outage in the wider Moscow region (Russia).

90 Bad Reichenhall collapse January 2,

The roof of the skating rink at Bad Reichenhall (Germany) collapsed under a heavy snow 2006 load. At the time of the collapse, approximately 50 skaters were in the building. More than 10 of them were killed.

91 KTS Textile Mill fire February 23, At least 500 workers were inside the 4 story KTS Textile Mill (Dhaka, People's Republic of 2006 Bangladesh) when a fire started. Witnesses reported that the single main gate of the mill was locked.

92 Tommy Waste Dumping The Panamanian-flagged vessel Probo Koala discharged over 500 metric tons of toxic waste in the port of Abidjan (Ivory Coast). The Ivorian company Tommy, contracted to dispose of the cargo, dumped the sludge at 17 public locations in Abidjan.

93 Iran Air tour Mashhad crash During landing at Mashhad airport (Iran), the left wing of an aircraft hit the ground. The plane caught fire and 29 people died.

94 Esperanza fire

The vegetation fire, most likely been set by an arsonist, started on October $26^{\text {th }}$ near Palm Springs (California, USA). Winds up to $80 \mathrm{~km}$ per hour contributed to the rapid spread and an estimated $163 \mathrm{~km}^{2}$ were burned before containment.

95 Belakoba train bombing

August 19, 2006 A bomb, placed by terrorists, exploded in a passenger coach of a train en route from New 2006 Jalpaiguri to Haldiguri (India). The explosion caused a fire which generated such heat that one of the sides of the car was reported to have melted.

96 Ulus bombing May 22

The bombing was a suicide attack that occurred outside a shopping centre in the Ulus quarter of Ankara (Turkey). 5 people were killed and over 100 were reported injured.

97 Kerch Strait storm During a very heavy storm on the Black Sea, four oil tankers sank in the Kerch Strait September 1, 2006

October 26-30, 2006 (between Russia and Ukraine), resulting in a major fuel oil spill.

98 Lac Kivu earthquake The 5.9 magnitude earthquake, with its epicentre at Lake Kivu (Democratic Republic of Congo) shook several counties in Africa's Great Lakes region.

99 L'incendie des "Teachers Apartments High Rise » A 28-storey high-rise apartment building in the city of Shanghai (China) caught fire. Almost 60 people were killed.

100 La Gabriela mudslide After a period of extensive rain, a mudslide struck the city of Bello (La Gabriela district, 2007 November 11, 2007

February 3, 2008 November 15, 2010

December 5, Colombia) killing over 20 people. 



\section{Chapter}

\section{The Response Phase of the Disaster Management Life Cycle Revisited within the context of Disasters out of the Box}

The text represents the manuscript: De Smet, H., Schreurs, B., \& Leysen, J (2015). The response phase of the disaster management lifecycle revisited within the context of 'disasters out of the box'. Journal of Homeland Security and Emergency Management, 12, 319-350.

An earlier version of the study was presented in 2011 as: De Smet, H., Leysen, J., \& Lagadec, P., The Response Phase of the Disaster Life Cycle Revisited. Proceedings of the IIE 61st Annual Conference and Expo, Take your Career to new Heights; Reno, NV, May 21-25, 2011. 


\section{Abstract}

Since the second half of the last century the disaster landscape has experienced important changes. Disasters are not only increasing in quantity, they are also qualitatively different and seem to distress humanity to a considerably higher degree than in the past. This evolution does not only deeply affect modern societies; it might also have a disruptive impact on the intervening units of emergency management organizations. Recent disaster research mainly focuses on mitigation efforts, risk reduction and resilient societies. Though, despite good mitigation efforts and up-to-date preparation initiatives, still millions of people are affected and thousands killed annually by some kind of disaster. As a consequence, disaster response remains a vital aspect of disaster management and will even become more important in the future taking into consideration the changing disaster landscape. The aim of the study was to remodel the response phase of the disaster management life cycle focusing on a new and fresh approach. On that account, we conducted 24 in-depth interviews with disaster management specialists, either by experience as well as by education, and analyzed the data using the 'responsive interviewing approach' developed by Rubin and Rubin (2005). The results of the study reveal that the response phase is much more than a set of activities that disaster managers can appeal to in order to stabilize the situation, and to limit injuries, loss of life and damage to property and the environment. The data show that the response phase evolves as a comprehensive process through three succeeding stages that partly overlap and blend into one another (paralysis, operational response and strategic response), and which entail some important sub-processes (gradual buildup of capacities in the disaster zone, the coordination process and the event assessment process). 


\section{Introduction}

Every society and its constituents (e.g. individuals, groups, organizations, communities, etc.) sporadically, and generally in an unexpected way, experience disasters. Whether these events are triggered by a natural phenomenon, an industrial accident or a technological breakdown, or at the instigation of human beings, the normal functioning of the society is disrupted in a more or less serious way. Since the second half of the last century the disaster landscape has experienced important changes. On the one hand, disaster research shows that there has been a general increase in the quantity of disasters (Eshghi \& Larson, 2008; Granot, 1998; James, Wooten, \& Dushek, 2011; Rasmussen \& Batstone, 1989). On the other hand, several academics also mention a qualitative shift in the disaster landscape (Boin \& Lagadec, 2000; Helsloot et al., 2012b; Lagadec, 2009a; Rosenthal, 1998; Rosenthal, 2009). They state that several modern disasters are structurally different from those we had to deal with in the past and have the potential to become 'disasters out of the box', from the perspective of intervening units of emergency management organizations (EMO). A disaster becomes 'out of the box' when it causes an organizational crisis to the intervening emergency management units and as a consequence disrupts their performance (De Smet et al., 2012).

Over time, disaster scientists have developed disaster phase models in order to impose order and rationality on the complex reality of disasters and the human response to them (Richardson, 2005). The most popular of these models originates from recommendations of the National Governor's Association (1978), suggesting that disasters can be delineated into four different phases: mitigation, preparedness, response and recovery. For decades both disaster researchers and managers have been using this concept of the disaster life cycle and its disaster phases as a global framework for their activities. Scientists employ it to develop and organize research projects, to codify data, and to generate findings. Practitioners make use of it to handle disaster issues and to improve their disaster capabilities.

Recent disaster research mainly focuses on mitigation efforts, risk reduction and resilient societies (McBean, 2012; Weichselgartner, 2001). However, despite good mitigation efforts and up-to-date preparation initiatives, still millions of people are affected and thousands killed annually by some kind of disaster (International Federation of Red Cross and Red Crescent Societies, 2012). As a consequence, disaster response remains a vital aspect of disaster management and will even become more important in the future taking into consideration that several modern disasters are structurally different from those we had to deal with in the past (Boin \& Lagadec, 2000; Helsloot et al., 2012b; Lagadec, 2009a; Rosenthal, 1998; Rosenthal, 2009). Up to now, the response phase has merely been described as the third phase of the disaster management life cycle during which a variety of activities aimed at stabilizing the situation following a disaster impact take place (National Governors' Association, 1978). Despite academic warnings about the changing disaster landscape and the resulting need for a renewed understanding 
responding to modern disasters (Lagadec, 2009a; Robert \& Lajtha, 2002) and especially 'disasters out of the box (De Smet et al., 2012), no supplementary in-depth research of the response phase has been done. However, when the context changes, accepted theories and practices become outmoded and need to be revisited if we want to be well prepared to deal with future events. The present study aims at contributing to the understanding of modern disaster management by remodeling the response phase of the disaster management life cycle. We do so by taking a fresh approach. First, we study the response phase within the context of 'disasters out of the box'. Second, we consider the response phase not just as an enumeration of potential activities, but as an unfolding global process of stages and sub-processes following a disaster impact. The advantage of a process-based approach is that it supports complex and non-linear explanations about how and why sequences of events occur (Pugliese, Bortoluzzi, \& Zupic, 2016), which is typical for disaster response and especially for a context in which more disasters have the potential to evolve into 'disasters out of the box'. The paper begins with a clarification of the changing disaster landscape and an explication of the notion 'disaster out of the box', and is followed by an overview of existing disaster phase research. Next, the study's method and data analysis are discussed. Results of the analysis are then presented. The paper concludes with a discussion of the findings.

\section{The Changing Disaster Landscape: More 'Disasters out of the Box'}

Several scholars (Eshghi \& Larson, 2008; Granot, 1998; Rasmussen \& Batstone, 1989), research reports (International Federation of Red Cross and Red Crescent Societies, 2007) and statistics of disaster databases such as EM-DAT (Centre for Research on the Epidemiology of Disasters at the University of Louvain in Belgium), NatCad (Munich Reinsurance Company) and Sigma (Swiss Reinsurance Company) record a steady increase in the number of disasters since the second half of the last century. Statistics indicate the following. First, the number of disasters related to natural hazards has risen significantly since the 1950s. Second, since the 1970s societies are more often hit by technological disasters. And third, more disasters related to health (e.g. infectious diseases and epidemics) and acts of terrorism disrupt social order in recent years.

In addition to this general upward trend, several disasters we face today are structurally different from those we had to deal with in the past. Modern disasters or 'disasters of the $21^{\text {st }}$ century' (Boin \& Lagadec, 2000; Lagadec, 2009a; Rosenthal, 1998) can no longer be considered as more of the same. They add to the ancient ones, which have not disappeared, but they are intrinsically different. A new ball game (De Smet et al., 2012) which, according to the disaster literature, is characterized by two general features: impact or magnitude and managerial complexity. First of all, 'disasters of the $21^{\text {st }}$ century' demonstrate a qualitative jump in severity (Lagadec \& Carli, 2005). They are of an increasing magnitude and have a more devastating impact on societies, with more 
infrastructures destroyed and more people affected at the same time. Secondly, 'disasters of the $21^{\text {st }}$ century' are increasingly complex events which become extremely hard to manage in an effective way. According to disaster literature, complexity can be explained from three different issues: the impact often generates cross-border spillover effects which reach far from the trigger event (Mongillo \& Zierdt-Warshaw, 2009; Perrow, 1999b), the potential to create major cascade effects even if the trigger event is considered a minor emergency (Quarantelli, 1996; Smith, 2005), and the unknown and even inconceivable aspects of many modern disasters (Lagadec, 2009b).

Due to the evolution of the disaster landscape, we can expect that the work of the responding units of emergency management organizations (EMOs) will be more heavily challenged, notwithstanding improved disaster and emergency management capacities and procedures. The objective of EMO-units intervening during a disaster is to manage the event efficiently and effectively. However, the performance of intervening units can be jeopardized in different ways. If a unit is hit and affected partly, or even entirely, by the disaster itself, it loses its capacities (i.e. resources, processes and/or knowledge). Also, the disruption of supporting infrastructures and services external to the intervening unit can compromise its work (e.g. the breakdown of a power station may disrupt communications, destroyed bridges complicate the accessibility to the disaster zone, etc.). Finally, disasters may be of such complexity that the intervening emergency workers are confronted with an event for which they do not have readymade responses and cannot fall back on pre-established plans and procedures. In each of these situations, a disaster becomes 'out of the box' to the responding EMO-unit. We define a 'disaster out of the box' as a disaster that jeopardizes the performance of a responding EMO-unit, so the unit goes through an organizational crisis (De Smet et al., 2012).

\section{Disaster Phase Research}

From the beginning of the $20^{\text {th }}$ century, the life cycle concept was widely used by social scientists. They usually employ it in a metaphorical way to simplify complex social phenomena "by invoking familiar schema in scientific thought" (O'Rand \& Krecker, 1990, p. 242). Accordingly, disaster scientists have identified and defined different phases during the course of a disaster to impose order and rationality to a complex reality (Richardson, 2005).

Although disaster's pioneer Prince had previously mentioned three different stages during disaster relief activities (Prince, 1920), the idea of disaster phases was first explicitly introduced and described by Carr, who uses a four-stage pattern (1932, pp. 221222). The first phase is the preliminary or prodromal phase during which the forces that are to cause the ultimate collapse are building up. Next comes the dislocation and disorganization phase with injured, deaths and losses caused by the collapse of a community's protection system. The third phase is called the readjustment and reorganization 
phase and consists of the community's attempt to respond to the disaster. Carr also considers a confusion-delay phase, reflecting the period between the onset of the disaster until the time the emergency plans begin to operate. Later, other researchers like Powell (1954), Fritz and Mathewson (1957), Chapman (1962), and Stoddard (1968) expanded and complemented Carr's initial phase model. A common feature of early disaster studies is that they consider a set of disaster phases occurring sequentially, are thus linear, in time (Coetzee \& van Niekerk, 2012) and essentially focus on response and relief efforts, ignoring recovery and mitigation (Barton, 1970; Neal, 1997).

This traditional approach to disaster management started to change during the 1970s, a period characterized by a substantial increase in disaster events. With the growing human and economic losses following disasters came the realization that predisaster activities must supplement the traditional approach (Lewis, O'Keefe, \& Westgate, 1976). In addition, researchers found that disasters follow a general temporal sequence regardless of the disaster agent (e.g. explosion, flooding, etc), so they consequently argued for an all hazards approach (Dynes, 1970; Quarantelli, 1982b). By the end of the 1970s, the National Governors' Association (1978) developed the four phase comprehensive emergency management (CEM) concept, a holistic approach to disaster management. The initial phase is mitigation and focuses on reducing societal vulnerability and preventing or stopping disasters before they happen (Lindell \& Perry, 1992). Obviously, mitigation efforts cannot prevent all disasters from happening, so a preparedness phase is required to build up the readiness to respond to a disaster (Haddow, Bullock, \& Coppola, 2011). Despite good mitigation efforts and up-to-date preparation initiatives disasters will always happen. As a consequence, response activities remain necessary to save as many lives and property as possible and to prevent an escalation of the situation. Finally, recovery activities focus on restoring the normal, i.e. the predisaster state of the society. Though it is not exactly clear when exactly the traditional sequential and thus linear disaster phase model became illustrated in a cyclical manner (Coetzee \& van Niekerk, 2012), the National Governors' Association argues that CEM is cyclical in relationship rather than linear (1978), because all activities lead individually and cumulatively back to the mitigation phase (FEMA, 1995, p. II-2). Today, the use of the four phase CEM model is widely adopted as a holistic disaster management framework (Cronstedt, 2002) and as a useful device for disaster researchers to develop and organize research projects, to codify data and to classify findings (Neal, 1997).

Present-day disaster studies mainly focus on mitigation efforts, risk reduction and resilient societies (McBean, 2012; Weichselgartner, 2001). Unfortunately, despite the most effective mitigation efforts and the most comprehensive preparedness programs, disasters will still strike and disrupt entire societies (Coppola, 2011; Wildavsky, 1988). As a consequence, disaster response remains a vital aspect of disaster management and will even become more important given that societies will, by all odds, be more heavily affected in the future and that a lot of modern disasters have the potential to become 'out of the box' to the intervening EMO-units (Boin \& Lagadec, 2000; De Smet, Schreurs, 
\& Leysen, 2014; Helsloot et al., 2012b; Lagadec, 2009a; Rosenthal, 1998). The disaster context has changed considerably and the dominant response theories and practices have become outdated, as demonstrated by recent events such as the 9/11 disaster (2001), the Southeast Asia Tsunami (2004), the Deepwater Horizon oil spill (2010), Hurricane Katrina (2005), Haitian earthquake (2010), etc. Therefore, academics emphasize the need for a renewed understanding of responding to modern disasters (Lagadec, 2009a; OECD, 2003; Robert \& Lajtha, 2002).

Until the present day, the response phase has simply been described as the third phase of the disaster management life cycle, during which a variety of activities aimed at stabilizing the situation and at limiting injuries, loss of life and damage to property and the environment, take place (National Governors' Association, 1978). However, recent research demonstrates that the nature of disasters affecting a society has experienced important changes, so a lot of modern disasters have an increased potential to become 'out of the box' to the intervening EMO-units (De Smet et al., 2014). On that account, the study described in this chapter takes a new and fresh approach. We aim to remodel the response phase within the context of the changing disaster landscape, and do so from a process-based perspective. We consider the response phase of the disaster management life cycle as an unfolding global process of stages and sub-processes rather than just an enumeration of potential activities. The advantage of a processbased approach is that it supports the complex and non-linear explanations about how and why sequences of events occur (Pugliese et al., 2016). As such, our study responds to Neal's call to reexamine empirically and theoretically the issue of disaster phases (Neal, 1997) as well as to the need for a renewed understanding of responding to modern disasters (Lagadec, 2009a; OECD, 2003; Robert \& Lajtha, 2002). It therefore addresses and makes a contribution to the existing disaster and emergency management literature.

\section{Method}

\section{Sample and Procedure}

In order to develop the global response phase process, we selected people having considerable experience with emergency planning and disaster management to participate in the study as illustrated in Table III - 3. 
Chapter 3

Table III - 3: Interviewee sample selection

\begin{tabular}{|c|c|c|c|}
\hline Function & Expertise & Number contacted & Number participated \\
\hline $\begin{array}{l}\text { Public officials at the } \\
\text { provincial level in } \\
\text { Belgium }\end{array}$ & $\begin{array}{l}\text { As a commissioner of the federal as well } \\
\text { as the regional government, the public } \\
\text { official is responsible for the execution } \\
\text { and application of federal law. Within this } \\
\text { context, he is responsible for disaster } \\
\text { planning in his province. } \\
\text { He is also the formal authority during } \\
\text { disasters on a provincial level and } \\
\text { responsible for strategic coordination } \\
\text { and decision-making. }\end{array}$ & 10 & $\begin{array}{l}8 \\
\text { (participants 1-8) }\end{array}$ \\
\hline $\begin{array}{l}\text { Public servants } \\
\text { responsible for } \\
\text { emergency planning in } \\
\text { the Belgian provinces }\end{array}$ & $\begin{array}{l}\text { As an advisor to the governor of the } \\
\text { province, he is responsible for the } \\
\text { actualization of the existing emergency } \\
\text { planning, the organization of emergency } \\
\text { exercises and disaster training, the } \\
\text { elaboration of a risk analysis, etc. He also } \\
\text { is the principle assistant of the governor } \\
\text { during disasters on a provincial level. }\end{array}$ & 10 & $\begin{array}{l}9 \\
\text { (participants } 9-17)\end{array}$ \\
\hline $\begin{array}{l}\text { People in charge of } \\
\text { EMOs }\end{array}$ & $\begin{array}{l}\text { People having a leading function in } \\
\text { formal EMOs such as the Belgian Federal } \\
\text { Police, the Belgian Fire services, the } \\
\text { Belgian Civil Protection, The US Coast } \\
\text { Guard, FEMA, etc. }\end{array}$ & 6 & $\begin{array}{l}4 \\
\text { (participants } 18-21 \text { ) }\end{array}$ \\
\hline $\begin{array}{l}\text { Experienced } \\
\text { emergency managers }\end{array}$ & $\begin{array}{l}\text { People having an experience as a senior } \\
\text { emergency worker during disasters such } \\
\text { as the Heysel Stadium soccer riot } \\
\text { (Belgium, 1985), the Herald of Free } \\
\text { Enterprise disaster (Belgium, 1987), the } \\
\text { Ghislenghien gas explosion (Belgium, } \\
\text { 2005), Hurricane Katrina (USA, 2005), } \\
\text { etc. }\end{array}$ & 5 & $\begin{array}{l}3 \\
\text { (participants } 22-24)\end{array}$ \\
\hline
\end{tabular}

Each person was e-mailed a letter in which we described our research. We also explained the notion of 'disaster out of the box', presented the research questions and asked the addressee for a face-to-face interview. The research questions are:

- How should an emergency worker or a disaster manager react when his/her organization was hit by a 'disaster out of the box'?

- How should a disaster management organization be organized to deal with a 'disaster out of the box' efficiently and effectively?

- How can disaster managers plan and coordinate their activities, and train their staff in order to manage a 'disaster out of the box' efficiently and effectively?

We contacted 31 people: 28 in Belgium, 2 in the United States and 1 in France (see Table III - 3). If the person agreed to cooperate, an appointment was made and the interview took place at the time and the location of his/her choice. 
In total, 24 persons (77.42 \%) accepted an interview: 22 in Belgium, 1 in the United States (a senior emergency manager who was given full command of the Bush administration's Hurricane Katrina onsite relief efforts) and 1 in France (an expert in risk management and the management of international crises). All the interviews were conducted by the same researcher between April 2008 and February 2009. The interviews were audio recorded and transcribed verbatim to keep detailed records. This permitted us to systematically analyze the raw data. The interviews had an average duration of one hour and no person was consulted more than once.

\section{Data Collection and Analysis}

Data collection and analysis was performed using the 'responsive interviewing approach' developed by Rubin and Rubin (2005) and used by several other researchers (Bauman, 2012; Revell, 2013; Simpson, Fougere, \& McGee, 2013). The methodology is based on social constructionism which states that meaning is not inherent (Harris, 2010) but depends on what people make of the world around them. Interpretive research aims at understanding the production of meaning and concepts by social actors belonging to a particular group or cultural arena (Gephart, 2004).

In our case, the group consists of disaster management specialists, by experience as well as by education. The data obtained by the approach represent the interviewees' interpretation and understanding of reality, i.e. their social construction of reality. As such, the method allows us to identify common experiences and meanings, but also unexpected or divergent views held by disaster management experts.

At the beginning of each interview, the interviewer briefly clarified the 'disaster out of the box' concept and recapitulated the three research questions. During the interview, the research questions were used as a road map to 'guide' the conversation. The interviewer's main task was to listen carefully and to ask follow-up questions to further explore areas of specific significance.

Data analysis for this research occurred in two stages. During the first stage each interview was immediately transcribed and then thoroughly examined for concepts (i.e. a core idea important to the research problem) and themes (i.e. a statement that explains what something means - themes are built up from the concepts) (Rubin \& Rubin, 2005) related to the research questions. The identified concepts and themes were consistently defined, relying on literature where appropriate, and used to code the interview. Coding was done using ATLAS.ti (version 5.2.17). Although each interview covered the same broad topics, we used the concepts and themes identified on the basis of previous interviews to ask more specific questions. This approach of chronologically and systematically analyzing the interviews permitted us to elicit further rich details, to explore areas of special significance and to complete our set of concepts and themes (Holstein \& Gubrium, 2004). At the completion of this first stage of the analysis a set of 49 concepts and 8 themes was identified (Table III -4), which constituted the final codebook. 


\section{Chapter 3}

During the second phase, all the interviews were analyzed and recoded a second time in the same chronological order, using the final codebook (code by list).

Table III - 4: Responsive interviewing - Themes and concepts

Themes Concepts

Event assessment process

Assessment process during which the responsible authority evaluates the event he and his organization have to deal with.

Action plan

A sequence of activities that must be performed by the intervening EMO-units to deal with the event in an efficient and effective way.

Decide action plan

A formal decision made by the responsible authority about the action plan to be executed.

Update action plan

Regular update of the action plan in accordance to the latest available information.

Classify the event

Put bounds and limits on what is really going on for the purpose of being able to develop an action plan.

Critical thinking

Reasonable reflective thinking focused on deciding what to do (Ennis, 1997).

Implement action plan

The definitive action plan must be communicated to all intervening EMO-units for instant implementation.

Execute action plan

The action plan must be executed without further discussion, contest or resistance.

Mental model

Mental models are cognitive representations of external reality that people use to anticipate events, reason, and form explanations (Craik, 1943; Jones et al., 2011).

Routine disaster

Similar events have been faced many times before in a way that people have developed rules and practices which make them potentially manageable (Leonard \& Howitt, 2007).

No routine disaster

The event demonstrates a significant novelty as a result of what it cannot be completely assimilated and that existing rules and practices are inadequate (Leonard \& Howitt, 2007).

Coordination

Coordination is mutually agreed linking of activities of two or more groups (Quarantelli, 1988).

Communication

The dissemination of timely and accurate information.

High level coordination

High level coordination is performed at the level of the responsible authority who has a

holistic vie of the situation.

Low coordination

Low level coordination is based on informal linkages or interpersonal contacts

(Alexander, 1998) by people on site who have a narrow view of the situation. 


Themes Concepts
$\begin{aligned} & \text { Decision-making } \\ & \text { Decision-making is making a choice between various courses of action. } \\ & \qquad \text { Effective decision-making } \\ & \text { An effective decision is a decision with high quality and which is accepted by those who } \\ & \text { must execute the decision (Maier, 1963). } \\ & \text { Quick decision-making } \\ & \text { Decisions in disasters need to be taken very urgently since delay may cost lives. }\end{aligned}$

Disruptive disaster

A disaster becomes disruptive or 'out of the box' to (De Smet et al., 2012) an intervening EMO-unit when its effects produce an organizational crisis to that unit (i.e. the EMO-unit can no longer realize its objectives).

Disruptive in decision-making

The leader of an organization is no longer capable of make further decisions and looses command and control.

Disruptive in magnitude

The disaster is of such a magnitude and complexity that it becomes 'out of the box' to the intervening EMO-unit(s).

Disruptive in resources

An intervening EMO-unit is disruptive in resources when it has not enough resources to deal with the disaster.

Unprecedented

Never before experienced (inconceivable).

Disaster Management Organization (DMO) building up process

The process during which the DMO is built up in a progressive way.

\section{Multiteam system}

Multiteam systems (MTS) are complex entities that contain multiple teams that must work cooperatively and interdependently toward a common set of goals, which demands both vertical and horizontal alignment of sub-goals and synchronized actions with other teams in the MTS (Marks et al., 2005).

Parent organization

Parent organizations provide MTSs with resources, structures, and practices, and install specific cultures, knowledge, and languages within their separated teams (Uitdewilligen \& Waller, 2012).

Disaster Management Organization

A DMO is a temporary MTS, composed of units coming from different EMOs (e.g. fire brigade, civil protection, police, etc.), which objective is to manage the disaster in the most efficient and effective way.

DMO structure

The way the DMO is organized.

DMO authority

The person who has the legitimate authority to make decisions.

Legitimate authority

Legitimate authority is authority which is based on rational grounds and anchored in impersonal rules that have been legally enacted or contractually established (Weber, 1947).

Organizational (dis)trust

Members of units coming from the same EMO typically work closely with one another and develop trust easier than members of units coming from different EMOs, having different cultures, norms, values, skills, etc. 


\begin{tabular}{ll}
\hline Themes & Concepts \\
\hline (Lack of) cooperation \\
The EMO-units of a DMO have to work cooperatively and interdependently toward a \\
collective goal which implies that the different proximal goals of the EMO-units must be \\
aligned with the distant DMO-goal (Mathieu, Marks, \& Zaccaro, 2001). \\
Organizational conflict \\
The presence of units coming from different EMOs, having different cultures, norms, \\
values, skills, etc., suggest a greater likelihood of conflict.
\end{tabular}

Leadership

The ability of an individual to influence, motivate, and enable others to contribute towards the effectiveness and success of an organization (House et al., 2004, p15).

\section{Directive leadership}

A directive or autocratic leader makes decisions alone, using information that is readily available or that is collected by followers (Vroom \& Yetton, 1973).

\section{Empowering leadership}

Empowering leaders share power with followers by providing additional responsibility, autonomy, and decision-making authority. Empowering leadership manifests through specific behaviors such as encouraging followers to express opinions and ideas, supporting information sharing, promoting teamwork etc. (Lorinkova et al. 2013, p573).

Combined leadership

A leader who has the ability to combine directive and empowering leadership according to the situation.

\section{Lack of leadership}

A lack of leadership should be interpreted as laissez-faire leadership as describes by Bass and Avolio (1990, p. 20): "the absence of leadership, the avoidance of intervention, or both".

Need to decide

Even if decision-making is the key distinctive activity of all managers, the need for it increases dramatically in a disaster context because any delay may cost lives (Cosgrave, 1996).

Legal obstacles to decide

Restrictions placed on disaster managers by administrative practices (Kirschenbaum, 2004) or legislation.

Response phasing process:

The process during which different consecutive response activities take place.

Disbelief

A confusion-delay phase reflecting the period between the onset of the disaster until the emergency plans begin to operate (Carr, 1932).

Operational response

Operational response activities essentially focus on saving as much live and property as possible. The emphasis is on quick reaction and the greater part of the actions is short term oriented (De Smet et al., 2011).

Organized response

Disaster response by units coming from different formal parent EMOs.

Lifesaving operations

Actions which have as main characteristic saving as much lives as possible.

Private initiatives

Initial actions after the impact of a disaster executed by people on site or people accidently in the vicinity.

Strategic response:

Strategic response consists of premeditated actions and are long-term oriented. 


\begin{tabular}{|c|c|}
\hline Themes & Concepts \\
\hline \multicolumn{2}{|c|}{$\begin{array}{l}\text { Training: } \\
\text { Training is } \\
\text { consists of } \\
\text { performan }\end{array}$} \\
\hline & $\begin{array}{l}\text { Expanded routine level } \\
\text { An expanded routine level is attained by implementing lessons learned and experience in } \\
\text { the existing routine level }\end{array}$ \\
\hline & $\begin{array}{l}\text { Train responsible authorities } \\
\text { Training should not only be done by followers and operational team leaders, but also by } \\
\text { strategic DMO-level leaders. }\end{array}$ \\
\hline & $\begin{array}{l}\text { Learning critical training } \\
\text { Learn and train critical thinking. }\end{array}$ \\
\hline & $\begin{array}{l}\text { Normal training } \\
\text { Training of routine activities. }\end{array}$ \\
\hline & $\begin{array}{l}\text { Disruptive training } \\
\text { Training beyond routine activities. }\end{array}$ \\
\hline & $\begin{array}{l}\text { Knowing each other } \\
\text { To have an experience of working together (or at least knowing each other in a more or } \\
\text { less formal way) which facilitates collaboration. }\end{array}$ \\
\hline & $\begin{array}{l}\text { Lessons learned } \\
\text { To learn from past experience (exercises and/or real events) in order to broaden the } \\
\text { actual knowledge. }\end{array}$ \\
\hline & $\begin{array}{l}\text { Scenario thinking } \\
\text { Scenario planning is not about predicting the future, but about thinking and describing } \\
\text { what is possible, about bringing together a wide range of perspectives in order to } \\
\text { consider scenarios other than the widely accepted ones (Wack, 1985) (2012; Wack, } \\
\text { 1985). }\end{array}$ \\
\hline & $\begin{array}{l}\text { Learn to be proactive } \\
\text { Proactive thinking means to think ahead, in anticipation of future changes or problems. }\end{array}$ \\
\hline
\end{tabular}

The analysis procedure allowed us to remodel the response phase of the disaster management life cycle within the context of 'disasters out of the box'. The study permitted us to identify, describe and understand the global response phase process and its ensuing sub-processes which are further clarified in the next paragraph.

\section{Findings}

The data from this study reveal that the response phase of the disaster management life cycle evolves as a global process through a series of stages (paralysis, operational response and strategic response) which entails some important sub-processes: the process of gradual buildup of capacities, the coordination process and the event assessment process (Figure III - 8). The subsequent sections discuss the findings in detail. 


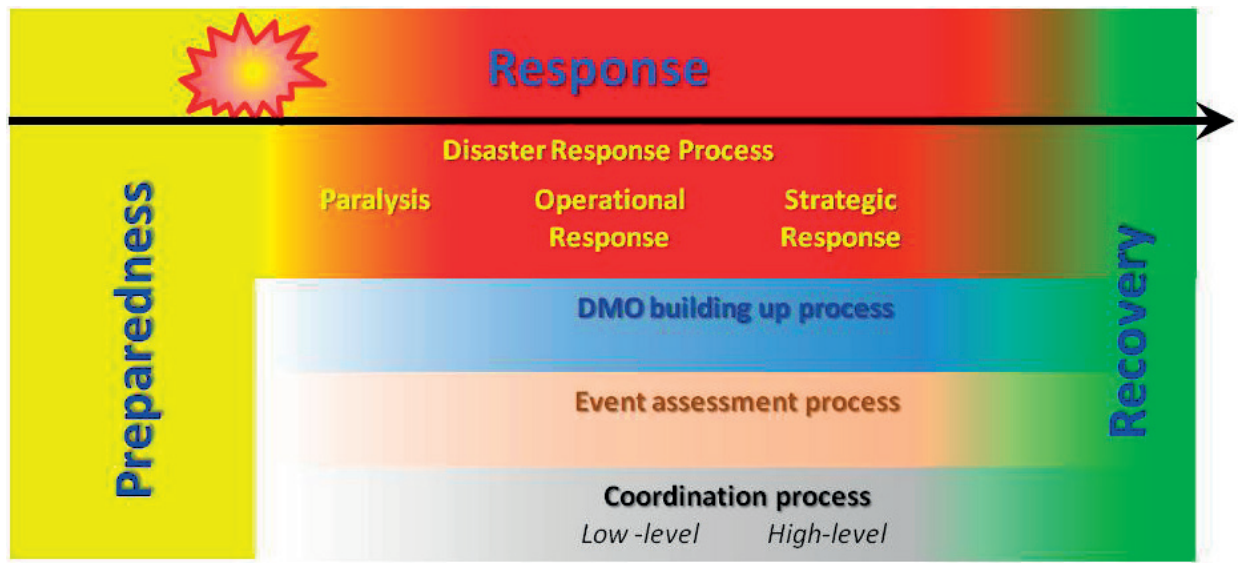

Figure III - 8: Response phase process

\section{The Disaster Response Process and the Gradual Building up of Capacities}

\section{Paralysis}

When a disaster hits a community or a society, at first there is confusion and disbelief among its residents and the people present in the stricken area, bringing about a state of paralysis. For a while, there is a gap of action in the relief work following a disaster. As interviewees pointed out:

The first reaction to a disastrous event is disbelief. People do not realize, neither believe, what is really going on. It takes time to become fully aware of what exactly happened to them, which provokes a state of paralysis. (Participant 16)

From the moment people are confronted with something severe, with circumstances beyond their control, they experience disbelief. It takes time for them to realize what happened. (Participant 20)

If the unthinkable happens, it takes time to realize the unthinkable has happened. (Participant 22)

The period of disbelief was first observed by Prince in his study of the 1917 Halifax disaster. Prince notes (1920, p. 42).

At first all was confusion. Some ran to the cellars. Some ran to the streets. Some ran to their shops. Those in the shops ran home. This was in the area of wounds and bruises. Farther north was the area of death.

In her narrative about the Halifax explosion, Mac Donald describes the time following the Halifax blast as following (2005, p. 69) : 
The air was the color of bruised plums. The first few moments were marked by a still silence until survivor's memories returned and they relived the moments preceding the explosion.

Later on Carr (1932) specified this period between the onset of the disaster until the plans begin to operate as the 'confusion-delay phase'. He further states that the duration of this period of inactivity can vary considerable from a few minutes to several days and is influenced by the characteristics of the disaster (scope, violence and complexity) and by the community's culture. Later on, researchers refer to this period as disaster shock or the disaster syndrome (Melick, 1985; Menninger, 1952), which is a state of detuned psychological incapacitation that results in the inability to take care of oneself or others (Auf der Heide, 2004). Their most important conclusions are that the disaster syndrome appears most frequently in sudden-onset and low forewarning events and that the symptoms are relatively mild and displayed by only a relatively small proportion of the disaster stricken population. They furthermore conclude that the syndrome usually persists for a maximum of a few hours following the impact (Perry \& Lindell, 2003). Our interviewees underline that when a disaster becomes 'out of the box', the period of paralysis and inactivity will be more significant.

When a disaster 'out of the box' hits a society, the social structure which is responsible for the wellbeing of its residents is totally cut off. Even the organizations responsible to intervene undergo the event. They are a victim as well and are not able to respond. (Participant 16)

In case of a real disrupting disaster, the local response organizations undergo a process evolving from unbelief to consciousness-raising. (Participant 13)

Sapirstein (2006) emphasizes that he duration of the state of paralysis is as well related to the community's degree of social resilience, i.e. the time needed for the community to respond and to bounce forward after a disaster.

\section{Operational Response}

After some time, when people begin to realize what is really happening, relief operations start and the response process evolves into the stage of operational response. Initial response arises from individual initiatives. The first to react are often the uninjured victims or people who are nearby. They start to search for survivors, care for those who are injured, and assist in protecting property from further damage. Disaster victims initiate such acts of first aid, rather than passively await intervention by governmental authorities. Such an attitude of responsible activism (Perry \& Lindell, 2003) is emphasized by several interviewees.

At first you always have the local civil society to react. People hear that something bad has happened and rush to the stricken area to lend assistance. These 
are personal initiatives which are very important and which are generally underestimated. (Participant 18)

Very important is the spontaneous mutual assistance [...]. The existence of a social climate of mutual aid should be stimulated. (Participant 6)

The naturally occurring civic first aid initiatives are gradually complemented and taken over by units coming from alarmed EMOs such as units from fire brigades, medical units, SAR-teams, etc. and the response activities become more structured. The major objective of these first response activities is to save as much life and property as possible. For that, they have limited time so they must decide quickly and seize initiative without having fear to "act first and think later". Quick reaction is the rule. Interviewees expressed this idea as follows.

During life-saving operations, there should be no concern of means and resources, no thinking about possible costs. (Participant 18)

All available resources must be put into action to save lives. Every saved person is important and the victims must realize that they are not left to fend for themselves, that they are taken care of. (Participant 4)

Because there is no time to be lost, quick decision-making at the risk of occasional error is preferable to extended deliberation and discussion (Mac Donald, 2005). Moreover, decision makers should be given full authority to carry out their roles and respond to the event as they feel appropriate without fear of future sanctions (McConnel \& Drennan, 2006).

Operational response activities mainly include search and rescue, first aid medical treatment, suppressing fires and securing the disaster area. These activities, which are part of the core duties of the intervening EMOs, can thus be considered as routine activities and reflexive action as stated by different interviewees.

It is the level of reflexive action implying routine decision-making. People rely on knowledge, acquired experience from earlier training and lessons learned from past events. (Participant 16)

We are learned and trained to react immediately, to taken instantaneous decisions and to execute them at once. This is the level of routine tasks. First responders have to master these activities; otherwise they are not worth to be called first responder. (Participant 15)

\section{The Gradual Buildup of Capacities}

During the operational response stage, the 'process of gradual building up of capacities' in the disaster zone into a full-fledged Disaster Management Organization (DMO) takes place. As stressed by different interviewees, a DMO is composed of organizational elements coming from different parent organizations. 
It is an architecture of different services. (Participant 14)

A lot of people belonging to different institutions are involved by the management of the disaster. (Participant 4)

The parent organizations of a DMO are essentially public EMOs such as a fire brigade, medical emergency services, civil protection, the police forces or national defence units and communication services. Therefore, a DMO can be considered as an organizationalbased temporary organization, occasionally complemented by emerging groups of volunteer responders (Kreps \& Bosworth, 2006), actors from the private sector (Boin \& McConnel, 2007) and non-governmental organizations (NGOs), and which is directed by a managing authority (DMO-authority) who is surrounded by a strategic group of advisory specialists. An organizational-based temporal organization is defined as an interorganizational constellation, "based on the temporary contributions of manpower, resources and organizational units provided by parent organizations over a limited period" (Raab et al., 2009, p. 173). The work of a DMO is thus of limited duration, but the contributors, the EMOs, are not.

\section{Strategic Response}

The responsibility of the DMO-authority is to direct all disaster management efforts efficiently and effectively. This necessitates extensive data collection and event assessment in order to organize and coordinate the activities required to stabilize the situation, to prevent further damage and even to prepare initial recovery activities. As underlined by several interviewees, emphasize shifts from operational quick reaction activities to strategic response, including long term thinking and well-considered and premeditated actions

During strategic response, where the emphasis is no longer on saving lives, you only take well thought, well-calculated and accepted risks. (Participant 18)

During this stage in the disaster, it is better to wait until a higher level of authority, which is surrounded by specialists, gives well-evaluated instructions because reflexive actions can sometimes do more harm than good. Well-thought-out plans entail the establishment of priorities which are based on an assessment of the entire disaster zone. (Participant 17)

It is clear that the leitmotiv of decision-making during this stage of disaster response changes from 'act first, think later' into 'think first, and act later'.

\section{An Evolving Coordination Process}

The first operational response activities, and especially the individual first aid initiatives, are essentially uncoordinated, as noted by several interviewees. 
During the first phase of response activities, there are many individual initiatives which are extremely important and which are very often underestimated. And of course, these activities are absolutely uncoordinated. [...] The first aid activities are essentially uncoordinated, but this is not bad. You always try to avoid an overlap of activities, but at that moment this is not the most important issue. Every saved person is of vital importance so the victims have the feeling that they are not left to fend for themselves. (Participant 16)

I think, at that stage of the operations, it would be a mistake to have a rigid structure. This is about organizing. And organizing takes time, which you don't have. (Participant 4)

Once EMO-units arrive on the disaster scene, response activities become more structured. Yet, these units have generally an imperfect view of the situation, often limited to their zone of intervention. Consequently, low-level coordination activities are restricted in time and space and essentially exist of the exchange of information.

Involved units will automatically exchange information to get a better view of the situation. (Participant 5)

Later, once the DMO has been created and the DMO-authority and his group of specialists supervise the operations, high-level coordination becomes more important. Based on a global and panoramic view of the whole disaster zone, the DMO is able to put in place the capacities to respond to the disaster in the most adequate way.

We had a broad view of the situation and consequently knew more. (Participant 18)

Your ability to take a broad view of things and trying almost lift yourself up and look down at the earth and say "if I would detach and look down, what would this look like if I wasn't in the middle of it. (Participant 24)

Connecting the different dots becomes the key to success. (Participant 11)

The manager has to be seen as the conductor of an orchestra. He may not fall into details, but must be interested in the overall sound and how the orchestra is going to end the piece. (Participant 9)

\section{The Event Assessment Process}

It is obvious that decision-making is very important during disasters. High-quality decisions are based on good situational assessment, even within the context of quick reaction during the operational response stage (e.g. triage by which victims are ranked according to the seriousness of their injuries, ensuring that the highest priority cases are transported to medical facilities before less serious ones). During the strategic stage, 
situational assessment evolves into a more holistic assessment of the entire event as highlighted by the interviewees.

You need to assess what is going on. Only then you can give good directions to deal with the event. Otherwise it is conceivable that you worsen the situation. (Participant 11)

Individuals need to assess the event to optimize the chances for success. (Participant 24)

Within the context of the changing disaster landscape, and particular with 'disasters out of the box', the significance of strategic responses increases considerably. Existing disaster and emergency management theory does not provide clear-cut answers for such events and disaster managers cannot fall back on pre-established plans and procedures to deal with them (De Smet et al., 2012; McConnel \& Drennan, 2006). According to an experienced emergency manager, the major challenge for the DMO-authority is to create a clear mental model of the situation, following a three-step event assessment process (Figure III - 9) that allows the DMO-authority to 'take' and 'make' time to make appropriate strategic decisions.

\section{DMO-authority 'event assessment process'}

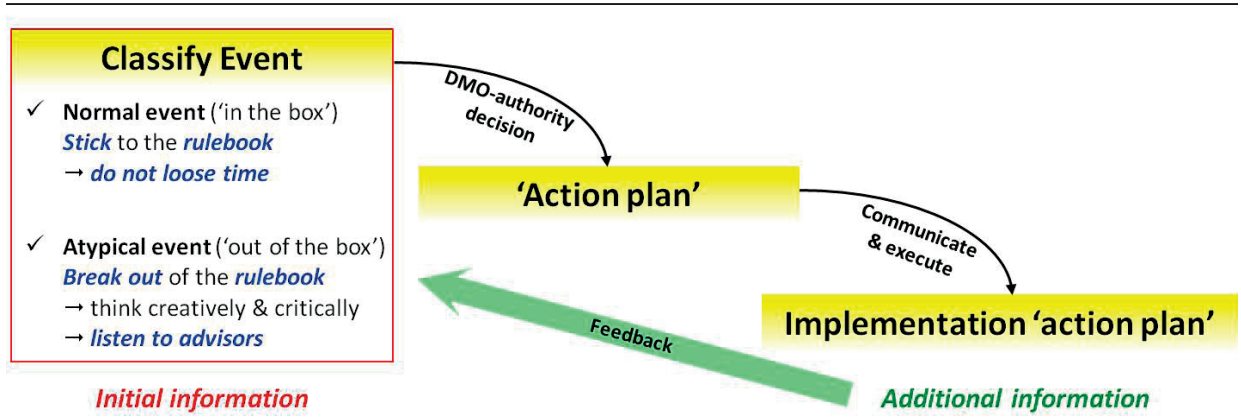

Figure III - 9: Event assessment process

In everybody's mind who was dealing with the event, this was just a hurricane. What I did that was different was that I was operating beyond their mental model and their paradigm on how to do disaster response. (Participant 24)

The first step of the event assessment process consists of classifying and defining the event. In other words, determine what is 'really' going on. The same emergency manager underlines that the DMO-authority must decide if one is dealing with a normal event for which a rulebook (i.e. known and trained procedures) exists and can be implemented, or if one faces an atypical event -'out of the box'-for which the normal procedures do not fit any-more. 
The first thing to do for a responsible authority is to take a step back and think, before making any decision. Is this a normal disaster? If not, at what point it is not? [...] We have lots of hurricanes in the United States and the way hurricane response works in the United States works. What we did not understand when Katrina came ashore, was that we were dealing with something that was beyond current institutions and current planning to deal with. Therefore, you have to figure out, to classify the event and then to decide. None of that happened. And the reason none of that happened is that in everybody's mind this was just a hurricane. What happened was that Katrina was not a hurricane. When the levees were breached in New Orleans, the effect was the equivalent of having a weapon of mass effect used on the city of New Orleans without criminality. In such a context, basic rules won't apply, existing procedures and agreements may be inadequate to the task. (Participant 24)

Other interviewees further state that when dealing with normal events, the rulebooks must be followed as closely as possible in order not to lose any time.

You do not deviate from existing procedures as far as possible, because people are used to routines. (Participant 22)

Emergency plans are very useful. When an emergency hits, immediately implement them. (Participant 11)

On the other hand, when facing a 'disaster out of the box', they also agree that the DMO-authority is forced to operate beyond normal limits. Consequently, standard procedures will not be sufficient and people need to break out of the rulebook. They must think in a creative and critical way to deal with the situation.

If an emergency does not fit in the rulebook, then you cannot follow the rulebook. If it is 'out of the box', you need to get out of your rulebook. (Participant 10)

You have to understand when you are not operating within normal limits any more. (Participant 24)

Once the disaster is classified and defined, the DMO-authority, in close cooperation with his group of advisory specialists, must decide the appropriate course of actions (Cosgrave, 1996). He must define the objectives of the interventions, determine the criteria for success and develop an action plan based on a holistic and long-term view of the situation. Interviewees agree that the DMO-authority should trust his advisors (listen to them), but that he has full responsibility for making the final decisions about what has to be done. A good DMO-authority therefore must be a strong leader; directive if possible, empowering when needed (Arnold et al., 2000; Lorinkova et al., 2013). 
Before an emergency, you have prepared, planned and trained personnel to deal with normal emergencies. When this happens, you want your people to follow the rulebook immediately (Participant 23)

When you leave the terrain of routine-business, the decision-maker must take a step back, think and listen to his advisors. (Participant 12)

You need somebody who takes the decisions, who establishes priorities and dares to cut the knot based on the available information. (Participant 17)

In an emergency situation, there is need for strong leadership, for someone who dares to take the responsibility to take decisions. (Participant 13)

The final step implies the implementation of the action plan. The majority of the interviewees accentuate that once the decision about the action plan has been made, it must be executed as fast as possible without any contestation.

At that moment, there is no time for contestation. The plan cannot be contested and consequently it must be accepted. All what matters is the speed and effectiveness of the execution of the plan. (Participant 4)

When the leader takes a decision, it has to be enforceable. (Participant 19)

First, the plan has to be communicated to all the involved units in order to execute a unified response to the situation. Once implementation is started, the action plan must be updated and adapted frequently, on the basis of the latest available information.

What we ended up doing was to make a plan each day and we were telling the people what we were going to do the next day. (Participant 24)

A plan should be a living document. It must be up-to-the-minute and adapted accordingly. (Participant 17)

\section{Discussion}

Using the 'responsive interviewing approach' (Rubin \& Rubin, 2005), this study explored how the response phase of the disaster management life cycle can be remodeled, taking a new and fresh approach. First, we studied the response phase within the context of the changing disaster landscape. Recent research has revealed that a lot of modern disasters have the potential to evolve into 'disasters out of the box' for the intervening EMO-units (De Smet et al., 2014), which should enforce us to rethink the acquired paradigms if we want to be well prepared to deal with future events (Lagadec, 2009a; Robert \& Lajtha, 2002). Second, we followed a process-based approach to explain the complex sequence of response events and activities after disaster impact (Pugliese et al., 2016). Our study reveals that the response phase is more than just a set of activities 
that disaster managers can appeal to in order to stabilize the situation, and to limit injuries, loss of life and damage to property and the environment. The data show that the response phase evolves as a comprehensive process through three succeeding stages (paralysis, operational response and strategic response), which entail some important sub-processes (gradual buildup of capacities in the disaster zone, the coordination process and the event assessment process). Therefore, our study provides an important contribution disaster scholarship.

\section{A Response Process of Three Succeeding Stages}

Even though the four phase CEM model has been widely adopted as the standard management framework and is considered a cornerstone of modern disaster management and research (Cronstedt, 2002), academics have raised some important observations which are also appropriate to the three stages of the response phase. A first conclusion is that the four phases of the CEM model cannot be considered as discrete and successive events that mutually exclude each other (Haas, Kates, \& Bowden, 1977; Hogg, 1980; Phillips, 1991; Quarantelli, 1982a). They overlap and blend into one another and are mutually interconnected such that activities within one phase may influence a subsequent phase (Neal, 1997). This observation is equally applicable to the stages of the response phase. There are no strict limits between the different stages. Paralysis progressively merges into and partly overlaps with operational first response activities, which gradually become more strategic in nature.

A second significant comment with regard to the phases of the disaster management life cycle is that different regions within the disaster area may experience and go through the disaster phases at different times. This entails that different disaster phases may occur simultaneously during the same disaster. As such, individuals or groups within the stricken area may pass from response to recovery more quickly than others. Therefore, Neal (1997) emphasizes that disaster activities are forced back to social time rather than clock time. Disaster management activities must be executed according to the needs and opportunities, just like farmers will harvest crops when they are ready and not on an a priory fixed date (Giddens, 1987). This observation is also valid for the three stages of the response phase. For example, when a vast region is struck by a disaster, human impact and consequently paralysis will be more explicit in the vicinity of the impact zone. As a result, operational response activities can last for several days in that area. At the same time, more strategic activities such as precautionary evacuation of people can take place further away from the direct impact zone. In addition, the three stages (paralysis, operational response and strategic response) should not be interpreted in a deterministic way, assuming that each stage must necessarily be passed through before the next stage can occur. During some disasters, there will hardly be any paralysis and relief activities start immediately. In addition, certain operational response activities generally continue during strategic response. 


\section{Paralysis}

The data of our research show that when a disturbing event hits a community or a society, a period of paralysis follows. This stage of inactivity can be linked up with the 'cosmology episode' defined by Weick (1985). A cosmology episode occurs when an event, which is for instance highly unlikely or inconceivable (Lanir, 1989), strips away all frames of reference (structure) and causes a disintegration of sense making or a loss of meaning (Weick, 1993). Richardson (2005) for instance, describes the period of time immediately after the trigger event as an cosmology episode.

Though Weick (1993) links the cosmology episode to panic, several authors point out that the state of paralysis after a disaster impact should not necessarily be confused with panic. Quarantelli for example defines panic as "an acute fear reaction marked by a loss of self-control which is followed by non-social and non-rational flight" (1954, p. 272). Consequently, panic involves irrational flight that is carried out with complete disregard for others (Clarke, 2002; Scanlon, 1992). In this context, Auf der Heide (2004) emphasizes that antisocial behavior in the immediate aftermath of a disaster is uncommon. Moreover, several studies demonstrate that panic is essentially a media-driven stubborn myth (Cocking \& Drury, 2014; Dynes, 2003) and thus a common misconception. It has nothing to do with the state of paralysis as described in this article.

\section{Uncoordinated Operational Response Operations are not that Bad}

Disaster response is a process of gradual building up of capacities. On site first aid civic initiatives are gradually complemented and taken over by units coming from the alarmed EMOs and finally a full-fledged well-structured DMO is established. The first response operations are poorly structured and essentially uncoordinated. Due to the context, this is understandable and even not that bad as emphasized by Van Heerden (2006) in his account about what went wrong during Hurricane Katrina: "[...] the local first responders achieved remarkable success following Katrina. The effort [...] was anything but coordinated, but it saved many lives." (2006, pp. 133-134).

The operational response activities essentially concentrate on search and rescue operations such as locating victims, extracting victims from no matter what condition has trapped them and providing initial medical first aid treatment to stabilize victims so they may be transported to regular emergency medical practitioners (Coppola, 2011).

\section{The Established DMO}

Though disasters have profiles (Gunn, 1992), it is clear that every event is unique, entailing specific challenges (Kirschenbaum, 2004). Consequently, the size and complexity of the established DMO will depend on the particular situation. Environmental circumstances such as the magnitude of the event (small emergency versus enormous disas- 
ter), the type of the trigger event (e.g. explosion, nuclear incident, earthquake, terrorist attack, etc.), the location (e.g. small village, densely populated area, difficult accessible region, etc.), and so forth, will influence the established DMO-framework on site. Furthermore, the DMO evolves with the identified and changing requirements of the dynamic disaster environment (DeChurch et al., 2011). Therefore, a DMO is more than an organizational-based temporal organization. It responds according to the definition of a cross-boundary multi-team system (MTS) (Mathieu et al., 2001). This is an organization which is composed of teams coming from different embedding or parent organizations, each possessing specific core missions, expertise, resources, structures, norms and operating procedures, but who have to work interdependently in the pursuit of the common set of DMO-goals (Keyton, Ford, \& Smith, 2012; Zaccaro, Marks, \& DeChurch, 2012). Such a form of aggregating complementing organizations has many advantages, but there is also an inherent potential for conflict (Betts, 2012). Distrust, lack of confidence and other relationship conflicts have been shown to have negative effects on task performance (De Dreu \& Weingart, 2003b).

\section{The Context of 'Disasters out of the Box'}

The specific contribution of this research is that the response phase has been studied as an evolving systemic process, considering the changing disaster landscape and the ensuing need for a renewed understanding of dealing with modern disasters and especially 'disasters out of the box'. Disasters are generally described as severe and exceptional events that impact with such severity that the affected society has to respond by taking exceptional measures (Carter, 1991; Comfort, 1994; Cutter, 2005). Despite the severe character of disasters, people have succeeded in developing means to cope with and survive such occurrences by putting in place specific emergency management procedures, which are essentially based on successful and less successful experiences (Kirschenbaum, 2004). Even if we take into account that there is no such thing as a routine disaster (Boin \& Lagadec, 2000), knowledge gained through operational experience allows emergency workers to be prepared to respond to conventional disasters, the ones understandable in terms of past disasters (Gundel, 2005; Hills, 1998).

Recent research has demonstrated a non-negligible trend towards more 'disasters out of the box' (De Smet et al., 2012). In addition, a lot of apparently conventional disasters may be followed by a series of unexpected events (Hills, 1998) for which emergency workers and disaster managers cannot fall back on pre-established plans and procedures which do no longer provide clear-cut answers. Within the context of a changing disaster landscape, they are very rapidly confronted with the 'unknown', particularly since the existing emergency management approaches, plans, and procedures are usually relying on a traditional linear way of thinking in which decisions are made on the basis of acquired paradigms. Consequently, they must be aware that in such circumstances, ruling theories and best practices often turn into pitfalls or as Lagadec states 
(2009a, p. 473): "Our cherished models, those that have been so meticulously built in the last decades, are increasingly less relevant as new horizons of risks and crises unfold". The described event assessment process is of utmost importance when dealing with 'disasters out of the box'. DMO-authorities are enforced to abandon the traditional way of thinking. They must 'take' and 'make' time to assess the event and dare to call into question acquired paradigms. Consequently, they must pay more attention to creatively think about the unthinkable and take into account inputs from advisory specialists if they do not want to lose legitimacy (Ripley, 2008). Reasoning out of the box and creativity become extremely important if we want to be prepared to manage today's disasters. Therefore, the acquisition of such competencies must be stimulated during training sessions. Accordingly, dealing with modern disasters also necessitates that DMOauthorities have to break through the conventional limits of traditional leadership, or as LaPorte states (2007, p. 62): "Leaders must prepare to be very surprised and no longer rely exclusively on existing plans". They must be prepared not to systematically fall into procedural thinking, to exhibit innovation and to take the initiative during extremely trying circumstances (Townsend, 2006). Their responsibility is to stabilize the situation, to prevent further damage and to prepare recovery activities in order to bring things back to normal. Failing is not an option for DMO-authorities, so they should avoid being tainted by the disaster and exploit its dynamic potential (Boin \& 't Hart, 2003). Accurate strategic decision-making during disasters, and especially during 'disasters out of the box', is thus very intertwined with leadership. Unfortunately to date only few researchers have studied this issue (Cosgrave, 1996; Deitrick, Roberts, \& Campbell, 2012; Klann, 2003; Wooten \& James, 2008).

\section{Conclusion}

For years, disaster researchers by and large rely on the four-phase comprehensive emergency management model to structure their research, findings and recommendations about disasters. Whereas early disaster studies mainly focused on response and relief efforts, there is a clear shift of emphasis to mitigation activities and reducing societal vulnerability in recent disaster research. Unfortunately, despite well elaborated mitigation efforts and preparation initiatives, disasters continue to affect and disrupt societies. Moreover, recent research demonstrates that the nature of disasters affecting a society has experienced important changes. Notwithstanding the improved capacities and procedures which have been systematically developed over time, modern disasters have an increased potential to become 'out of the box' to the intervening EMOunits (De Smet et al., 2014). The changing disaster landscape should enforce us to call into question and rethink the acquired paradigms of disaster management if we want to be well prepared to deal with future events. Disaster response planning and operations 
thus will remain a vital aspect of disaster management and disaster response research should not be neglected.

As researchers systematically need to explore disasters in order to obtain more clarity in the field (Quarantelli, 1995) and to help disaster managers in developing more adequate response capabilities, our research aims to remodel the response phase of the disaster management life cycle within the context of 'disasters out of the box'. Our findings clearly reveal that the response phase is much more than just a set of activities aiming at limiting injuries, loss of life and damage to property. The response phase evolves as a comprehensive process through three succeeding stages (paralysis, operational response, and strategic response) including some importing sub-processes such as the gradual buildup of capacities, the coordination process and the event assessment process. As such, the study contributes to the existing disaster and management literature.

\section{Note}

Most of the excerpts in this paper have been translated from Dutch or French by the first author. In the translations we have attempted to keep the content and tone of the excerpts as close to the original version as possible. 


\section{Chapter}

\section{Tightening the Reins or Letting Go: The Importance of Contingent Leadership when Dealing with Routine or Non-Routine}

Situations

An earlier version of the study was presented in 2014 as: De Smet, H., Schreurs, B., \& Leysen, J., Decision making in a disaster management organization: a leadershipapproach. Proceedings of the CRHNet 11th Symposium; Vancouver, Canada, October 22-24, 2014 


\begin{abstract}
In the literature, there is an ongoing debate on which leadership style is best suited for enhancing the performance of decision-making teams and under which condition. Using the contingency leadership model as the theoretical backbone, in this study we claim that the effect of leadership style depends on the environmental situation in which the teams operate. Using an experimental setup (216 participants forming 72 decisionmaking teams), we tested the hypothesis that directive leadership is more beneficial in routine situations, whereas empowering leadership is more beneficial in non-routine situations. Multilevel analysis revealed that teams led by a directive leader made more accurate decisions in routine situations. Teams led by empowering leaders, outperformed teams led by directive leaders in non-routine situations. Teams led by a directive leader made faster decisions, particularly in routine situations. The findings are consistent with contingency models of leadership and suggest that in non-routine situations leaders should reserve time for consultation, even though this may be timeconsuming.
\end{abstract}




\section{Introduction}

Many of today's teams operate in dynamic and complex environments, where decisions have to be made fast on the basis of incomplete information (Riolli-Saltzman \& Luthans, 2001). This is true in business, as well as in medical, military and emergency contexts. In such environmental conditions, stakes are often high and any delay in decision-making may deteriorate the situation to a large extent. The need for rapid decision-making generally implies that teams "avoid the need for total agreement" (Hollenbeck, Beersma, \& Schouten, 2012, p. 90). They prefer finding a 'satisficing' (Simon, 1955) solution to respond to the situation rather than going through the time-consuming process of providing the optimal course of action. However, not only decision speed but also decision accuracy, reached by the integration of knowledge and expertise of different team members, is crucial for optimal team functioning (Hollenbeck et al., 1998; Humphrey et al., 2002). Since in real-world settings, highly accurate decisions that are made too late, are as bad as quick decisions that lack accuracy, decision accuracy and decision speed should be considered simultaneously since they both constitute important criteria for team decision quality and thus team performance.

It has long been found that leaders play a key role in facilitating the team decisionmaking process (Durham, Knight, \& Locke, 1997; Vroom, 2003; Zaccaro, Rittman, \& Marks, 2001). Yet it is not clear which leadership behaviors yield the best team decision quality (Ensley, Hmieleski, \& Pearce, 2006; Lorinkova et al., 2013; Yun et al., 2005). Several team scholars found that empowering leadership -where leaders encourage team members to actively participate in decision-making- is best suited for multidisciplinary team decision-making (Chen et al., 2007; Kirkman \& Rosen, 1999). Yet others found support for the benefits of directive leadership, where teams make decisions with little or no consultation of team members by the team leader (Ensley et al., 2006; Yun et al., 2005). Literature demonstrates that it is not obvious which of these leadership styles is actually better for enhancing team decision quality. So, the mixed findings raise the question under what condition the effect of directive or empowering leadership is more beneficial for team decision quality and thus team performance.

In this study, we investigate whether the effect of leadership style on team decision quality, depends on the environmental situation wherein multidisciplinary decisionmaking teams operate. The environmental situation varies in complexity and can be classified as consisting of routine or non-routine decision-making problems. Routine decisionmaking problems have a low level of variability, are familiar and the possible courses of actions are pre-specified, so team members can draw upon their knowledge and experience to rapidly identify a satisficing solution (Lei et al., 2016). Non-routine decisionmaking problems on the other hand have a high degree of uncertainty and require a complex problem solving approach (Fox \& Ochoa, 1997; Jehn, 1995). Accordingly, team members cannot rely on executable scripts and need to engage in collective information processing (Waller, 1999; Wang, Gray, \& Meister, 2014). Given these characteristics we ex- 
pect that a directive leadership style will be more beneficial in routine situations whereas an empowering leadership style is better suited in non-routine situations.

In the following, we first advance a contingency leadership model of multidisciplinary team decision quality (see Figure IV - 10). Second, using an emergency management simulation, we test the possibility that leadership style and environmental situation interact in predicting team decision quality. In doing so, we aim to contribute to the existing body of literature in two important ways. First, though contingency theory has a long history in leadership research, academics emphasize that traditional contingency theories of leadership are generally too abstract too apply to specific situations (Sims Jr. et al., 2009), and that research on situational factors had not received much empirical support over the years (Podsakoff et al., 1995; Yun et al., 2005). Podsakoff et al. even state that finding empirical support for moderators of leadership can be characterized as "searching for a needle in a haystack" (Podsakoff et al., 1995, p. 422). By examining the environmental situation, i.e. the extent to which a team decision-making problem can be executed routinely or not, as a moderator of the relationship between leadership style and decision quality, we aim to extend the literature on contingent leadership. Second, by demonstrating that the effectiveness of a given leadership style (directive versus empowering) on team decision quality depends on the environmental situation, we help to resolve the existing ambiguity about which leadership style is actually better for enhancing team decision quality and therefore contribute new insights to the leadership and team science literature. Of particular interest in our study is the dual outcome measure of decisions accuracy and decision speed.

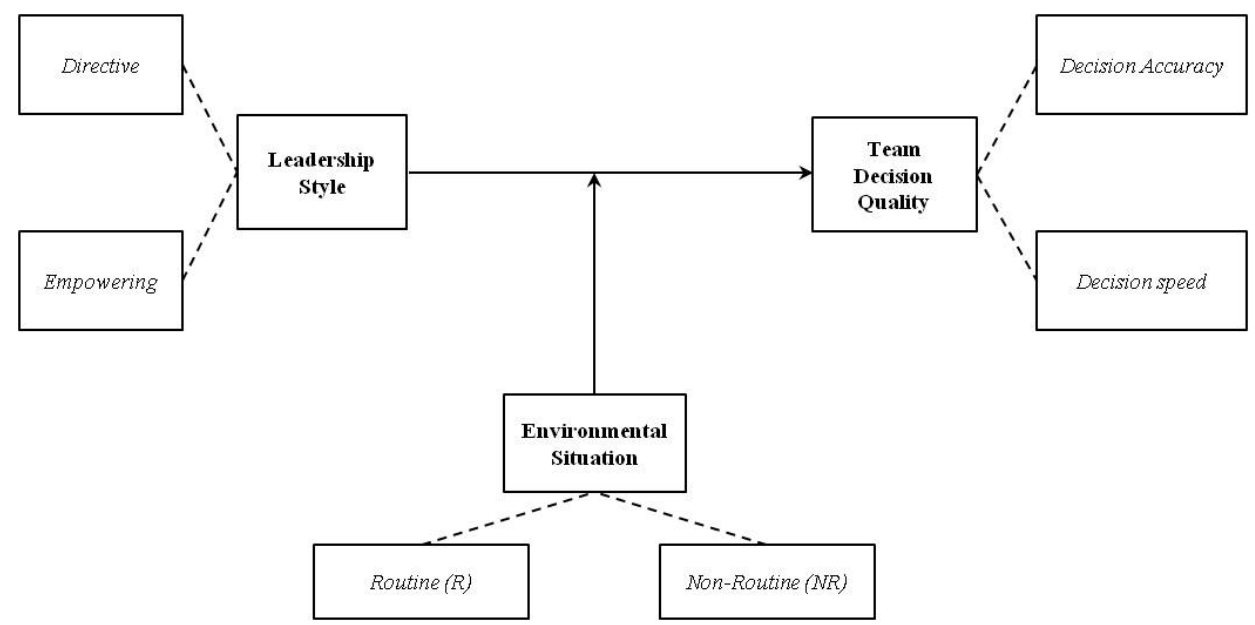

Figure IV - 10: Contingency leadership model of multidisciplinary team decision quality 


\section{Theory and Hypotheses Development}

\section{Leadership style and team performance}

In the literature, team leadership has been explored from different angles. The most common perspectives are coaching related activities (Hackman \& Wageman, 2005), shared or co-leadership (Bergman et al., 2012; Carson, Tesluk, \& Marrone, 2007), promoting team learning (Day \& Gronn, 2004), boundary spanning (Druskat \& Wheeler, 2003), leader behavior studies (Burke et al., 2006) and contingency leadership theory (House, 1996; Lorinkova et al., 2013; Yun et al., 2005). The last approach is of particular interest for the current research. Though the contingency leadership theory is one of the most widely known leadership theories, it remains among the less well-substantiated models (Gardner et al., 2010; Thompson \& Vecchio, 2009). The approach mainly retains substantial intuitive appeal and therefore needs more academic guidance (Sims Jr. et al., 2009). A particular concern remains that empowering leadership has not yet been fully incorporated within contingency leadership theories (Sharma \& Kirkman, 2015).

In multidisciplinary teams, members are highly interdependent, which is particularly the case for team leaders who bear full accountability for the final team decision and thus for the team's performance (Durham et al., 1997; Vroom, 2003; Zaccaro et al., 2001). Though every team member contributes to the team's success by sharing relevant information, team leaders are often responsible for weighing each team member's advice and taking responsibility for the final decisions (Humphrey et al., 2002). A poor team leader thus can neutralize the effects of a good staff and vice versa, a reason why in the literature, weak leader behaviors are often cited as the main cause of poor team performance (Bergman et al., 2012; LePine et al., 1997). As a consequence, extensive research has emphasized the importance of leader behaviors for team performance (Burke et al., 2006; Judge, Piccolo, \& Ilies, 2004; Lorinkova et al., 2013; Srivastava et al., 2006).

The use of participative behaviors by the team leader has received special attention (Locke, Alavi, \& Wagner, 1997). The extent to which leaders are willing to share decision power with their team members ranges from none to very active (Vroom \& Yetton, 1973). Some leaders make decisions with minimal consultation of team members. They let their team members know exactly what is expected of them by giving clear orders and expect compliance without discussion (Yun et al., 2005). Such leaders are generally labeled as directive (House \& Mitchell, 1974), which is similar to the autocratic leadership style in the Vroom and Yetton's decision-making model (1973) or what Manz and Sims Jr. (1991) called the strong man. Other leaders share their decision power with their team members. These empowering (Arnold et al., 2000) or participative (House \& Mitchell, 1974) leaders encourage team members to contribute ideas and to take responsibility for team performance, so they only make decisions after extensive consultation of their staff and a thorough evaluation of their views and ideas. 
There is abundant evidence that empowering leadership behaviors are positively associated with individual and team performance. For example, Kirkman and Rosen (1999) demonstrated that highly empowered teams are more effective than less empowered teams. Chen and colleagues (2007) found a positive relationship between team empowerment and team-level performance. Furthermore, Srivastava et al. (2006) showed that empowering leadership was positively related with knowledge sharing and team efficacy, which in turn were both positively related to team performance. Some scholars even accentuate that mainly directive leadership appears to be a root cause of team malfunctioning which leads to poor team decisions and thus poor team performance (Moorhead \& Montanari, 1986; Tetlock et al., 1992).

Yet, another group of researchers provided evidence that directive leadership makes task accomplishment easier for team members which in turn leads to better team performance (Ensley et al., 2006). In their study on the effects of participative and directive leadership in electronic groups, Kahai et al. (2004) found that structure provided by directive leaders was relevant for keeping group members focused on crucial aspects of the problem, which led to better team performance. Similarly, Yun and colleagues (2005) demonstrated that directive leaders provided better health care than did empowering leaders when the patient was severely injured.

Due to the lack of consistency in scientific findings, it remains unclear whether empowering leadership is superior to directive leadership or vice versa for enhancing team decision quality and thus team performance. According to Lorinkova et al. (2013), the leadership research essentially focuses on whether empowering or directive leadership is beneficial overall, and largely ignores the question of "when empowering leadership might be most or least effective" (p. 574). To this end, the researchers examined the influence of both leadership styles on team performance over various phases of team interaction and development, and provided evidence that teams led by a directive leader initially outperform those led by an empowering leader, but that over time, empowering leadership becomes more beneficial. Nevertheless, many questions remain, one of them being under which situational circumstances empowering versus directive leadership is more effective for enhancing team decision quality. Therefore, in our research we focus on the moderating role of the environmental situation on the relationship between leadership style and team decision quality.

\section{Routine versus Non-Routine: Environmental Situation as a Moderator}

Multidisciplinary decision-making teams often operate within a complex and dynamic setting where time pressure and stakes are high. Yet, the environmental situation teams face vary in complexity and can by and large be classified as routine or non-routine decision-making problems (Jehn, 1995). The central premise of this paper is that leadership effectiveness depends on the environmental situation, and more particularly, on the extent to which decision-making problems can be executed routinely or not. Specif- 
ically, we argue that multidisciplinary team leaders in routine situations benefit from a directive leadership style whereas in non-routine situations, an empowering leadership style is more favorable.

When the situation is recognized as an instance of something a team has encountered many times before, it is classified as a routine event. Routine events have a low level of variability, are familiar and can be dealt with in the same way each time with predictable outcomes because the possible courses of action are pre-specified (Jehn, 1995; Leonard \& Howitt, 2012). In such case, team leaders can draw upon their own experience and knowledge to fit the requirements of the decision-making problem and easily identify a familiar solution (Sommer \& Pearson, 2007). Because of the well-known routines they have a good awareness of what information is available in the team and which members hold this information (Wegner, 1986). The team member's input indispensability is rather low and merely comprehends the sharing of unique information essential for making accurate team decisions (De Dreu, Nijstad, \& van Knippenberg, 2008). If the task is identified as routine, teams can rely on highly developed and effective standard operating procedures, implying that they can perform the task the same way each time. Then, substantial debate of task strategy is unnecessary (Gladstein, 1984) since the task conflict that arises is more likely to interfere with those procedures than improve them (De Dreu \& Weingart, 2003a; Jehn, 1995). Furthermore, previous research has shown that task conflict and disagreement about task strategy are disruptive to team performance (De Dreu \& Weingart, 2003b; Schwenk \& Cosier, 1993). Therefore, we argue that when the environmental situation is recognized as a routine decision-making problem, teams with directive leaders make more accurate decisions than teams with empowering leaders.

In contrast, when the environmental situation represents significant novelty, routines are challenged. The event does not fit a pre-existing pattern and team leaders cannot rely on an executable script that is known or identifiable, and which provides a comprehensive and adequate response (Sommer \& Pearson, 2007). Consequently, when confronted with non-routine situations, leaders are in need of additional insights and knowledge and engage in active group participation (Waller, 1999; Wang et al., 2014). It has been demonstrated that teams dealing with non-routine events benefit from the diverse ideas and inputs of team members (De Dreu et al., 2008). When team members are allowed to identify and discuss diverse and dissenting viewpoints, they may find superior alternatives to deal with the problem, which enables the team to make more accurate decisions (Jehn, 1995). Previous research also indicates that nonroutine situations motivate team members to engage in active thinking and become more active in personal exchanges with others (Louis \& Sutton, 1991; Van de Ven, Delbecq, \& Koenig, 1976). Consequently, the above findings suggest that in non-routine situations, teams with empowering team leaders make more accurate decisions than teams with directive leaders. Therefore, we hypothesize the following: 
Hypothesis 1: The extent to which the task situation is routine moderates the effect of leadership style on decision-making accuracy, in such a way that in routine situations teams led by a directive leader make more accurate decisions than teams led by an empowering leader, whereas, in non-routine situations, teams led by an empowering leader make more accurate decisions than teams led by a directive leader.

Though the accuracy of the decision is important, it is not the only criterion for team decision quality in real-world decision-making problems. In such a context, any delay in decision-making may deteriorate the situation to a large extent. As a result, decisionmaking becomes critically time bound (Cosgrave, 1996).

Directive leadership is usually associated with the leader's positional power, meaning that directive leaders use their position of authority to force others to comply (Sims Jr. et al., 2009). They are primarily concerned with task accomplishment and focus on immediate performance. Therefore, they provide clear guidance and specific instructions to team members. By actively managing team members' interactions, they act as explicit coordination mechanism and help team members to focus their efforts towards their individual tasks (Kahai, Sosic, \& Avolio, 2004; Pearce et al., 2003). On the contrary, empowering leaders tend to establish participative and collaborative norms among team members. They convey confidence in team members' capabilities to handle challenging work and expect team members' involvement in decision-making by encouraging them to voice their ideas and opinions, and allow them to take responsibility for the team's performance (Kirkman \& Rosen, 1999).

When dealing with routine situations, the specific cues of the situation trigger stored knowledge and experience. Sommer and Pearson (2007) have shown that when decision makers develop routines through practice and experience, they can hone the options and quickly find a satisficing solution to respond to the situation. Therefore, directive leaders, who act with minimal consultation with other team members (Yun et al., 2005), can speed up the team decision-making considerably. Empowering leaders on the other hand share power with their team members. They involve them in the decision-making process, even when confronted with routine decision-making tasks for which effective standard operating procedures have been developed.

Faced with non-routine decision-making problems, team leaders lack cues to trigger stored knowledge (Schraagen \& van de Ven, 2008). Due to the novelty of the situation, no answers are readily available. Consequently, team leaders feel unsatisfied with their existing knowledge, which triggers the need for additional information (Wang et al., 2014), even for directive leaders who are used to structure team members' work, not to consult them. However, research has shown that consulting additional knowledge sources is instrumental in dealing with non-routine situations (Chung \& Jackson, 2013; Jehn, 1995; Van de Ven et al., 1976). Empowering leaders are used to consult with subordinates and evaluate their opinions (Yukl, 2010). Consequently, empowering leaders, 
whose focus is mainly on the followers, can easily locate expertise in the team and integrate the comments of other team members, which facilitates an effective team process. For empowering leaders information-seeking and sharing is the 'default' option -it is business as usual. These qualities come into their own when dealing with novel situations in which team members are required to speak their mind and share unique insights. Empowering leaders are programmed to quickly identify and integrate knowledge that is distributed among the team members.

However, team member consultation includes more voices and gives rise to potentially more discussion, which slows down the decision-making process (Lorinkova et al., 2013; Vroom, 2003; Yang, 2010). Therefore, we claim that teams led by directive leaders make faster decisions than those led empowering leaders, but that the effect is stronger when the team engages in routine decision-making tasks. Based on these arguments, we propose the following hypotheses:

Hypothesis 2: The effect to which the task situation is routine or not moderates the effect of leadership style on decision-making speed, in such a way that teams led by a directive leader make faster decisions than teams led by an empowering leader, but the effect is stronger in routine situations than in non-routine situations.

\section{Method}

\section{Sample}

Participants in this study were 216 undergraduate students from a small Belgian university $(N=144)$ and a medium Dutch university $(N=72)$ who were divided into 72 three person multidisciplinary teams. Participants' age varied between 18 and 29 years $(M=$ $22.08, S D=1.84)$ and $73.15 \%$ of them were male. Each team was tested in a separate experimental session. The sessions lasted on average two hours and were organized within the context of existing courses. Neither complementary course credits, nor price certificates were allocated to the participants.

\section{Task overview}

Participants were randomly assigned to teams and, with exception of the team leaders who were intentionally selected (see the 'Leadership manipulation' section), were randomly assigned to the team roles. Each team was hierarchically structured and consisted of a formal leader (fire brigade commander) and two staff members (police officer and chemical specialist). Teams worked on a modified version of the Maastricht Univer- 
sity Emergency Management Simulation $\left(\mathrm{MUEMS}^{3}\right)$ which is a team decision-making task involving emergency situations. Leadership style of each experimental session was manipulated by selecting and instructing team leaders who displayed either directive or empowering leadership behaviors (between team factor). All teams had to respond to four experimental disaster scenarios (within team factor), two of which were under the condition of a 'routine situation' and two under the condition of a 'non-routine situation'. Routine scenarios were constituted as decision-making problems similar to those the teams had encountered before in the training phase, so they could easily recognize the situation and formulate a solution. Non-routine scenarios included significant novelties and therefore were without standard solutions so teams were challenged to find a feasible solution. Before each experiment, teams were explicitly reminded that they had to make quick but accurate decisions.

MUEMS was developed in such a way that the team members are highly interdependent and need to interact and share information in order to successfully respond to the scenarios. Each team member disposes of unique information. They formulate individual advices according to their responsibilities in order to contribute to an integrated qualitative team decision. The final decision is formalized by the team leader. Team members and their leader are seated face to face on separate desks in a way that they can easily interact.

\section{Procedure}

Each experimental session followed a precise sequence divided in four distinct steps: The leadership manipulation, individual instructions and practice, team training, and the four experimental disaster scenarios (see Figure IV - 11). Each step is described in more detail below.

Leadership manipulation. Consistent with Lorinkova and colleagues (2013), we manipulated leadership using a two-step approach to maximize the effectiveness of the manipulation: Selection and instruction. A week before each experimental session, participants were asked to fill in an online 20-item leadership pre-questionnaire developed by Lorinkova and colleagues (2013) to evaluate their preferred leader behavior. Subjects were asked to indicate the extent to which they would feel comfortable performing directive-leader behaviors or rather preferred empowering-leader behaviors. Responses to the 20 items were summed to form a global 'directive score' and a global 'empowering score' for each participant. Participants with the highest directive score were selected to serve as team leader in the directive leadership condition $(N=36)$, whereas participants with the highest empowering score were selected to serve as

3 MUEMS was developed by dr. Uitdewilligen who is assistant professor at the Faculty of Psychology and Neuroscience (Department of Work and Social Psychology) of the Maastricht University. The original MUEMS algorithms were adapted to the specificities of the experimental research described in this study, i.e. routine versus non-routine environmental situations. 
team leader in the empowering leadership condition $(N=36)$. The results of a pairedsamples t-test show that the selected leaders in the directive leadership condition felt significantly more comfortable performing directive-leader behaviors $(M=57.44, S D=$ 4.65) than empowering-leader behaviors $(M=53.39, S D=5.65), t(35)=6.15, p=.000, d$ $=.78$. In the empowering leadership condition, the selected leaders felt significantly more comfortable performing empowering-behaviors $(M=58.81, S D=6.13)$ than directive behaviors $(M=53.42, S D=4.51), t(35)=-6.99, d=1.00$.

\begin{tabular}{|c|c|c|c|c|c|c|c|c|c|}
\hline \multicolumn{2}{|c|}{$\begin{array}{l}\text { Leadership } \\
\text { manipulation }\end{array}$} & \multirow{2}{*}{ 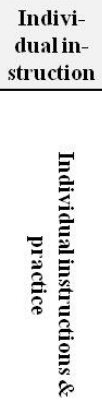 } & \multicolumn{2}{|c|}{ Team training } & \multirow[b]{2}{*}{ 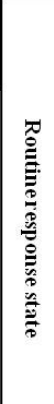 } & \multicolumn{4}{|c|}{ Experimental conditions } \\
\hline 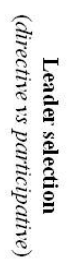 & 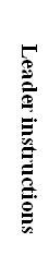 & & 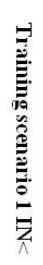 & 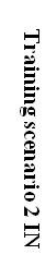 & & 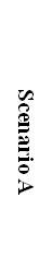 & 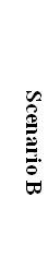 & 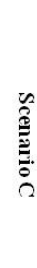 & 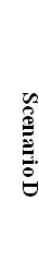 \\
\hline
\end{tabular}

Figure IV - 11: Experimental sequence

Leader instructions. Upon arrival, the experimenter asked the team leader to take place at the fire brigade commander's seat. The leader then was informed about his or her selection as a team leader and was asked to read intently the leader instructions. The leadership instruction sheets contained information about the kind of behaviors to exhibit during the different scenarios, as well as a list of key verbal prompts that were suggested for use during interaction with the team. Next the leader was shown a 5minute movie scene illustrating the desired leadership style. The scene was taken from "Apollo 13" in case of a directive leadership manipulation and from "Cube" in case of an empowering leadership manipulation. During the movie scene, the experimenter pointed out behaviors exemplary of the particular leadership style that team leaders were expected to display to be sure the leader understood his or her role.

Individual instructions and practice. The two remaining participants were informed about their role and the goal of the experiment. Then they were all trained for twenty minutes to attain the necessary expertise in their respective roles. Participants were first asked to read the individual instruction sheet which was complemented by a map helping them to visualize the disaster zone. The instruction sheet described their specific goals, tasks and responsibilities, and contained some individual exercises intended as a comprehension check. Next, they were asked to solve the individual training task with guiding questions intended to clarify what kind of individual judgments they were expected to make. Throughout the individual practice, the experimenter was actively helping the team members by assisting them in finding the correct answer. 
Team training. The next part of the experiment consisted of a team training. The teams received two team training tasks, each under the conditions of a 'routine' situation. Teams were given 15 minutes to complete the first training task and 10 minutes to complete the second one. After each training task the team had five minutes to reflect on how they performed as a team. During the training tasks, the experimenter did not intervene. The training scenarios and the reflection periods allowed the teams, and in particular the team leaders, to discover which were the specific goals, tasks and responsibilities of each team member and how the team had to respond to disaster situations under the condition of a 'routine' situation. After having completed the training scenarios, the teams were considered to be prepared to deal with routine situations.

Experimental conditions. During the experiment, teams completed four experimental disaster scenarios, either in the directive or the empowering leadership condition. Two scenarios were routine situations (scenarios $A$ and $B$ ), the other two nonroutine situations (scenarios $C$ and $D$ ). Scenarios were presented in a random order, which resulted in a counterbalanced experimental design. Teams had maximum 10 minutes to complete each scenario and the team leader had the responsibility to communicate the team decisions through an online answer sheet. After each scenario, team members were asked to fill in an online survey measuring their perceptions of leadership style and the environmental situation (see below).

\section{Measures}

\section{Manipulation checks.}

The leadership style manipulation check consisted of six items adapted from Lorinkova et al. (2013) (from 1 = Strongly disagree to 5 = Strongly agree), asking team members to assess the extent to which their team leader behaved in a directive way (3 items) and empowering way (3 items). A sample item for directive leadership is: "The team leader gave instructions to the team members." A sample item for empowering leadership is: "The team leader encouraged team members to express ideas and suggestions." Cronbach's alphas were .92 (directive leadership) and .89 (empowering leadership). We assessed within team agreement in leadership style by calculating $r_{w g}$, using the expected variance of a 5-point scale with a uniform null distribution $\left(\sigma_{E U}^{2}=2\right.$ ) (James, Demaree, $\&$ Wolf, 1984). The mean $r_{w g}$ across scenarios were .88 (directive leadership) and .84 (empowering leadership). Both values exceed the conventionally acceptable value of .70, indicating high interrater agreement (LeBreton \& Senter, 2008).

The environmental situation manipulation check consisted of five items developed for the purpose of this study. Team members had to indicate the extent to which the presented scenario differed from the scenarios they had to deal with during the training sessions on a scale ranging from 0 (no difference) to 100 (very different). A sample item is: "How different was this scenario from the training sessions in terms of difficulty?" The Cronbach's alpha was .74. We assessed within team agreement by means of the 
$r_{w g}$-index (James et al., 1984), using an expected random variance given by $\left(\sigma_{E U}^{2}=\right.$ $\frac{A^{2}-1}{12}=850$ ), with $A=101$ (James et al., 1984). The mean $r_{w g}$ was .81 for both routine and non-routine situations, suggesting strong agreement among team members (LeBreton \& Senter, 2008).

\section{Team decision quality.}

We used two indicators of team decision quality: Decision accuracy and decision speed. At the end of each scenario, the team leader had to enter a number of team decisions into an excel sheet, including the type and number of emergency units to use in which specific building, which roads to close leading to the emergency zone, whether or not to evacuate people from buildings, etc.

Decision accuracy was computed based on the modified MUEMS algorithm, specifically designed for each of the four scenarios. The rationale behind the algorithm is that the team has to make a number of decisions with the aim of minimizing costs in terms of damage to buildings, environmental pollution, traffic congestions, and safety risks. For instance, the teams incurred costs by closing roads leading to the emergency zone. The fewer roads they would close, the lower this cost would be. However, they would need to close sufficient roads, so that all emergency services could reach the crisis location. Decision accuracy per scenario was calculated as the costs a team made per scenario relative to the minimal amount of costs they would have incurred in case they had made the optimal combination of decisions. Scores per scenario were then converted to a score between 0 and 100, and inverted to facilitate interpretation, so that higher scores reflect higher accuracy.

Decision speed was operationalized as the time needed to make a decision from the moment the teams were told to start reading the instructions until the moment the fire brigade commander finished entering their decisions. Since emergency decisions are critically time bound, quick decision making is beneficial. Therefore, the longer it takes to make the team decision, the worse the team scores on decision speed. In the study, decision speed ranged from 111 to 600 seconds (i.e. the maximum time available to complete each scenario). To facilitate interpretation, scores were inverted, so that higher scores reflect faster decisions.

\section{Analytical strategy}

The study setup consisted of a repeated measure design with four disaster scenarios nested within each team. Given the nested data structure, we used a two-level hierarchical linear modeling (HLM) approach to test our hypotheses. The dependent (i.e., decision accuracy and decision speed) and moderating (i.e., environmental situation) variables were scenario (level 1 ) variables, whereas the independent variable (i.e., leadership style) was a team (level 2) variable. Accordingly, the assumption that environ- 
mental situation and leadership style will interact in predicting decision accuracy and speed is a cross-level interaction hypothesis (Klein, Dansereau, \& Hall, 1994). To estimate our models, we used the nlme package in $\mathrm{R}$ (version 3.0.3), an open source software well suited for multilevel modeling (Bliese, 2013). We used full maximum likelihood for parameter estimation because this allows comparing models that differ in the fixed part (Hox, 2010).

We first built an intercept-only model (Null model) for the individual level outcome variables decision accuracy and decision speed that served as baseline model for subsequent analyses and indicates how much variance in accuracy and speed resides within and between teams. Next, we entered test location (Belgian university students = 0; Dutch university students $=1$ ) as a control variable into the equation (Step 1). In the second step we added leadership style (directive leadership = -1; empowering leadership = 1) and environmental situation (non-routine $=-1$; routine $=1$ ), and we allowed the slope of environmental situation to vary across teams (random-intercept, randomslope model) (LaHuis \& Ferguson, 2009). Then we entered the cross-level interaction of environmental situation and leadership style into the equation (Step 3). We estimated the models using full maximum likelihood estimation method to compare model fit.

\section{Results}

\section{Manipulation checks}

\section{Leadership style.}

The results of an independent samples $t$-test indicate that teams in the directive leadership condition $(M=3.97, S D=0.42)$ perceived the team leader to be significantly more directive than teams in the empowering condition $(M=3.55, S D=0.59), t(70)=3.44, p$ $<.01, d=.82$. However, teams in the empowering $(M=3.80, S D=0.43)$ and directive condition $(M=3.77, S D=0.42)$ did not significantly differ in their perceptions of empowering leadership, $t(70)=-.36, n s, d=.07$. To further assess the validity of the leadership manipulation, we asked two coders, who were blind to the experimental conditions, to independently judge the leadership style in the experimental sessions that had been recorded on videotape $(n=45)$. The coders were asked to assess directive and empowering leadership using the Likert scale items of the empowering and directive leadership scale used by Lorinkova et al. (2013). The Cronbach's alphas were 78 (directive leadership) and .72 (empowering leadership). We calculated the interrater agreement index $r_{w g}$ (James et al., 1984) using a uniform null distribution $\left(\sigma_{E U}^{2}=2\right)$. The mean $r_{w g}$ were .81 (directive leadership) and .92 (empowering leadership), values which exceed the conventionally acceptable value of .70, indicating high interrater agreement (LeBreton \& Senter, 2008). The results of an independent samples $t$-test confirmed the earlier findings as regards directive leadership. Leaders in the directive 
condition $(M=3.86, S D=0.49)$ were perceived more directive than leaders in the empowering condition $(M=3.59, S D=0.34), t(43)=2.15, p<.05, d=.64$. Also, raters perceived team leaders in the empowering condition $(M=3.72, S D=0.33)$ significantly more empowering than those in the directive condition $(M=3.51, S D=0.22), t(43)=$ $2.22, p<.05, d=.64$. Taken together, the results provide sufficient support for the validity of the leadership manipulations.

\section{Environmental situation.}

The results of an independent samples $t$-test indicate that non-routine scenarios $(M=$ $62.33, S D=10.94)$ were perceived significantly more different from the training scenarios than the routine scenarios $(M=28.76, S D=9.08), t(142)=20.29, p=.00, d=3.38$, which allows us to conclude that the environmental situation manipulation was effective.

\section{Preliminary Results}

Table IV - 5 presents descriptive statistics and inter-correlations among the variables in the study for both environmental situations (i.e. routine versus non-routine). There is a negative correlation between leadership style and decision speed, indicating that directive leadership leads to faster decisions. Decision speed and decision accuracy are both positively correlated with environmental situation, meaning that when dealing with routine decision-making tasks, decisions are made faster and with more accuracy. Finally, decision accuracy and decision speed correlate positively implying that more accurate decisions are made faster as well.

Before testing our hypotheses, we first ran intercept-only models to examine whether there was systematic between-team variance in the dependent variables. ICC(1) was used as an indicator of non-independence for the dependent variables (Bliese, 2000). For decision accuracy, ICC(1) was .11, $F(71,216)=1.52, p<.05$; for decision speed, it was .09, $F(71,216)=1.38, p<.05$. These values indicate that there is a substantial amount of between-team variance in the dependent variables (LeBreton \& Senter, 2008). The results are shown in Table IV - 6 and Table IV - 7.

Table IV - 5: Descriptive Statistics and Correlations

\begin{tabular}{lcccllll}
\hline Variable & & $M$ & $S D$ & 1 & 2 & 3 & 4 \\
\hline Leadership style & 1. & 0 & 1 & - & - & & \\
Environmental situation & 2. & 0 & 1 & - & - & & \\
Decision accuracy & 3. & 71.26 & 25.76 & -.06 & $.23^{* * *}$ & - \\
Decision speed & 4. & 151.25 & 129.17 & $-.21^{* *}$ & $.63^{* * *}$ & $.29^{* * *}$ & - \\
\hline
\end{tabular}

Notes: $N=288$

Correlations are calculated on standardized values

Leadership style and Environmental situations are dichotomous variables comparing directive leadership style (coded -1) with empowering leadership style (coded +1), and non-routine situation (coded -1) with routine situation (coded +1 ).

${ }^{*} p<.05,{ }^{* *} p<.01,{ }^{* * *} p<.001$ 


\section{Test of Hypotheses}

Next, we examined the interaction effects between of leadership style and environmental situation on the two outcome variables, decision accuracy and decision speed. Hypothesis 1 predicted that in situations where a team engages in routine decision-making tasks, teams led by a directive leader would make more accurate decisions than teams led by an empowering leader. Conversely, when confronted with non-routine decisionmaking tasks, teams led by an empowering leader would outperform directive leaders. As is shown in the final step of Table IV - 6, leadership style and environmental situation interacted in predicting decision accuracy $(\gamma=-6.00, p<.001)$. Adding the interaction, the cross-level interaction of environmental situation and leadership style improved the model significantly $(\Delta-2 x \log =19.70, d f=1, p<.001)$. The interaction effect is graphically represented in Figure IV - 12 and the findings provide support for Hypothesis 1.

Table IV - 6: Fixed Effects Estimates (Top) and Variance Estimates (Bottom) for Models Predicting Decision Accuracy

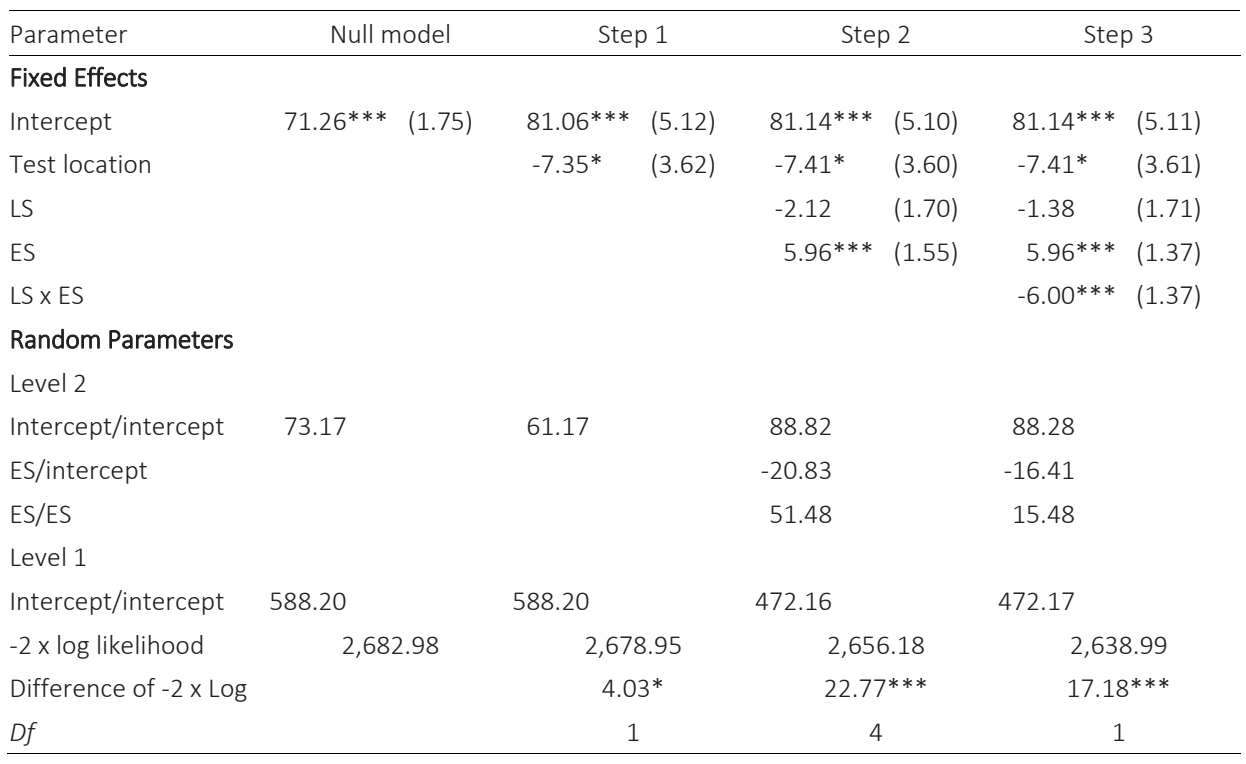

Note. Standard errors are in parentheses.

$* p<.05, * * p<.01, * * * p<.001$

LS: Leadership style (directive leadership style, coded -1; empowering leadership style, coded +1).

ES: Environmental situation (non-routine situation, coded -1 ; routine situation, coded +1 ) 


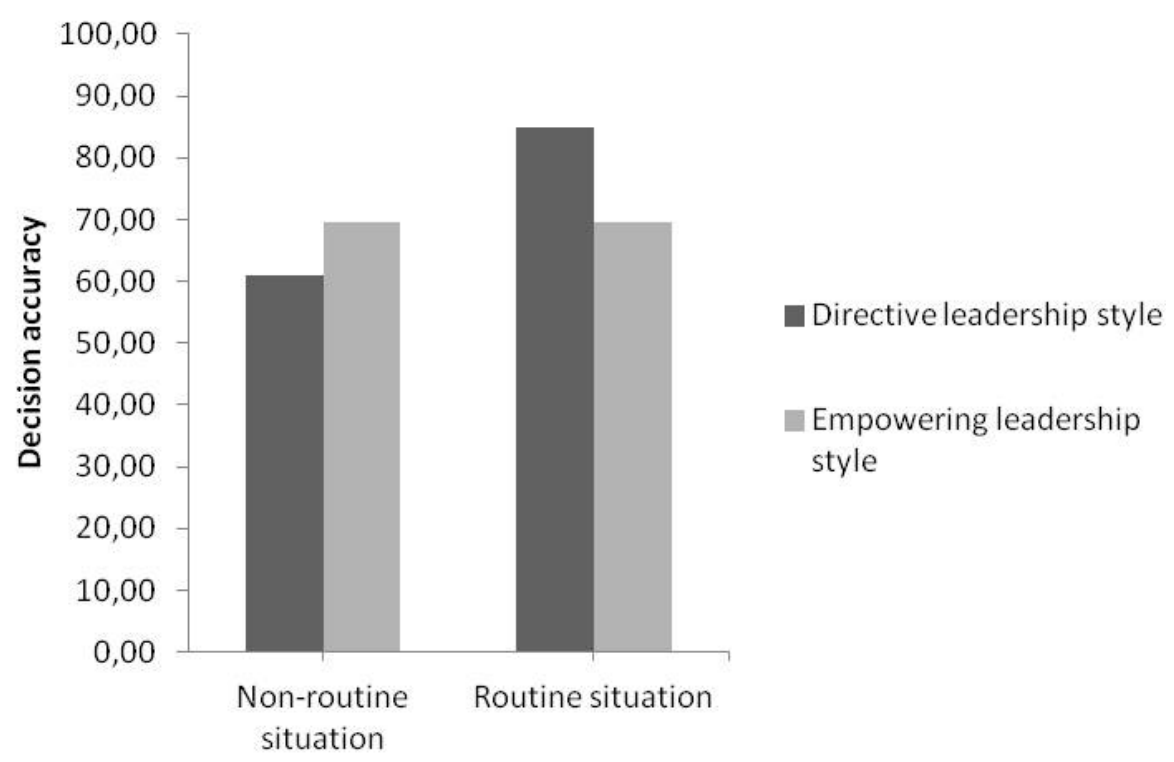

Figure IV - 12: Interaction of leadership style and environmental situation in predicting team decision accuracy

Hypothesis 2 predicted an interaction effect between leadership style and the extent to which the task situation is routine or not on decision speed, in such a way that teams led by a directive leader make faster decisions than teams led by an empowering leader, but that the effect is stronger in routine decision making tasks. The final step of Table IV - 7 shows that leadership style and environmental situation interacted in predicting decision speed $(\gamma=-13.26, p<.05)$ and that the model fit improved significantly when adding the cross-level interaction of environmental situation and leadership $(\Delta-2 x \log =$ $6.14, d f=1, p<.05)$. The effect is graphically presented in Figure IV - 13. Consequently, the findings support Hypothesis 2, meaning that directive leadership resulted in faster team decision-making, more so in routine than in non-routine situations.

\section{Additional Findings}

Step 4 of both models revealed some additional results. First, the results showed that that leadership style was negatively related to decision speed $(\gamma=-26.39, p<.01)$, meaning that teams led by empowering leaders make slower decisions than those led by directive leaders. Furthermore, environmental situation was positively related to both decision accuracy $(\gamma=5.96, p<.001)$ and decision speed $(\gamma=81.45, p<.001)$, implying respectively that decision-making is more accurate and faster wen the environmental situation is recognized as a routine decision-making problem instead of a nonroutine decision-making problem. 


\section{Chapter 4}

Table IV - 7: Fixed Effects Estimates (Top) and Variance Estimates (Bottom) for Models Predicting Decision Speed

\begin{tabular}{|c|c|c|c|c|}
\hline Parameter & Null model & Step 1 & Step 2 & Step 3 \\
\hline \multicolumn{5}{|l|}{ Fixed Effects } \\
\hline Intercept & $151.25 * * *(8.50)$ & $176.64 * * *(25.36)$ & $156.27^{* * *}(21.60)$ & $156.27 * * *(21.62)$ \\
\hline Test location & & $-19.04 \quad(17.93)$ & $-3.76 \quad(15.05)$ & $-3.76 \quad(15.08)$ \\
\hline LS & & & $-17.44^{*} \quad(7.10)$ & $-26.39 * * \quad(7.95)$ \\
\hline ES & & & $81.45^{* * *}(5.51)$ & $81.45 * * *(5.29)$ \\
\hline LS $x$ ES & & & & $-13.26^{*} \quad(5.29)$ \\
\hline \multicolumn{5}{|l|}{ Random Parameters } \\
\hline \multicolumn{5}{|l|}{ Level 2} \\
\hline Intercept/intercept & $1,375.51$ & $1,294.98$ & $3,217.21$ & $3,137.06$ \\
\hline ES/intercept & & & $1,452.92$ & $1,334.41$ \\
\hline ES/ES & & & 826.51 & 650.67 \\
\hline \multicolumn{5}{|l|}{ Level 1} \\
\hline Intercept/intercept & $15,251.45$ & $15,251.46$ & $5,304.43$ & $5,304.41$ \\
\hline$-2 \times \log$ likelihood & $3,613.63$ & $3,612.50$ & $3,393.30$ & $3,387.16$ \\
\hline Difference of $-2 \times \log$ & & 1.13 & $219.20 * * *$ & $6.14^{*}$ \\
\hline$D f$ & & 1 & 4 & 1 \\
\hline
\end{tabular}

Note. Standard errors are in parentheses.

$* p<.05, * * p<.01, * * * p<.001$

LS: Leadership style (directive leadership style, coded -1 ; empowering leadership style, coded +1 ).

ES: Environmental situation (non-routine situation, coded -1 ; routine situation, coded +1 )

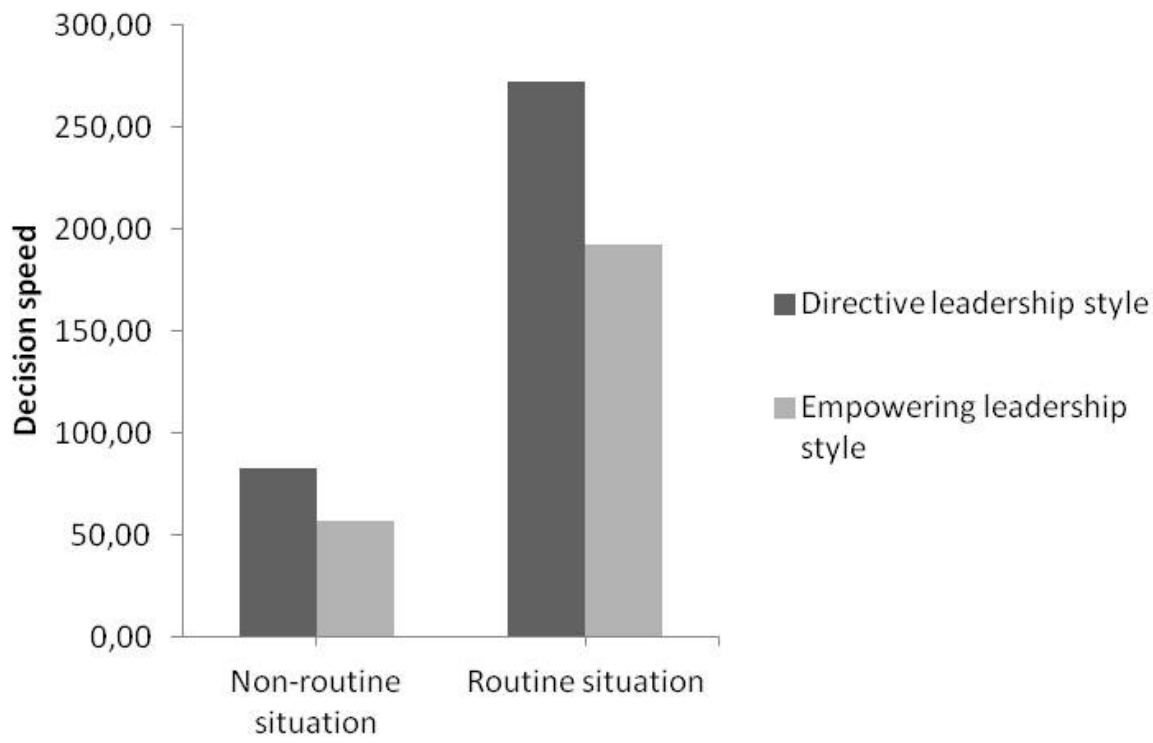

Figure IV - 13: Interaction of leadership style and environmental situation in predicting team decision speed 


\section{Discussion}

Many researchers advocate empowering leadership over directive leadership for enhancing team performance (Kirkman \& Rosen, 1999; Srivastava et al., 2006), even though leadership scholars have repeatedly documented the beneficial effects of its counterpart, directive leadership (Ensley et al., 2006; Kahai et al., 2004; Yun et al., 2005). Literature shows clearly that empowering leadership is not consistently superior to directive leadership (Durham et al., 1997). Therefore, it remains unclear which of both styles is actually better for improving team decision quality and thus team performance. According to Lorinkova and colleagues (2013), the lack of consistency in scientific findings is due to the fact that researchers focus on whether a given leadership style is beneficial overall but ignore the question that there might be contingencies involved. To help resolve the existing theoretical equivocality and to contribute new insights to the leadership and team science literature, we draw attention to the effect of the environmental situation on the relationship between leadership style and team decision quality. Consistent with the approach used by Lorinkova et al. (2013), we studied the effect of two distinct and opposite leadership styles, directive versus empowering leadership, on team decision quality which allowed us to provide insight in when a particular leadership style becomes more beneficial.

The results of our experimental research show that teams led by a directive leader make more accurate decisions when confronted with routine decision-making tasks, whereas teams led by empowering leaders outperform directive leaders when a team engages in non-routine decision-making tasks. Furthermore, teams led by a directive leader make faster decisions independently of whether the team engages in routine or non-routine decision-making tasks, but are particularly fast in routine situations as compared to empowered teams.

\section{Theoretical contributions}

Our findings extend previous research in some important ways. Firstly, in our study, we found empirical evidence for the contingency theory of leadership which, according to Posakoff and colleagues (1995), is often a challenge. Our findings indicate that the extent to which team decision-making problems can be executed routinely or not (i.e. the environmental situation), emerges as a moderator of the relationship between leadership style and team decision quality. Therefore, our findings extend the existing body of literature on contingency leadership theory.

Secondly, by comparing directive and empowering leadership instead of studying the effectiveness of a single leadership style (e.g., Peterson, 1997; Srivastava et al., 2006), our findings advance leadership theory by helping to resolve the existing ambiguity about which leadership style is better for enhancing team decision quality and thus team performance. Conceptually, our findings corroborate the results of earlier studies 
in highlighting that empowering leadership is not consistently superior to directive leadership (Durham et al., 1997). We found that empowering leadership only gives rise to more accurate team decision-making when teams are dealing with non-routine situations. Only under these situational circumstances, teams benefit from the inputs and unique ideas of team members to make more accurate team decisions (De Dreu et al., 2008; Jehn, 1995; Wang et al., 2014). We also found evidence to disprove the critique that associates directive leadership with poor team decision-making (Moorhead \& Montanari, 1986; Tetlock et al., 1992). Our results show that that directive leadership appears to be a better predictor for team decision accuracy when dealing with routine situations. The cues of routine situations trigger compiled knowledge, so teams led by directive leaders can straightforwardly make accurate decisions without extensive team member input (De Dreu et al., 2008; Sommer \& Pearson, 2007). Our results also indicate that teams led by a directive leader made decisions faster, then teams with empowering leaders, regardless whether the team is dealing with a routine or a nonroutine situation. Results demonstrate that directive leadership resulted in faster team decision-making, more so in routine than in non-routine situations. One viable explanation is that participants in our sample who were designed as directive leaders were essentially task oriented (House, 1971), and focused on finding a satisficing solution within the shortest possible time.

Of particular interest in our study is the consideration of decision quality as a combination of decision accuracy and decision speed. To the best of our knowledge, our study is the first to empirically examine leadership in high-dynamic and complex realworld settings where both decision accuracy and decision speed are studied simultaneously. In dynamic and high-velocity settings stakes are very high, so mishandling the situation usually has important negative and long-term consequences (Garcia, 2006). Though many real-world decision-making problems are time bound (Cosgrave, 1996), decision accuracy cannot be sacrificed for the sake of speed (Pearson \& Clair, 1998). This implies that highly accurate decisions which are made too late are as bad as quick decisions which lack accuracy. Our empirical findings indicate that when a team engages in routine decision-making tasks, a directive leadership style is best suited for enhancing team decision quality (i.e. teams making accurate and fast decisions). Empowering leadership on the contrary gives rise to less team decision quality (i.e. slower and less accurate decision making). When considering non-routine situations, both directive and empowering leadership style can lead to high decision quality. As shown in Figure IV 14, directive leadership results in fast but less accurate decisions, whereas empowering leadership guarantees accurate but slower decision-making. This implies that the determination of which leadership style is best suited depends on the weight of the constituent criteria of decision quality. 


\begin{tabular}{|c|c|c|}
\hline & Routine situation & Non-routine situation \\
\hline \multirow[t]{2}{*}{ Directive leadership style } & - Accurate & - Less accurate \\
\hline & - $\quad$ Fast & - $\quad$ Fast \\
\hline \multirow[t]{2}{*}{ Empowering leadership style } & Less accurate & - Accurate \\
\hline & - Slower & - Slower \\
\hline
\end{tabular}

Figure IV - 14: Decision quality

\section{Limitations and Suggestions for Further Research}

Like any research, our study has some limitations highlighting areas for future research. A first possible limitation is that our sample was composed of undergraduate students. Though experimental research using students as a substitute for a larger group of interest has been criticized as having little external validity (e.g., Kam, Wilking, \& Zechmeister, 2007; Sears, 1986), Drukman and Kam (2011).argue that that student subjects are not an inherent problem to experimental research and state that the burden of proof should lie with critics rather than experimenters To complement our findings, future research may benefit from using people having experience of working in real-world multidisciplinary teams.

Second, studying human behaviors in real-world settings is complex, so to manage complexity researchers bound the situation under consideration and usually focus on one or a few isolated variables in laboratory experiments to draw conclusions (Woods, 1993). In our research, we reduced the reality of complex settings by studying one-shot decision problems (a team is confronted with a situation which is routine or non-routine and has to make a decision) and by considering two contrasting leadership styles of the continuum of participation in decision-making (Durham et al., 1997): Directive and empowering leadership. However, results on one-shot decisions are usually considered of restricted relevance for dynamic real-world settings where decision-making is not limited to one-shot decisions (Kleinmuntz \& Thomas, 1987). When multidisciplinary teams are confronted with dynamic real-world problems, they have to make an initial decision to engender a first response. Meanwhile the situation further evolves and additional information comes in over time so the teams have to make successive decisions until the situation is stabilized. With regard to the use of discrete leadership manipulations, research on leadership has revealed that effective leaders do not limit to one leadership style, but use several types of leadership behavior (Yukl, 2010). Accordingly, leaders should easily move back and forth along the continuum of participation in decisionmaking (i.e. from directive to empowering leadership and vice versa) so as to enable them to make qualitative team decisions to deal with different environmental situations. Taking into account the used reductions and considering the realm of dynamic settings, future research should engage longitudinal designs wherein teams are confronted with settings which evolve over time from routine to non-routine decision- 
making problems or vice versa and wherein leaders have to adapt their behaviors in order to obtain the most qualitative decisions.

Finally, Fox and Ochoa (1997) emphasize that the level of experience of leaders is an important prerequisite for accurate routine decision-making since they must be able to use compiled knowledge to determine how useful a solution to the problem might be. In our study however, experience was not considered a determinative variable. All teams were trained the same way in order to be prepared to deal with routine situations. Future research could examine whether our findings hold when team leaders have varying levels of experience.

\section{Practical Implications}

The findings of our study offer valuable insights for leaders who are responsible for teams which have to make decisions in dynamic real-world environments such as health care officials, military commanders, and disaster or emergency managers. Previous research has shown that in such contexts decision makers usually apply a recognitionprimed decision strategy to quickly make accurate decisions (Klein, Calderwood, \& Clinton-Cirocco, 2010; Lipshitz, Klein, \& Orasanu, 2001). The core concept of the strategy is that a decision is made via a process of recognition of key elements (i.e. pattern matching) and analysis (i.e. mental simulation). Leaders us their experience to identify a workable course of action and subsequently conduct a mental simulation to see if it will work in the situation they face. The final decision is primed by the way the leader recognizes the situation. We argue that when leaders recognize the environmental situation as a routine decision-making problem, they can facilitate team functioning by using a directive leadership style. On the contrary, when teams face a non-routine situation both directive and empowering leadership style can lead to high team decision quality as clarified earlier. To determine which leadership style is best suited, depends on the weight of the outcome variables decision speed and decision accuracy. When the importance of the outcome variable decision speed exceeds that of decision accuracy, teams led by directive leaders outperform those led by empowering leaders. This can be the case for instance when people who are in great danger have to be rescued urgently. When on the other hand decision accuracy is the most important outcome variable, teams led by empowering leaders will make more qualitative decisions than those led by empowering leaders. This arises for example when during emergencies important decisions which can compromise the further course of actions have to be made.

\section{Conclusion}

The study described in this chapter demonstrates that the situation at hand may call for either directive or empowering leadership. Directive leadership prompts quick deci- 
sions; it yields accurate solutions in in routine situations, but less so in non-routine situations. Empowering leadership is generally slower. It yields accurate decisions in nonroutine situations, but less so in routine situations. We conclude that no one leadership style is universally better than the other, and that familiarity with the situation (routine vs non-routine) determines which leadership style is most effective. 

Chapter

General Discussion and Conclusion 



\section{Concluding Remarks}

Early efforts to study disasters date back to the beginning of $20^{\text {th }}$ century and were essentially based on a physical agent approach. Systematic social science disaster research started in the 1950s (Quarantelli, 2005) and ever since, numerous studies contributed to the field which allowed to develop a rich knowledge of disaster intelligence and best practices to deal with these events (Lagadec, 2009a). Nevertheless, there is still much to learn, especially when considering novel mutations in the disaster landscape. Since the beginning of the third millennium, several researchers call attention to the fact that disasters are changing shape (Boin \& Lagadec, 2000) and state that recent disasters differ structurally from those we had to deal with in the past. If such a trend is real, we can expect that societies will be more violently affected in the future and that the work of the intervening units of emergency management organizations will be more challenged, notwithstanding the improved disaster intelligence and emergency management capacities and procedures. Consequently, researchers, public authorities, disaster managers and emergency workers face critical challenges. So extending our knowledge is imperative if we want to avoid to be continually one disaster behind (Davis, 2006). Quarantelli (1996) states that "[i]f one is interested in what we will face by way of disasters to come, one cannot extrapolate only from the past" (Quarantelli, 1996, p. 228). Naturally, when the context changes, accepted theories and practices become outmoded and need to be revisited, so "[t]he inescapable challenge is to rethink the issues, not to open additional boxes fixing the same models" (Lagadec, 2009a, p. 473).

The main aim of this dissertation is to facilitate a better understanding of the key consequences of the mutating disaster landscape and to provide academics and practitioners with a more comprehensive view of modern disaster management. After reviewing the literature on the core concepts of disaster research and outlining the actual situation as well as the challenges involved, I defined the general research question as follows: 'Are modern disasters marked by important mutations, and if this is the case, what are the major consequences for the intervening emergency management organizations and for the people leading those organizations?'

In pursuing the main objective, partial research questions were developed on which the three studies that build the core of the dissertation were based. In a first study, I investigated whether de facto there is a mutation of the disaster landscape towards more disasters of the $21^{\text {st }}$ century. Next, I focused on the response phase of the disaster management life cycle. Taking into consideration the changing disaster landscape, I aimed to remodel the response phase, focusing on a new and fresh approach. Finally, I assessed whether the effect of leadership style on team decision quality as a measurement of team performance depends on the environmental situation wherein decisionmaking teams are operating. In the following, the main findings are summarized. Subsequently, the theoretical contributions and practical implications are discussed, limita- 
tions are highlighted, and areas for future research are proposed. I end this dissertation with a general conclusion.

\section{Summary of the empirical findings}

Decades of disaster research allowed building a rich knowledge of disasters and developing a toolkit of best practices to deal with them (Lagadec, 2009a). Yet, thousands of people are still killed, injured or affected by some disaster on a yearly basis. Given recent disaster reports and disaster research, it looks like if our planet has become a more dangerous place to live than ever before. First, disaster statistics record an important increase in the quantity of disasters per time frame since the second half of the last century, with important peaks at the beginning of the third millennium (International Federation of Red Cross and Red Crescent Societies, 2015). Second, since the end of the $20^{\text {th }}$ century, several disaster researchers warn about a qualitative shift in the disaster landscape. Unfortunately, no academic study has been found in disaster literature providing empirical evidence for such an evolution. The objective of the first empirical study (Chapter 2) was to find an answer to the following partial research question: 'How much evidence is there to support the hypothesis that there is a trend towards more disasters of the $21^{\text {st }}$ century which are qualitatively different from historical ones?' To that purpose, I extensively reviewed recent disaster literature to identify the main characteristics of disasters of the $21^{\text {st }}$ century and then introduced the notion of 'disasters out of the box'. A disaster becomes 'out of the box' to an intervening emergency management organization when it jeopardizes the performance of that organization. Next, I developed the 'Disaster Impact and Complexity Diagram' (DI\&C-Diagram), a tool allowing the examination of trends in the qualitative evolution of disasters over the years. Finally, I studied 100 disasters between 1900 and 2010, considering five time frames: 1900-1924, 1925-1949, 1950-1974, 1975-1999, and 2000-2010. For each of the considered time frames, I randomly selected twenty disasters out of the Disaster Database Project, a disaster database developed by Green III (2011), which I have studied in detail using the DI\&C-Diagram. The results of the study indicate a significant jump in severity and magnitude since the 1950s, whereas from the mid-seventies disasters obviously become more complex to manage. Additionally, I found a strong positive correlation between impact and complexity, assuming that the larger the impacts are, the more complex the disaster. Further statistical analysis of the data confirms the trend towards more disasters of the $21^{\text {st }}$ century, entailing the possibility that more disasters of the future will evolve into 'disasters out of the box'.

Finding empirical evidence for a qualitative trend in the disaster landscape implies that we can expect that societies will be more greatly affected in the future and that the work of the responding units of emergency management organizations will be more heavily challenged, notwithstanding the improved disaster and emergency manage- 
ment capacities and procedures. In the study elucidated in Chapter 3, I therefore addressed the following partial research question: 'How can we re-conceptualize the response activities of intervening units of emergency management organizations within the context of disasters of the $21^{\text {st }}$ century?' Though recent disaster research essentially focuses on reinforcing mitigation efforts and establishing more resilient societies (McBean, 2012), disasters still continue to strike and disrupt entire societies each year (Coppola, 2011). As a consequence, disaster response remains a vital aspect of disaster management and even will become more important in the future given the evolution of the disaster landscape. The purpose of the second empirical study was to remodel the response phase of the disaster management life cycle, focusing on a new and fresh approach. On that account, I carried out a qualitative study, using the 'responsive interviewing approach' developed by Rubin and Rubin (2005). The results reveal that the response phase is much more than just a set of different activities aimed at stabilizing the situation and at limiting injuries, loss of life and damage to property and the environment (National Governors' Association, 1978). The data show that the response phase evolves as a comprehensive process through three succeeding stages that partly overlap and blend into one another (paralysis, operational response and strategic response), and which entails some important sub-processes: the gradual buildup of capacities in the disaster zone, the coordination process and the event assessment process. The data also make obvious that the sub-process of event assessment is highly important when dealing with disasters of the $21^{\text {st }}$ century that have a high potential to become 'out of the box'. Existing disaster and emergency management theory does not provide clear-cut answers for such events and disaster managers cannot fall back on pre-established plans and procedures to deal with them.

Many of today's teams, such as disaster decision-making teams, operate in dynamic and complex environments, where decisions have to be made very fast from incomplete information (Riolli-Saltzman \& Luthans, 2001). In such environments, stakes are high and any delay in decision-making may worsen the situation to a large extent. Therefore, qualitative team decisions have to be accurate and at the same time made fast. When a decision-making team faces a recognizable or routine situation, team members can draw upon their knowledge and experience to rapidly identify a satisficing solution (Lei et al., 2016). When faced with an non-routine situation, the team members lack cues to trigger stored knowledge (Schraagen \& van de Ven, 2008). Though it has long been found that leaders play a key role in facilitating the team decision-making process, in the literature there is an ongoing debate on which leadership style is best suited and under which condition. This brings us to the partial research question related to the third empirical study: 'Which leadership style yields the best performance when an emergency management decision-making team is confronted with real life situations that vary in complexity?' Therefore, I first developed a contingency leadership model of multidisciplinary team decision quality (as a measurement for team performance) and subsequently tested the possibility that leadership style and environmental situation 
interact in predicting team decision quality and thus team performance. Using an experimental setup, I studied the effect of two distinct and opposite leadership styles, directive versus empowering leadership, on team decision-making quality which allowed us to provide insight in when a particular leadership style becomes more beneficial. Multilevel analysis revealed that that teams led by a directive leader make more accurate decisions when confronted with routine decision making tasks, whereas teams led by an empowering leader outperform directive leaders when a team engages in nonroutine decision-making tasks. The results also show that teams led by a directive leader make faster decisions independently of whether the team engages in routine or nonroutine decision-making tasks, but are particularly fast in routine situations as compared to empowered teams. Of particular interest in our study is the dual outcome measure of decision accuracy and decision speed. Our findings indicate that when a team engages in routine decision-making tasks, a directive leadership style is best suited for enhancing team decision quality (i.e. teams making accurate and fast decisions). Empowering leadership, on the contrary, gives rise to less qualitative team decisions (i.e. slower and less accurate decisions). When a team faces a non-routine decisionmaking task, both leadership styles can lead to high team decision quality. The determination of which leadership style is best suited depends on the weight of the fundamental criteria of decision quality. When decision speed is judged the most important criterion, teams led by a directive leader, do better than teams led by an empowering leader. When decision accuracy is considered the decisive criterion, teams led by an empowering leader will make more qualitative decisions than those led by a directive leader, implying that leaders should reserve time for consulting the team members, even though consultation is more time consuming.

\section{Theoretical Contributions}

The originality of the research described in this dissertation and the innovative character of its findings lie in the consideration of the assumed evolution towards modern disasters which take on new dimensions and which are often referred to as disasters of the $21^{\text {st }}$ century (Boin \& Lagadec, 2000; Rosenthal, 1998). Many academics have discussed the issue since the end of last century (e.g. Helsloot et al., 2012b; Lagadec, 2009a; Leonard \& Howitt, 2007; Rosenthal, 2009), but few analytic research about the subject has been found. However, the same academics emphasize that the mutating disaster landscape challenges the ruling intellectual framework and the operational answers to a large extend, which leaves us with many unknowns (Helsloot et al., 2012b). We enter a new territory of disasters of the $21^{\text {st }}$ century that requires a paradigm shift, a demand to find some new orientations and adapted managerial and decision-making capabilities. To fill this gap, I decided to study a coherent set of aspects related to this terra incognita (Lagadec, 2009a), i.e. the evidence of the mutating disaster landscape, 
its impact on disaster response, and the challenges for people leading the response organizations In doing so, I intended to extend the current knowledge in several ways. In this paragraph, I discuss the theoretical contributions of the empirical studies elaborated in this dissertation.

According to disaster researchers, more disasters of the $21^{\text {st }}$ century are occurring each year, with greater intensity (Coppola, 2011). They state that these disasters have a far more devastating impact and affect a great many more people in either a direct or an indirect way. At the same time, academics emphasize that disasters of the $21^{\text {st }}$ century are much more difficult to manage due to their complexity (Boin \& Lagadec, 2000) and their significant novelty (Leonard \& Howitt, 2012). They stress that several of today's disasters are not distinct events, but unfold as a process where many forces interact in unforeseeable and disturbing ways (Rosenthal, Boin, \& Comfort, 2001). Recent events such as the Southeast Asian Tsunami (2004), Hurricane Katrina (2005), and the earthquakes in Kashmir (2005), Haiti (2010) and East Japan (2011) are good examples. Though the issue that actual disasters are changing shape has been discussed by several scholars, no academic study has been found providing empirical evidence for such an evolution. Consequently, it remained unclear whether these cited events should be viewed as isolated events occurring from time to time, or whether they were part of a significant evolution in the disaster landscape. To fill this gap in knowledge, I developed the DI\&C-Diagram, a tool that allows studying disasters over the years in order to determine qualitative trends, which I used to conduct a detailed research of a random selected set of disasters which occurred between 1900 and 2010. The findings of the first study provide empirical evidence for the assumption that in recent time, there is a trend towards more disasters of the $21^{\text {st }}$ century, which have the potential to become 'disasters out of the box' to the intervening emergency management organizations. This implies that we will have to deal with more disasters like Hurricane Katrina or the Southeast Asian Tsunami -and possibly even worse- in the future (Townsend, 2006), disasters of a different nature which add to the traditional ones that have not disappeared. Traditional disasters, i.e. the ones understandable regarding past disasters (Gundel, 2005; Hills, 1998), are referred to as routine events because they can be anticipated and prepared for (Leonard \& Howitt, 2012). In that case, lessons of the past still have their place and the developed toolkits and procedures remain meritorious or can easily be adapted, so that these events can be well managed (Lagadec, 2006). Though, when the context changes fundamentally, applying a straightforward "more of the same logic" (Lagadec, 2009a, p. 473) including more detailed plans, more powerful tools, more coordination, etc. is not effective. Traditional policy assumptions of disaster and emergency management become outdated and therefore need to be revisited meticulously. The mutating disaster landscape thus poses conceptual and theoretical challenges to disaster researchers which should above all focus on a new paradigm for disaster research (Quarantelli, 1998) in order to upgrade disaster and emergency management capacity. The results of the first study empirically confirm this need for a paradigm shift 
and therefore extend the existing body of literature on disasters and disaster management in an important way.

Second, the dissertation also contributes to the disaster and emergency management literature by reexamining the response phase of the disaster management life cycle within the context of the mutating disaster landscape. Disasters occur at the intersection of the physical and social environments and consequently are complex phenomena by nature (McEntire \& Smith, 2007). To invoke familiar schemes in scientific thought and to simplify the complexity (O'Rand \& Krecker, 1990), disaster scientists have identified different phases during a disaster (Richardson, 2005). Disaster phase research goes back as far as to the 1930s (Neal, 1997) and initially focused on response and relief efforts (Quarantelli, 1987a). Due to the dramatic increase in disasters of the 1970s, characterized by more deaths and greater economic losses, the traditional approach was complemented by pre-disaster thinking and planning (Lewis et al., 1976) and the disaster management life cycle was designed. A widely used disaster life cycle model is the comprehensive management approach (CEM), developed at the end of the 1970s by the National Governors' Association during its study of emergency preparedness (Donahue \& Joyce, 2001; National Governors' Association, 1978). CEM is a holistic approach to disaster management including four phases: mitigation, preparedness, response and recovery. Though present-day disaster studies mainly focus on mitigation, risk reduction and resilient societies (McBean, 2012; Weichselgartner, 2001), we note that still thousands of people are affected each year by some disaster. Well-developed mitigation efforts in combination with effective preparedness programs do no stop disasters from disrupting our societies. Consequently, disaster response remains a vital aspect of disaster management and even will become more important given the evolution towards more disasters of the $21^{\text {st }}$ century. Up to now, the response phase of the disaster life cycle has simply been described as the third phase of the disaster management life cycle during which a variety of activities aimed at limiting injuries, loss of life and damage to property and the environment take place (National Governors' Association, 1978). During the response phase, existing emergency plans, generally based on a best practice approach, are executed to address the short term direct effects of the disaster. When dealing with traditional disasters, this best practice approach appears to be quite effective. However, recent research confirms an evolution towards more disasters of the $21^{\text {st }}$ century (De Smet et al., 2012) that present a new class of adversity with many unknowns (Helsloot et al., 2012b), so the ruling plans become outmoded and even might turn into serious pitfalls (Lagadec, 2009a). Therefore, Rosenthal and colleagues (2001) argued to study disasters as a process rather than as a discrete event. On that account, I aimed to analyze the response phase taking a new and fresh approach. I decided to remodel the response phase within the context of the mutating disaster landscape, and do so from a process-based perspective. The findings show that the response phase evolves as a global process through three succeeding and partly overlapping stages, entailing some important sub-processes. Therefore, the study ad- 
dresses and makes a contribution to the existing disaster and emergency management literature.

During disaster response, action must be undertaken. Accordingly, disaster managers are frequently challenged to take critical decisions often from limited and fragmented information. A specific contribution to literature is the elaboration of the three-step event assessment sub-process of the disaster response phase, as a framework for disaster decision-making teams to make appropriate decisions. The most critical step of the framework is the classification of the event, as it guides further actions. Is it a routine event for which the rulebook (i.e. the developed toolkits and procedures) is applicable, or is it an atypical or non-routine event for which the normal procedures do not fit anymore? In the first case, immediate decision and action are possible and necessary. In the second case, plans are heavily confounded and disaster managers and emergency workers are forced to break out of the rulebook. When dealing with non-routine events, existing plans are inadequate or even counterproductive (Leonard \& Howitt, 2007). Consequently disaster decision-making teams must realize that they are vacillating between immediate decisions and resulting actions, and possible long term effects (Rosenthal et al., 2001) which may be much harder to manage due to the interconnected nature of current social infrastructures (Erikson, 1994; Smith, 2005). Our data reveal that when facing non-routine events, decision makers must 'take' and 'make' time to make appropriate decisions so not to deteriorate the situation. The finding is quite original because disaster decision-making is in essence critically time bound (Cosgrave, 1996).

Within the context of the actual disaster landscape where disaster decision-making teams have to deal with both traditional events and disasters of the $21^{\text {st }}$ century, the role of the team leader is very important. Though it has long been found that leaders play a key role in facilitating the team decision-making process (Durham et al., 1997; Zaccaro et al., 2001), it still remains unclear which leadership behaviors yield the best team decision quality and thus team performance (Lorinkova et al., 2013; Yun et al., 2005). In disaster situations, stakes are often high and any delay in decision-making may deteriorate the situation to a large extent (Garcia, 2006). However, decision accuracy cannot be sacrificed for the sake of speed (Pearson \& Clair, 1998), a view that is corroborated by the findings of the second study (i.e. when confronted with non-routine decision-making tasks, the decision maker must 'take' and 'make' time to make appropriate decisions). Decision speed and decision accuracy thus both constitute important criteria for team decision quality. My study adds to the leadership and team decision-making literature by empirically examining leadership in high-dynamic and complex real-world settings where both decision accuracy and decision speed are studied simultaneously. On that account, I advanced a contingency leadership model of multidisciplinary team decision quality in order to examine the relationship between leadership style (i.e. directive vs. empowering leadership) and team decision quality, and taking into account the moderating role of the environmental situation (i.e. routine vs. non-routine situa- 
tion). The results of an experimental research reveal that in situations where a decisionmaking team engages in routine decision-making tasks, teams led by a directive leader make more accurate decisions than teams led by an empowering leader. Conversely, when confronted with a non-routine decision-making task, teams led by an empowering leader outperform those led by a directive leader. Furthermore, findings also show that decision-making teams led by a directive leader make faster decisions than teams led by an empowering leader, independently of whether the team engages in routine or nondecision-making tasks, but that they are particularly fast in routine situations compared to teams led by an empowering leader. By comparing directive and empowering leadership instead of studying the effectiveness of a single leadership style (e.g. Srivastava et al., 2006), my findings advance leadership theory by helping to resolve the existing ambiguity about which of both leadership styles is better for enhancing team decision quality and thus performance. Also, by finding empirical support for the environmental situation as a moderator of the relationship between leadership style and decisionmaking quality, my research extends the literature in contingency leadership (Podsakoff et al., 1995; Yun et al., 2005).

Of particular interest in the third study is the dual outcome measure of decision accuracy and decision speed. Many real-world decision-making problems are time bound (Cosgrave, 1996), which implies that highly accurate decisions that are made too late are as bad as quick decisions which lack accuracy. The current findings indicate that when a team engages in routine decision-making tasks, a directive leadership style is best suited for making fast and accurate decisions, and thus for enhancing team performance. When a team engages in non-routine situations, both directive and empowering leadership style can lead to high decision quality. Directive leadership results in fast but less accurate decisions, whereas empowering leadership guarantees accurate but slower decision-making. The determination of which leadership style is best suited depends on the weight of the constituent criteria of decision quality, accuracy or speed.

\section{Practical Implications}

The knowledge gained from this dissertation is not only relevant to the scientific community; it also has practical implications that go beyond academic impact.

The findings of the first empirical study of this dissertation have an important impact on preparation and training. First, we still are and will always be confronted with traditional disasters for which we can easily fall back on pre-established plans and procedures. Therefore, traditional preparation and training remains crucial, meaning that existing plans and procedures must be adjusted in accordance with lessons learned, and trained on a regular base. Second, the results of the study confirm the sensed change in character and impact of disasters, meaning that we are confronted with more disasters that present "a new class of adversity with many unknowns" (Helsloot et al., 2012b, p. 
5). In such a context, the usual modes of response are no longer as effective and might even become counterproductive (Lagadec \& Carli, 2005). Besides, the policy of adjusting the existing and known textbooks by lessons learned is not an option to deal with disasters of the $21^{\text {st }}$ century (Lagadec, 2009a). The changes in the disaster landscape thus challenge the disaster management practitioners and emergency workers to a high degree so preparation and training should both be pushed to another level. One of the main defies during preparation is about shaping the future (Lagadec, 2009b). The traditional approach of going back to the same state that existed prior to the event can be considered as a failure to utilize the knowledge gained through experience (Baker \& Refsgaard, 2007). Creativity must come first. This was expressed by President Obama when facing mounting criticism of his handling of the BP Gulf Oil gusher (June $14^{\text {th }}$, 2010): "In the same way that our view of our vulnerabilities and our foreign policy was shaped profoundly by $9 / 11$, I think this disaster is going to shape how we think about the environment and energy for many years to come [...]. And one of the biggest leadership challenges for me going forward is going to be to make sure that we draw the right lessons from this disaster and that we move forward in a bold way, in a direction that finally gives us the kind of future oriented - or the kind of visionary policy that we so vitally need and has been absent for so long" (Obama, 2010). Another key challenge concerns training. As Lagadec $(2012$, p. 21) states, "the goal is not to strive to foresee the unforeseeable but to train ourselves to cope with it". In complex phenomena, the relationships between cause and consequences (effects) are seldom linear in nature so making relevant prognoses about what will happen after the trigger event becomes very tough (De Smet et al., 2012). Therefore, disaster managers and emergency workers must be able to creatively think about the unthinkable, learn to reason out of the box, and dare to be extravagant in scenario thinking; competences which should be stimulated during training sessions. As LaPorte states (2007, p. 62): "Leaders must prepare to be very surprised and no longer rely exclusively on existing plans". They must be prepared not to systematically fall into procedural thinking, to exhibit innovation and to take the initiative during extremely trying circumstances (Townsend, 2006).

When dealing with traditional disasters, routine skills are readily applicable and the available ready-made answers which are based on lessons learned from the past lead to satisfying outcomes. In such case, fast decision making and quick response is the core paradigm (see Lagadec \& Carli, 2005; Rosenthal et al., 1994). However, current disaster managers and emergency workers have to tackle problems they have never before confronted with increasing frequency (Britton, 2002). As a consequence, the mutation in the disaster landscape calls for new paradigms and other strategies. The findings of Chapter 3 show that the response phase evolves as a global process through three stages. Immediately after disaster impact, there is confusion and disbelief, bringing about a state of paralysis. When people realize what happened, relief operations start and the process evolves into the stage of operational response during which the emphasis is on instant response activities to save as much life and property as possible. The 
disaster management decision-making authority is responsible for directing all the response efforts efficiently and effectively so as to stabilize the situation, prevent further damage and prepare initial recovery activities. During the strategic stage he must assess the event thoroughly and carefully to clearly understand what the essence is and what are possible pitfalls (Lagadec, 2012). If the event is classified as regular or routine, the rulebook is applicable. When the event is classified as atypical, the disaster decisionmaking authority is often faced with many unknowns and difficult dilemmas that must be negotiated before addressing the event (Boin \& Lagadec, 2000). This implies that he has to take a step back and think before making any decision, which is a new mindset which conflicts with the traditional paradigm of fast decision-making and quick response. In the context of atypical events, the crucial difficulty consists in aligning the existing knowledge, which exists to a large extent outside domains traditionally drawn upon in disaster management, with the ongoing event (von Lubitz, Beakley, \& Patricelli, 2008). Therefore, several authors emphasize that during the strategic stage of the response phase, Boyd's OODA decision cycle (Boyd, 1987) can be of great help and should be fully understood and implemented (e.g.: Lagadec, 2013; von Lubitz et al., 2008). The OODA Loop comprises four interconnected and sequential stages (observation, orientation, decision and action) and provides a conceptual framework for governing human behavior in unpredictable and dynamically changing environments. The observation stage, which is associated with several inputs from outside and inside the operational environment, allows to detect the 'inconceivable' (Lagadec, 2012). The orientation stage allows readjusting the reading of very rapidly unfolding processes and therefore shapes the course of the two following stages, being the decision of the actions to be taken and the full implementation of the planned activities.

In real-world environments, teams and their decision makers need to be increasingly able to adapt to the changing situational context. In the study reported in Chapter 4, I investigated under what environmental condition -routine vs. non-routine situationsthe effect of directive or empowering leadership was more beneficial for team decisionmaking quality. Research has shown that in highly dynamic and complex real-world environments, which are characterized by time pressure and ambiguous and often incomplete information, decision makers usually apply the recognition-primed decision making strategy (Klein et al., 2010; Lipshitz et al., 2001). The strategy allows to make satisficing decisions (Simon, 1955) without having to perform extensive analysis (Beach et al., 1997). The core concept is that decisions are made using a process of recognition of key elements (i.e. pattern matching) and analysis via mental simulation. This implies that decision makers use their experience to identify a workable course of action and then conduct a mental simulation to see if it will work in the situation they face. I found that when teams recognized the environmental situation as a routine decision-making task, a directive leadership style is best suited for making fast and accurate decisions, and thus for enhancing team decision-making quality and performance. On the contrary, when teams recognize the environmental situation as a non-routine decision making 
task, I found that both leadership styles, directive and empowering, can lead to high decision-making quality. When for example people are in great danger and need to be evacuated immediately, decision speed is the decisive criterion to make a high-quality decision. In that case, I found that teams led by a directive leader outperform those led by an empowering leader. When, on the other hand decision accuracy becomes the most important criterion of decision quality, our results indicate that teams led by empowering leaders tend to make more qualitative decisions than those led by directive leaders. This occurs, for instance, when important decisions which can compromise the further course of action have to be made. When dealing with non-routine decisionmaking tasks, the determination of which leadership style is best suited for making high quality team decisions depends on the weight of the outcome variables, decision speed and decision accuracy. To that account, the findings of our research offer valuable insights for leaders of multidisciplinary teams, such as disaster managers and emergency workers.

\section{Limitations and Areas for Further Research}

Though the three empirical studies that build the core of the dissertation make a meaningful contribution to the current knowledge of disaster and emergency management, leadership and team decision-making, some limitations are worth noting. Therefore, in this section, I will warrant some attention and consideration to the most important limitations and provide some lines of thought for future research.

A first potential limitation of this dissertation is related to the empirical study described in Chapter 2 and concerns the use of disaster data and disaster statistics. Disaster databases are a primary source to store and manage a range of data on disasters, and by consequence are an important tool for analyzing disasters and disaster characteristics (Huggel et al., 2015). Different disaster databases are available either as open source or not. However their quality, consistency and completeness remain a major concern so the data and statistics should be looked at with great caution (Guha-Sapir \& Below, 2002; Quarantelli, 2001). One of the major concerns is the lack of international consensus related to the way in which disaster data are compiled and the nonexistence of an unambiguous definition of the concept disaster (Perry \& Quarantelli, 2005). The current practice in disaster databases shows that inclusion criteria are arbitrary and often not handled in a consistent way. Consequently, there are large differences in reporting, documentation, completeness and quality of disaster databases (United Nations Development Programme, 2013). Researchers thus have to determine which database(s) best answers to their research objectives. As reference to examine qualitative trends in the disaster landscape I have chosen one source of information, the Disaster Database Project developed by Green III (2011), which at the time of consultation was a living information source containing data of more than 2,500 disasters. I decided 
to use this particular database because in addition to quantitative data such as the number of fatalities, people injured, economic costs, etc., it also disaggregates each disaster into phases as defined by Fink (2002). The detailed description of each stage as well as a narrative of the event during each phase, offered vital information necessary for the study of the 17 parameters of the DI\&C-Diagram. Unfortunately, due to a lack of funding, the Disaster Database Project has closed abruptly in late 2011, making followup studies using the same data source impossible. As a disaster database, combining qualitative and quantitative data is of great value for disaster researchers, it should be recommended to continue the effort of Green III and colleagues (2011). Furthermore, as disaster data are the key input for many disaster management research projects, further work is needed concerning standardization of methods for collecting, assessing and reporting disaster data.

Another limitation of the present dissertation is related to the second study, and more precisely to the use of qualitative research. Though qualitative data are considered to be a source of well-grounded and rich descriptions and explanations of processes in identifiable contexts helping researchers to get beyond initial conceptions and to generate or revise conceptual frameworks (Miles \& Huberman, 1994), qualitative research also has limitations. One of the most important limitations is that the findings of qualitative research are not tested to discover whether they are statistically significant or due to chance (Atieno, 2009). Therefore, additional research using for instance case studies or field research could be used to refine the discovered response phase process.

A next limitation is related to the third empirical research in which I used undergraduate students as experimental participants to test our hypotheses. Though many researchers use students as a substitute for a larger group of interest, the practice has been widely criticized. A point of particular concern is that students form a 'narrow database' (Sears, 1986) and that a student sample "lacks external generalizability" (Kam et al., 2007, p. 421). However, Druckman and Kam (2011) argue that students "are not an inherent problem to experimental research" (Druckman \& Kam, 2011, p. 41) and therefore made a strong argument for increased usage and acceptance of the practise. Yet, to complement our findings, future research may benefit from using people having experience of working in real-world multidisciplinary teams.

A fourth limitation concerns the use of laboratory experiments, a method of data collection which is widely used by scholars to manage the complexity of real-world settings. Using laboratory experiments, researchers bound the situation under consideration by focusing on one or a few variables to draw conclusions (Woods, 1993). In our study I bounded the situation in two ways. Firstly, I studied one-shot decision-making problems, meaning that a multidisciplinary team faces a situation which is routine or non-routine and has to make a decision. Dynamic real-world settings are hardly ever limited to one-shot decision-making problems (Kleinmuntz \& Thomas, 1987). When multidisciplinary teams face dynamic and complex real-world problems, they have to make a first decision to initiate response activities. By then, the situation further evolves 
and supplementary information becomes available, so the teams have to make additional and successive decisions to stabilize the situation. Secondly, I confined myself to two contrasting leadership styles -directive vs. empowering leadership- on the continuum of participation in decision-making (Durham et al., 1997) to manipulate our experiments. However, leadership research has revealed that effective leaders do not limit to one leadership style, but use several types of leadership behavior (Yukl, 2010). Leaders thus should easily move back and forth along the continuum of participation in decision-making (i.e. from directive to empowering leadership and vice versa) so as to enable them to make qualitative team decisions to deal with changing environmental situations. Future research should focus on the investigation of multidisciplinary decisionmaking teams in longitudinal designs wherein teams are confronted with settings which evolve over time from routine to non-routine decision-making problems and vice versa so leaders have to adapt their behaviors to make the most qualitative decisions.

Finally, Fox and Ochoa (1997) emphasize that the leader's experience level is an important prerequisite for accurate routine decision-making. Real-world decision makers directing multidisciplinary teams usually apply a recognition-primed decision strategy to make accurate decisions (Klein et al., 2010). They use their experience to size up the situation and to generate a plausible solution to the decision-making problem they face. In the context of our research, experience was not considered a determinative variable. All participating teams were trained the same way to deal with experimental scenarios under the condition of routine situations. Additional research could investigate whether our findings hold when team leaders have varying levels of experience.

Despite the limitations, which already motivate additional research, the finding of empirical evidence for the mutating disaster landscape, has some major implications for future disaster research. As mentioned earlier in the body of this dissertation, disasters occur at the junction of the physical and the social environments (McEntire \& Smith, 2007), i.e. when a hazardous situation intersects with the human system (Perry, 1998). Traditional disasters have not disappeared so the ruling theories and existing strategies remain valuable for dealing with these kinds of events. However, both the physical and the social environments are changing in a significant way and confront humans with a lot of new complexities that create new and higher level problems. Lagadec (2006) emphasizes that priority must be given to the understanding of these new challenges even though in the academic world the general trend is to treat anything new with great caution. Therefore, I propose some additional future research avenues.

A first line of investigation concerns the profound study of the conditions and of the causes that generate more disasters of the $21^{\text {st }}$ century. For example, issues that need special attention are climate change, the complexity of modern society and the increasing threat of terrorist attacks. Climate change and its impact on the occurrence of more extreme events like severe floods, destructive tropical storms, long-term droughts, etc., is considered as one of the main factors that exacerbate the vulnerability of modern societies to a high extent. Though it has become evident that the global climate is 
changing and will continue to change over the coming decades and centuries, people are still grappling with how to make sense of climate change and how to negotiate collective courses of action (Norgaard, 2011). Climate change thus still is an unmapped and much unknown territory characterized by complexity and interdependence which requires new ways of knowing (Endter-Wada \& Ingram, 2012). Another important issue is the complexity of modern social infrastructures which are characterized by interdependence, interconnectivity, tight coupling and a stunning increase in the worldwide mobility of goods and people. Such complex environments can easily amplify minor emergencies and transform them into major disasters in no time (OECD, 2011; Quarantelli, 1996; Smith, 2005). Therefore, it is necessary to integrate the nonlinearity of events in future disaster research (Pescaroli \& Kelman, 2017; Soave \& de Maupeau, 2016). Furthermore, high-profile attacks in France, Belgium, the United Kingdom, Sweden, Spain, etc., seem to indicate that terrorism is on the rise. Though the association of disasters with terrorism is not new, the scale of terrorist attacks and their impact on society have changed dramatically since the 9/11 disaster (Waugh, 2006). Besides, the next terrorist attack could take many forms; from the more common assaults such as firearm or bomb attacks, to a biological attack or a nuclear blast. Terrorist attacks are very complex events and their nature often changes rapidly during the course of an event so there is an urgent need to develop a comprehensive strategy to deal with the hazard of modern terrorism.

A second important line of investigation relates to the disaster management capacity. In this dissertation, I addressed important issues related to disaster response activities and the people leading the response organizations. Response is crucial as we indicated in Chapter 3, but so are the other phases of the disaster management life cycle. Therefore, Helsloot et al. argue for balanced efforts in disaster mitigation, prevention, recovering and recovery (Helsloot et al., 2012b). Therefore, future disaster research should focus on the disaster management life cycle in a holistic way; i.e. considering the four phases and their interconnectivity as a never-ending process or a spiral to continuous improvement.

\section{Conclusion}

The leitmotif throughout the dissertation is that the world is facing a mutating disaster landscape which calls for new paradigms and other disaster management strategies. The research presented aimed to address the following key issues. First, is there empirical evidence for an evolution towards more disasters of the $21^{\text {st }}$ century which occur with greater intensity and are characterized by a greater complexity to manage? Second, taking into account the mutating disaster landscape, how can we re-conceptualise the disaster response activities of intervening units of emergency management units? And third, which leadership style yields the best performance when an emergency 
management decision-making team is facing real-world situations that vary in complexity. The findings reported in the empirical chapters of this dissertation should facilitate a better understanding of the main consequences of the mutating disaster landscape, and should to provide academics and practitioners with a more comprehensive view of modern disaster management as to be better prepared for future disasters. 

References 



\section{Reference List}

't Hart, P. (2013). After Fukushima: Reflections on Risk and Institutional Learning in an Era of Mega-crises. Public Administration, 91, 101-113.

't Hart, P. \& Sundelius, B. (2013). Crisis management revisited: A new agenda for research, training and capacity building within Europe. Cooperation and Conflict, 48, 444-461.

Albala-Bertrand, J. (1993). The Political Economy of Large Natural Disasters. Oxford: Claredon Press.

Alexander, D. (2005). An Interpretation of Disaster In Terms Of Changes In Culture, Society And International Relations. In E.L. Quarantelli \& R.W. Perry (Eds.), What is a disaster? New Answers to Old Questions. (pp. 25-38). Philadelphia: Xlibris Corporation.

Alpaslan, C. M. \& Mitroff, I. (2011). Swans, swine, and swindlers: coping with the growing threat of megacrises and mega-messes. Stanford, CA: Stanford University Press.

Ammon, C. J., Lay, T., Kanamori, H., \& Cleveland, M. (2011). A rupture model of the 2011 off the Pacific coast of Tohoku Earthquake. Earth Planets Space, 63, 693-696.

Ansell, C., Boin, R. A., \& Keller, A. (2010). Managing Transboundary Crises: Identifying the building Blocks of an Effective Response System. Journal of Contingencies and Crisis Management, 18, 195-207.

Ansell, J. \& Wharton, F. (1992). Risk: Analysis, assessment, and management Chichester, UK: John Wiley and Sons.

Arnold, J. A., Arad, S., Rhoades, J. A., \& Drasgow, F (2000). The empowering leadership questionnaire: The construction and validation of a new scale for measuring leader behaviors. Journal of Organizational Behavior, 21, 249-269.

Atieno, O. P. (2009). An analysis of the strengths and limitation of qualitative and quantitative research paradigms. Problems of Education in the 21st Century, 13, 13-18.

Auf der Heide, E. (2004). Common Misconceptions about Disasters: Panic, the "Disaster Syndrome," and Looting. In M. O'Leary (Ed.), The First 72 Hours: A Community Approach to Disaster Preparedness (pp. 340-380). Lincoln (Nebraska): iUniverse, Inc.

Baker, D. \& Refsgaard, K. (2007). Institutional development and scale matching in disaster response management. Ecological Economics, 63, 331-343.

Balter, M. (2005). The seeds of civilization. Smithsonian, 36, 68-74.

Barkun, M. (1974). Disaster and the Millennium. New Haven, CT: Yale University Press.

Barton, A. H. (1970). Communities in Disaster: A Sociological Analysis of Collective Stress Situations. New York: Doubleday Anchor Book.

Bass, B. M. \& Avolio, B. J. (1990). Transformational leadership questionnaire: Manual for the Multifactor Leadership Questionnaire. Palo Alto, CA: Consulting Psychologists Press.

Bauman, S. (2012). Emerging forms of awareness about forgiveness and leadership. An analysis of what high profile leaders think. Antioch University, Culver City, CA.

Beach, L. R., Chi, M., Klein, G., Smith, P., \& Vicente, K. (1997). Naturalistic Decision Making and Related Research Lines. In C.E. Zsambock \& G. Klein (Eds.), Naturalistic Decision Making (pp. 29-35). Mahwah, NJ: Lawrence Erlbaum Associates, Inc.

Beck, U. (1986). Risk Society: Towards a new modernity. London: SAGE Publications.

Bergman, J. Z., Rentsch, J. R., Small, E. E., Davenport, S. W., \& Bergman, S. M. (2012). The Shared Leadership Process in Decision-Making Teams. The Journal of Social Psychology, 152, 17-42.

Betts, K. R. (2012). Conflict in Multiteam Situations. In S.J. Zaccaro, M.A. Marks, \& L.A. DeChurch (Eds.), Multiteam Systems. An Organization Form for Dynamic and Complex Environments (pp. 289-322). New York: Routledge.

Birkland, T. A. (1997). After Disaster: Agenda Setting, Public Policy, and Focusing Events. Washington, DC: Georgetown University Press.

Birkmann, J., Buckle, P., Jaeger, J., Pelling, M., Setiadi, N., Garschagen, M. et al. (2010). Extreme events and disasters: a window of opportunity for change? Analysis of organizational, institutional and political changes, formal and informal responses after mega-disasters. Natural Hazards, 55, 637-655. 
Bliese, P. D. (2000). Within-group agreement, non-independence, and reliability: Implications for data aggregation and analysis. In K.J. Klein \& S.W.J. Kozlowski (Eds.), Multilevel theory, research and methods in organizations: Foundations, extensions, and new directions (pp. 349-381). San Francisco, CA: Jossey-Bass.

Bliese, P. D. (2013). Multilevel Modeling in R (2.5): A Brief Introduction to $R$, the multilevel package and the nlme package.

Boin, A. (2005). From Crisis to Disaster: Towards an integrative perspective. In E.L. Quarantelli \& R.W. Perry (Eds.), What is a disaster? New Answers to Old Questions. (pp. 153-172). Philadelphia: Xlibris Corporation.

Boin, A. \& 't Hart, P. (2003). Public Leadership in Times of Crisis: Mission Impossible? Public Administration Review, 63, 544-553.

Boin, A., 't Hart, P., Stern, E., \& Sundelius, B. (2005). The Politics of Crisis Management. New York: Cambridge University Press.

Boin, A., Ekengren, M., \& Rhinard, M. (2014). Sense-Making in Crises: What Role for the EU? In P. Pawlak \& A. Ricci (Eds.), Crisis Rooms: Tow (pp. 117-128). Paris: European Union Institute for Security Studies.

Boin, A. \& Lagadec, P. (2000). Preparing for the Future: Critical Challenges in Crisis Management. Journal of Contingencies and Crisis Management, 8, 185-191.

Boin, A. \& Lodge, M. (2016). Designing Resilient Institution for Transboundary Crisis Management: A Time for Public Administration. Public Administration, 94, 289-298.

Boin, A. \& McConnel, A. (2007). Preparing for Critical Infrastructure Breakdowns: The Limits of Crisis Management and the Need for Resilience. Journal of Contingencies and Crisis Management, 15, 50-59.

Boin, A., Rhinard, M., \& Ekengren, M. (2014). Managing Transboundary Crises: The Emergence of European Union Capacity. Journal of Contingencies and Crisis Management, 22, 131-142.

Boyd, J. R. (1987). Patterns of Conflict (unpublished briefing). http://danford.net/boyd/patterns.pdf [On-line]. Brinkley, D. (2006). The great deluge. New York, NY: HarperCollins Publishers.

Britton, N. R. (1998). Managing community risk. (2nd ed.) Wellington, N.Z.: Ministry of Civil Defence.

Britton, N. R. (2002). A new emergency management for the new millennium. Australian Journal of Emergency Management, 16, 44-54.

Britton, N. R. (2005). What's A Word? Opening Up The Debate. In E.L. Quarantelli \& R.W. Perry (Eds.), What is a disaster? New Answers to Old Questions. (pp. 60-78). Philadelphia: Xlibris Corporation.

Burke, C. S., Stagl, K. C., Klein, C., Goodwin, G. F., Salas, E, \& Halpin, S. M. (2006). What type of leadership behaviors are functional in teams? A meta-analysis. The Leadership Quarterly, 17, 288-307.

Burton, I., Kates, R., \& White, G. (1978). The environment as hazard. New York: Oxford University Press.

Carr, L. (1932). Disasters and the sequence-pattern concept of social change. American Journal of Sociology, 38, 207-218.

Carson, J. B., Tesluk, P. E., \& Marrone, J. A. (2007). Shared leadership in teams: An investigation of antecedent conditions and performance. Academy of Management Journal, -1217.

Carter, W. N. (1991). Emergency Management: An Emergency Manager's Handbook. Manila: Asian Development Bank.

Castells, M. (1996). The Rise of the Network Society. Oxford, UK: Blackwell Publishers Ltd.

Chapman, D. W. (1962). A brief introduction to contemporary disaster research. In G.W. Baker \& D.W. Chapman (Eds.), Man and Society in Disaster. (pp. 3-22). New York: Basic Books Publishing Co., Inc.

Chen, G., Kirkman, B. L., Kanfer, R., Allen, D, \& Rosen, B. (2007). A Multilevel Study of Leadership, Empowerment, and Performance in Teams. Journal of Applied Psychology, 92, 331-346.

Chung, Y. \& Jackson, S. E. (2013). The internal and external networks of knowledge intensive teams: the role of task routineness. Journal of Management, 39, 442-468.

Clarke, M. (2002). Panic: myth or reality? Crisis Response Journal, 1, 21-26.

Cocking, C. \& Drury, J. (2014). Talking about Hillsborough: 'Panic' as Discourse in Survivors' Account of the 1989 Football Stadium Disaster. Journal of Community \& Applied Social Psychology, 24, 86-99.

Coetzee, C. \& van Niekerk, D (2012). Tracking the evolution of the disaster management cycle: A general system theory approach. Jàmbá: Journal of Disaster Risk Studies, 4, 1-9. 
Cohrssen, J. J. \& Covello, V. T. (1989). Risk Analysis: A Guide to Principles and Methods for Analyzing Health and Environmental Risks. Washington, D.C.: Council on Environmental Quality.

Collins, S. M. (2006). Hurricane Katrina: A nation still unprepared-Special Report of the Committee on Homeland Security and Governmental Affairs (Rep. No. S.Rept 109-322). Washington: U.S Government Printing Office.

Comfort, L. K. (1994). Risk and Resilience: Interorganizational Learning Following the Northridge Earthquake of 17 January 1994. Journal of Contingencies and Crisis Management, 2, 157-170.

Comfort, L. K., Siciliano, M. D., \& Okada, A. (2012). Evolving systems in crisis management: The January 12, 2010 Haiti earthquake. In I. Helsloot, A. Boin, B. Jacobs, \& L.K. Comfort (Eds.), Mega-Crises: Understanding the Prospects, Nature, Characteristics and the Effects of Cataclysmic Events. (pp. 77-91). Springfield, IL: Charles C Thomas Publisher Ltd.

Cooper, C. \& Block, R. (2006). Disaster: Hurricane Katrina and the failure of Homeland Security. New York: Henry Holt and Company, LLC.

Coppola, D. P. (2011). Introduction to International Disaster Management. (Second ed.) Burlington, MA: Elsevier Inc.

Cosgrave, J. (1996). Decision making in emergencies. Disaster Prevention and Management, 5, 28-35.

Couch, S. (2000). The cultural scene of disasters. International Journal of Mass Emergencies and Disasters, 18, 21-38.

Covello, V. T. \& Mumpower, J. (1985). Risk analysis and risk management: An historical perspective. Risk Analysis, 5, 103-118.

Craik, K. J. W. (1943). The nature of explanation. Cambridge, UK: Cambridge University Press.

Cronstedt, M. (2002). Prevention, Preparedness, Response, Recovery-an outdated concept. The Australian Journal of Emergency Management, 17, 10-13.

Cutter, S. L. (2005). Pragmatism and Relevance: a Response to Wolf R. Dombrowski. In E.L. Quarantelli \& R.W. Perry (Eds.), What is a disaster? New Answers to Old Questions. (pp. 104-106). Philadelphia: Xlibris Corporation.

Davies, H. \& Walters, M. (1998). Do all crises have to become disasters? Risk and risk mitigation. Disaster Prevention and Management, 7, 396-400.

Davis, T. (2006). A Failure of Initiative: Final Report of the Select Bipartisan Committee to Investigate the Preparation for and the Response to Hurricane Katrina. Washington, DC: U.S. Government Printing Office.

Day, D. V., Gronn, P., \& Salas E. (2004). Leadership capacity in teams. The Leadership Quarterly, 15, 857-880.

De Dreu, C. K. W., Nijstad, B. A., \& van Knippenberg, D. (2008). Motivated Information Processing in Group Judgment and Decision Making. Personality and Social Psychology Review, 12, 22-49.

De Dreu, C. K. W. \& Weingart, L. R. (2003a). A contingency theory of task conflict and performance in groups and organizational teams. In M.A. West, D. Tjosvold, \& K. Smith (Eds.), International handbook of organizational teamwork and cooperative working (pp. 151-166). Chichester, UK: Wiley.

De Dreu, C. K. W. \& Weingart, L. R. (2003b). Task versus relationship conflict, team performance, and team member satisfaction: A meta-analysis. Journal of Applied Psychology, 88, 741-749.

De Smet, H., Lagadec, P., \& Leysen, J. (2012). Disasters out of the Box: A New Ballgame? Journal of Contingencies and Crisis Management, 20, 138-148.

De Smet, H., Leysen, J., \& Lagadec, P. (2011). The Response Phase of the Disaster Life Cycle Revisited. In IIE 61st Annual Conference and Expo, Take your Career to new Heights. Reno, Nevada: Institute of Industrial Engineers.

De Smet, H., Schreurs, B., \& Leysen, J. (2014). Facing the actual disaster landscape. A trend towards more Disasters out of the Box? In D. Etkin \& B.L. Murphy (Eds.), Disaster and Emergency Management in Canada (pp. 1-31). Vancouver, CA: CRHNET.

DeChurch, L. A., Burke, C. S., Shuffler, M. L., Lyons, R., Doty, D., \& Salas, E. (2011). A historiometric analysis of leadership in mission critical multiteam environments. The Leadership Quarterly, 22, 152-169.

Deitrick, L. D., Roberts, T. P., \& Campbell, S. T. (2012). Leadership and decision-making in crisis. In International Society for Third-Sector Research Siena, Italy: International Society for Third-Sector Research. 
Dinham, B. \& Sarangi, S. (2002). The Bhopal gas tragedy 1984 to ? The evasion of corporate responsibility. Environment \& Urbanization, 14, 89-99.

Dombrowsky, W.R. (1981). Another Step toward a Social Theory of Disaster. Preliminary Paper \#70. Newark, DE, Disaster Research Center.

Dombrowsky, W. R. (1998). Again and again: Is a disaster what we call a "disaster"? In E.L. Quarantelli (Ed.), What is a disaster? Perspectives on the question (pp. 19-30). New York, NY: Routledge.

Donahue, A. K. \& Joyce, P. G. (2001). A framework for analyzing emergency management with an application to federal budgeting. Public Administration Review, 61, 728-740.

Drabek, T. E. (1996). The social dimensions of disaster. Instructor guide. Emmitsburg, MD: Emergency Management Institute.

Drabek, T. E. \& Hoetmer, G. J. (1991). Introduction. In T.E. Drabek \& G.J. Hoetmer (Eds.), Emergency management: Principles and practice for local government. (pp. xvii-xxxiv). Washington, DC: International City Management Association.

Druckman, J. N. \& Kam, C. D. (2011). Students as Experimental Participants: A Defense of the 'Narrow Data Base'. In J.N. Druckman, D.P. Green, J.H. Kuklinski, \& A. Lupia (Eds.), Cambridge Handbook of Experimental Political Science (pp. 41-57). New York: Cambridge University Press.

Druskat, V. U. \& Wheeler, J. V. (2003). Managing from the boundary: The effective leadership of self-managing work teams. Academy of Management Journal, 46, 435-457.

Durham, C. C., Knight, D, \& Locke, E. A. (1997). Effects of Leader Role, Team-Set Goal Difficulty, Efficacy, and Tactics on Team Effectiveness. Organizational Behavior and Human Decision Processes, 72, 203-231.

Dynes, R. R. (1970). Organized Behavior in Disaster. Lexington, MA: Lexington Books.

Dynes, R. R. (2003). Finding order in disorder: Continuities in the 9-11 Response. International Journal of Mass Emergencies and Disasters, 21, 9-23.

Endter-Wada, J. \& Ingram, H. (2012). Global climate change as environmental mega-crisis. In I. Helsloot, A. Boin, B. Jacobs, \& L.K. Comfort (Eds.), Mega-Crises: Understanding the Prospects, Nature, Characteristics and the Effects of Cataclysmic Events. (pp. 300-318). Springfield, IL: Charles C Thomas Publisher Ltd.

Ennis, R. H. (1997). Incorporating Critical Thinking in the Curriculum: An introduction to Some Basic Issues. Inquiry: Critical Thinking Across the Disciplines, 16, 1-9.

Ensley, M. D., Hmieleski, K. M., \& Pearce, C. L. (2006). The importance of vertical and shared leadership within new venture top management teams: Implications for the performance of startups. The Leadership Quarterly, 17, 217-231.

Erikson, K. (1994). A new species of trouble: Explorations in disaster, trauma and community. London: W.W. Norton \& Company.

Eshghi, K. \& Larson, R. C. (2008). Disasters: lessons from the past 105 years. Disaster Prevention and Management, $17,62-82$.

Federal Emergency Management Agency (FEMA) (1997). Multi Hazard Identification and Risk Assessment - A Cornerstone of the National Mitigation Strategy. Washington, D.C.: FEMA.

FEMA (1995). Introduction to Emergency Management (Student Manual 230). Emmitsburg, MD: Emergency Management Institute.

Fink, S. (2002). Crisis management - planning for the inevitable. (2nd ed.) Lincoln: iUniverse Inc.

Fox, R. \& Ochoa, G. (1997). Routine Decision Making Using Generic Tasks. Expert Systems with Applications, $12,109-117$.

Friedling, J-L. (2005). La Homeland Security à l'épreuve de Katrina. Revue Défense Nationale, 11, 171-176.

Fritz, C. (1961). Disaster. Contemporary Social Problems, 651-694.

Fritz, C. E. \& Mathewson, J. H. (1957). Convergence behaviour in disasters: A problem in social control. (Rep. No. 476, Disaster study number 9). Washington: National Academy of Sciences - National Research Council.

Garcia, H. F. (2006). Effective leadership response to crisis. Strategy \& Leadership, 34, 4-10.

Gardner, W. L., Lowe, K. B., Moss, T. W., Mahoney, K. T., \& Cogliser, C. C. (2010). Scholarly leadership of the study of leadership: A review of The Leadership Quarterly's second decade, 2000-2009. The Leadership Quarterly, 21, 922-958. 
Genzmer, H., Kershner, S., \& Schütz, C. (2007). Great Disasters in History. Bath, UK: Parragon Books Ltd.

Gephart, R. P. Jr. (2004). Qualitative research and the Academy of Management Journal. Academy of Management Journal, 47, 454-462.

Giddens, A. (1987). Social Theory and Modern Sociology. Stanford California: Stanford University Press.

Gilbert, C. (1998). Studying Disaster: Changes in the main conceptual tools. In E.L. Quarantelli (Ed.), What is a disaster? Perspectives on the question (pp. 11-18). New York, NY: Routledge.

Gladstein, D. L. (1984). A model of task group effectiveness. Administrative Science Quarterly, 29, 499-517.

Granatt, M. (2014). Complexity Crises - Never Fight the Last War. [Videotaped communication to P. Lagadec (Ecole Polytechnique, Paris)].

Granot, H. (1998). The dark side of growth and industrial disasters since the Second World War. Disaster Prevention and Management, 7, 195-204.

Graumann, A., Houston, T., Lawrimore, J., Levinson, D., Lott, N., McCown, S. et al. (2005). Hurricane Katrina, a Climatological Perspective (Rep. No. 2005-01). Asheville, NC: US Department of Commerce.

Green III, W.G. (2011). The Disaster Database Project. Glen Allen, Virginia, International Disaster Times.

Guha-Sapir, D. \& Below, R. (2002). The quality and accuracy of disaster data: A comparative analysis of three global data sets. Louvain-la-Neuve, Belgium: WHO Centre for Research on the Epidemiology of Disasters, University of Louvain School of Medicine.

Guha-Sapir, D., Hargitt, D., \& Hoyois, P. (2004). Thirty years of Natural Disasters. 1974-2003: The numbers. Louvain-la-Neuve, Belgium: Presses universitaires de Louvain.

Guiberson, B. Z. (2010). Disasters. Natural and Man-Made Catastrophes Through the Centuries. New York, NY: Henry Holt and Company.

Gundel, S. (2005). Towards a New Typology of Crises. Journal of Contingencies and Crisis Management, 13, 106-115.

Gunn, A. M. (2008). Encyclopedia of Disasters: environmental catastrophes and human tragedies. (vols. 1) Westport, CT: Greenwood Press.

Gunn, S. W. A. (1992). The Scientific Basis of Disaster Management. Disaster Prevention and Management, 1, 16-21.

Haas, J. E., Kates, R. W., \& Bowden, M. J. (1977). Reconstruction Following Disaster. Cambridge Massachusetts: The MIT Press.

Hackman, J. R. \& Wageman, R. (2005). A theory of team coaching. Academy of Management Review, 30, 269287.

Haddow, G. D., Bullock, J. A., \& Coppola, D. P. (2011). Introduction to Emergency Management. (Fourth ed.) Burlington, MA: Elsevier Inc.

Handmer, J. W. \& Dovers, S. D. (1996). A Typology of Resilience: Rethinking Institutions for Sustainable Development. Organization and Environment, 9, 482-511.

Harrald, J. R. (2012). Hurricane Katrina: Crisis leadership that failed a country. In I. Helsloot, A. Boin, B. Jacobs, \& L.K. Comfort (Eds.), Mega-Crises: Understanding the Prospects, Nature, Characteristics and the Effects of Cataclysmic Events. (pp. 37-50). Springfield, IL: Charles C Thomas Publisher Ltd.

Harris, S. R. (2010). What Is Constructionism? Navigating Its Use in Sociology. Boulder, CO: Lynne Rienner Publishers.

Hellberg, I. \& Muller, E. (2012). The Mumbai terrorist attacks 2008. In I. Helsloot, A. Boin, B. Jacobs, \& L.K. Comfort (Eds.), Mega-Crises: Understanding the Prospects, Nature, Characteristics and the Effects of Cataclysmic Events. (pp. 168-185). Springfield, IL: Charles C Thomas Publisher Ltd.

Helmer, M. \& Hilhorst, D. (2006). Natural disasters and climate change. Disasters, 30, 1-4.

Helsloot, I., Boin, A., Jacobs, B., \& Comfort, L. K. (2012a). Mega-Crises. Understanding the Prospects, Nature, Characteristics and the Effects of Cataclysmic Events. Springfield, IL: Charles C Thomas Publisher Ltd.

Helsloot, I., Boin, A., Jacobs, B., \& Comfort, L. K. (2012b). The new challenges of Mega-crises. In I. Helsloot, A. Boin, B. Jacobs, \& L.K. Comfort (Eds.), Mega-Crises: Understanding the Prospects, Nature, Characteristics and the Effects of Cataclysmic Events. (pp. 5-11). Springfield, IL: Charles C Thomas Publisher Ltd.

Helsloot, I. \& Rosenthal, U. (2009). Mega-crises in the 21st century. (Magazine for National Safety \& Security and Crisis Management). Magazine for National Safety \& Security and Crisis Management; special issue. 
Hill, A. \& Cutter, S. L. (2001). Methods for Determining Disaster Proneness. In S.L. Cutter (Ed.), American Hazardscapes. The Regionalization of Hazards and Disasters. (pp. 13-36). Washington, D.C.: Joseph Henry Press.

Hills, A. (1998). Seduced by Recovery: The Consequences of Misunderstanding Disaster. Journal of Contingencies and Crisis Management, 6, 162-170.

Hogg, S. J. (1980). Reconstruction Following Seismic Disaster in Venzon, Friuli. Disasters, 4, 173-185.

Hollenbeck, J. R., Beersma, B., \& Schouten, M. E. (2012). Beyond team types and taxonomies: a dimensional scaling conceptualization for team description. Academy of Management Review, 37, 82-106.

Hollenbeck, J. R., Ilgen, D. R., LePine, J. A., Colquitt, J. A., \& Hedlund, J. (1998). Extending the multilevel theory of team decision making: Effects of feedback and experience in hierarchical teams. Academy of Management Journal, 41, 269-282.

Holstein, J. A. \& Gubrium, J. F. (2004). The active interview. In Silverman D. (Ed.), Qualitative research: theory, method and practice (2nd ed., pp. 140-161). London: SAGE Publications.

House, R. J. (1971). A path-goal theory of leader effectiveness. Administrative Science Quarterly, 16, 321-339.

House, R. J. (1996). Path-goal theory of leadership: Lessons, legacy, and a reformulated theory. The Leadership Quarterly, 7, 323-352.

House, R. J. \& Mitchell, T. R. (1974). Path-goal theory of leadership. Journal of Contemporary Business, 3, 8197.

Hox, J. J. (2010). Multilevel analysis. Techniques and applications. (2nd ed.) New York, NY: Routledge.

Huggel, C., Raissig, A, Rohrer, M., Romero, G., Diaz, A., \& Salzmann, N. (2015). How useful and reliable are disaster databases in the context of climate and global change? A comparative case study analysis in Peru. National Hazards \& Earth System Sciences, 15, 475-485.

Humphrey, S. E., Hollenbeck, J. E., Meyer, C. J., \& Ilgen, D. R. (2002). Hierarchical team decision making. Research in personnel and human resource management, 21, 175-213.

Hunter, L. M. (2004). Migration and Environmental Hazards. University of Colorado at Boulder: Institute of Behavioral Science.

Hyndman, D. W., Hyndman, D., \& Catto, N. (2008). Natural Hazards and Disasters. (First Canadian ed.) Toronto: Nelson Education Ltd.

International Federation of Red Cross and Red Crescent Societies (2007). World Disaster Report 2007: Focus on discrimination Satigny/Vernier, Switzerland: ATAR Roto Presse.

International Federation of Red Cross and Red Crescent Societies (2012). World Disaster Report 2012: Focus on forced migration and displacement. Geneva, Switzerland: International Federation of Red Cross and Red Crescent Societies.

International Federation of Red Cross and Red Crescent Societies (2015). World Disaster Report 2015: Focus on local actors, the key to humanitarian effectiveness. Geneva, Switzerland: International Federation of Red Cross and Red Crescent Societies.

IPCC (2013). Summary for Policymakers. In T.F. Stocker, D. Qin, G.-K. Plattner, M.M.B. Tignor, S.K. Allen, J. Boschung, A. Nauels, Y. Xia, V. Bex, \& P.M. Midgley (Eds.), Climate change 2013: The Physical Science Basis, Contribution of Working Group I to the Fifth Assessment Report of the Intergovernmental Panel on Climate Change. (pp. 1-27). Cambridge, UK: Cambridge University Press.

Jacobs, B. (2012). Mega-cities under adversity: Ideology, risk, and good urban governance. In I. Helsloot, A. Boin, B. Jacobs, \& L.K. Comfort (Eds.), Mega-Crises: Understanding the Prospects, Nature, Characteristics and the Effects of Cataclysmic Events. (pp. 237-259). Springfield, IL: Charles C Thomas Publisher Ltd.

James, E. H., Wooten, L. P., \& Dushek, K. (2011). Crisis Management: Informing a New Leadership Research Agenda. The Academy of Management Annals, 5, 455-493.

James, L. R., Demaree, R. G., \& Wolf, G. (1984). Estimating within-group interrater reliability with and without response bias. Journal of Applied Psychology, 69, 85-98.

Jehn, K. A. (1995). A multimethod examination of the benefits and detriments of intragroup conflict. Administrative Science Quarterly, 40, 256-282.

Jones, N. A., Ross, H., Lyam, T., Perez, P., \& Leitch, A. (2011). Mental Models: An Interdisciplinary Synthesis of Theory and Models. Ecology and Society, 16: 46. [online]. 
Judge, T. A., Piccolo, R. F., \& llies, R. (2004). The forgotten ones? The validity of consideration and initiating structure in leadership research. Journal of Applied Psychology, 89, 36-51.

Kahai, S. S., Sosic, J. J., \& Avolio, B. J. (2004). Effects of Participative and Directive Leadership in Electronic Groups. Group \& Organization Management, 29, 67-105.

Kam, C. D., Wilking, J. R., \& Zechmeister, E. J. (2007). Beyond the "Narrow Data Base": Another Convenience Sample for Experimental Research. Political Behavior, 29, 415-440.

Kaplan, S. (1997). The Words of Risk Analysis. Risk Analysis, 17, 407-417.

Kar-Purkayastha, I., Clarke, M., \& Murray, V. (2011). Dealing with disaster databases - What can we learn from health and systematic reviews? Application in practice. PLoS Currents, 3.

Keyton, J., Ford, D. J., \& Smith, F. L. (2012). Communication, Collaboration, and Identification as Facilitators and Constraints of Multiteam Systems. In S.J. Zaccaro, M.A. Marks, \& L.A. DeChurch (Eds.), Multiteam Systems. An Organization Form for Dynamic and Complex Environments (pp. 173-190). New York: Routledge.

Ki-moon, B. (2011). As disasters increase, risk reduction should a be a concern for all. http://www.un.org/apps/news/story.asp?NewsID=40031 [On-line]. Available: http://www.un.org/News/

Kirkman, B. L. \& Rosen, B. (1999). Beyond self-management: Antecedents and consequences of team empowerment. Academy of Management Journal, 42, 58-74.

Kirschenbaum, A. (2004). Chaos organization and disaster management. New York: Marcel Dekker Inc.

Klann, G. (2003). Crisis Leadership. Using Military Lessons, Organizational Experiences, and the Power of influence to Lessen the Impact of Chaos on the People you lead. Greensboro, NC: Center for Creative Leadership.

Klein, G., Calderwood, R., \& Clinton-Cirocco, A. (2010). Rapid Decision Making on the Fire Ground: The Original Study Plus a Postscript. Journal of Cognitive Engineering and Decision Making, 4, 186-209.

Klein, K. J., Dansereau, F., \& Hall, R. J. (1994). Levels issues in theory development, data-collection, and analysis. Academy of Management Review, 19, 195-229.

Kleinmuntz, D. N. \& Thomas, J. B (1987). The value of action and inference in dynamic decision making. Organizational Behavior and Human Decision Processes, 39, 341-364.

Knabb, R. D., Rhone, J. R., \& Brown, D. P. (2005). Tropical Cyclone Report: Hurricane Katrina 23-30 August 2005. Miami, Florida: National Hurricane Center.

Kreps, G. A. (1989). Disaster and the Social Order. In G.A. Kreps (Ed.), Social Structure and Disaster (pp. 31-51). Newark: University of Delaware Press.

Kreps, G. A. (1995). Disasters as Systemic Event and Social Catalyst: A Clarification of the Subject Matter. International Journal of Mass Emergencies and Disasters, 13, 255-284.

Kreps, G. A. \& Bosworth, S. L. (2006). Organizational Adaption to Disaster. In H. Rodríguez, E.L. Quarantelli, \& R.R. Dynes (Eds.), Handbook of Disaster Research (pp. 297-315). New York: Springer Science + Business Media LLC.

Kromm, C. \& Sturgis, S. (2008). Hurricane Katrina and the Guiding Principles on Internal Displacement. A Global Human Rights Perspective on a National Disaster. (Rep. No. Special Report, Volume XXXVI, N 1 \& 2). Durham, NC: The Institute for Southern Studies.

Kuipers, S., Boin, A., Bossong, R., \& Hegemann, H. (2015). Building Joint Crisis Management Capacity? Comparing Civil Security Systems in 22 European Countries. Risk, Hazards \& Crisis in Public Policy, 6, 1-21.

Lagadec, P. (2006). Crisis Management in the Twenty-First Century: "Unthinkable Events in "Inconceivable" contexts. In H. Rodríguez, E.L. Quarantelli, \& R.R. Dynes (Eds.), Handbook of Disaster Research (pp. 489507). New York: Springer Science + Business Media LLC.

Lagadec, P. (2009a). A new cosmology of risks and crises: time for a radical shift in paradigm and practice. Review of Policy Research, 26, 473-486.

Lagadec, P. (2009b). The Mega-Crisis Unknown Territory. In Search of Conceptual and Strategic Breakthroughs. In Working Conference on Mega-crises (pp. 1-15). The Hague, The Netherlands: Directorate for National Safety and Security of the Ministry of the Interior and Kingdom Relations.

Lagadec, P. (2012). The unknown territory of mega-crisis: In search of conceptual and strategic breakthroughs. In I. Helsloot, A. Boin, B. Jacobs, \& L.K. Comfort (Eds.), Mega-Crises: Understanding the Prospects, Na- 
ture, Characteristics and the Effects of Cataclysmic Events. (pp. 12-24). Springfield, IL: Charles C Thomas Publisher Ltd.

Lagadec, P. (2013). Navigating the Unknown: A practical lifeline for decision-makers in the dark. Lormont: Editions Préventique.

Lagadec, P. \& Carli, P. (2005). Crossing the Rubicon. Crisis Response Journal, 1, 39-41.

LaHuis, D. M. \& Ferguson, M. W. (2009). The Accuracy of Significance Tests for Slope Variance Components in Multilevel Random Coefficient Models. Organizational Research Methods, 12, 418-435.

Lanir, Z. (1989). The reasonable choice of disaster: The shooting down of the Libyan airliner on 21 February 1973. Journal of Strategic Studies, 12, 479-493.

LaPorte, T. R. (2007). Critical Infrastructure in the Face of a Predatory Future: Preparing for Untoward Surprise. Journal of Contingencies and Crisis Management [On-line].

LeBreton, J. M. \& Senter, J. L. (2008). Answers to 20 questions about interrater reliability and interrater agreement. Organizational Research Methods, 11, 815-852.

Lei, Z., Waller, M. J., Hagen, J., \& Kaplan, S. (2016). Team Adaptiveness in Dynamic Contexts: Contextualizing the Roles of Interaction Patterns and In-Process Planning. Group \& Organization Management, 41, 491525.

Lenski, G., Lenski, J., \& Nolan, P. (1991). Human Societies: An Introduction to Macrosociology. New York: McGraw-Hill.

Leonard, H. B. D. \& Howitt, A. M. (2007). Against Desperate Peril: High Performance in Emergency Preparation and Response. In D.E. Gibbons (Ed.), Communicable crises: prevention, response, and recovery in the global arena. (pp. 1-25). Charlotte, NC: AIP, Information Age Publishing, Inc.

Leonard, H. B. D. \& Howitt, A. M. (2012). Leading in crisis: Observations on the political and decision-making dimensions of response. In I. Helsloot, A. Boin, B. Jacobs, \& L.K. Comfort (Eds.), Mega-Crises: Understanding the Prospects, Nature, Characteristics and the Effects of Cataclysmic Events. (pp. 25-34). Springfield, IL: Charles C Thomas Publisher Ltd.

LePine, J. A., Hollenbeck, J. R., Ilgen, D. R., \& Hedlund, J. (1997). Effects of Individual Differences on the Performance of Hierarchical Decision-Making Teams: Much More Than g. Journal of Applied Psychology, 82, 803-811.

Lester, W. \& Krejci, D. (2007). Business "Not" as Usual: The National Incident Management System, Federalism, and Leadership. Public Administration Review, Special supplement to volume 67, 84-93.

Lewis, J., O'Keefe, P., \& Westgate, K. N. (1976). A Philosophy of Planning. (Rep. No. Occasional paper No. 5). Bradford, Yorkshire: Disaster Research Unit, University of Bradford.

Leysen, J. \& Van Nuffel, L. (2006). An Integrated Approach to Risk and Performance Management. Perspectives on Performance, 5, 20-24.

Lin, Y.-L., Robertson, K. E., \& Hill, C. M. (2000). Origin and Propagation of a Disturbance Associated with an African Easterly Wave as a Precursor of Hurricane Alberto. Monthly Weather Review, 133, 3276-3298.

Lindell, M. K. \& Perry, R. W. (1992). Behavioral Foundations of Community Emergency Planning. Washington, DC: Hemisphere Publishing Corporation.

Lipshitz, R., Klein, G., \& Orasanu, J. (2001). Taking Stock of Naturalistic Decision Making. Journal of Behavioral Decision Making, 14, 331-352.

Locke, E. A., Alavi, M., \& Wagner, J. (1997). Participation in decision making: An information exchange perspective. Research in personnel and human resource management, 15, 293-331.

Lorinkova, N. M., Pearsall, M. J., \& Sims Jr., H. P. (2013). Examining the differential longitudinal performance of directive versus empowering leadership in teams. Academy of Management Journal, 56, 573-596.

Louis, M. R. \& Sutton, R. (1991). Switching cognitive gears: From habits of mind to active thinking. Human Relations, 44, 55-76.

Mac Donald, L. M. (2005). Curse of the narrows. New York: Walker \& Company.

Maier, N. R. F. (1963). Problem Solving Discussions and Conferences: Leadership Methods and Skills. New York, NY: McGraw-Hill.

Manz, C. C. \& Sims, H. P., Jr. (1991). Superleadership - Beyond the myth of heroic leadership. Organizational Dynamics, 19, 18-35. 
Marks, M. A., DeChurch, L. A., Mathieu, J. E., Panzer, F. J., \& Alonso, A. (2005). Teamwork in multiteam systems. Journal of Applied Psychology, 90, 964-971.

Mathieu, J. E., Marks, M. A., \& Zaccaro, S. J. (2001). Multiteam Systems. In N. Anderson, D. Ones, H.K. Sinangil, \& C. Viswesvaran (Eds.), Organizational psychology: Vol. 2. Handbook of industrial work and organizational psychology (pp. 289-313). London: Sage.

McBean, G. A. (2012). Integrating risk reduction towards sustainable development. Current Opinion in Environmental Sustainability, 4, 122-127.

McConnel, A. \& Drennan, L. (2006). Mission Impossible? Planning and Preparing for Crisis. Journal of Contingencies and Crisis Management, 14, 59-70.

McEntire, D. A. \& Smith, S. (2007). Making sense of consilience: Reviewing the findings and relationships among disciplines, disasters and emergency management. In D.A. McEntire (Ed.), Disciplines, Disasters and Emergency Management. The Convergence and Divergence of Concepts, Issues and Trends from research literature. (pp. 320-336). Springfield, IL: Charles C Thomas Publisher, LTD.

Melick, M. E. (1985). The Health of Postdisaster Populations: A Review of Literature and Case Study. In J. Laube \& S. Murphy (Eds.), Perspectives on Disaster Recovery (pp. 179-209). New York: Appleton-CenturyCrofts.

Menninger, W. (1952). Psychological Reactions in an Emergency. American Journal of Psychiatry, 109, 128130.

Miles, M. B. \& Huberman, A. M. (1994). Qualitative Data Analysis. Thousand Oaks, CA: SAGE Publications, Inc.

Mileti, D. S. (1999). Disasters by Design: a Reassessment of Natural Hazards in the United States. Washington, D.C.: Joseph Henry Press.

Miller, A. (2001). The Los Angeles Riots: A Study in Crisis Paralysis. Journal of Contingencies and Crisis Management, 9, 189-199.

Mongillo, J. \& Zierdt-Warshaw, L. (2009). Encyclopedia of environmental science. Santa Barbara, CA: Greenwood Press.

Moorhead, G. \& Montanari, J. R. (1986). An empirical investigation of the groupthink phenomenon. Human Relations, 39, 399-410.

Moynihan, D. P. (2009). The Response to Hurricane Katrina. Geneva: International Risk Governance Council.

National Governor's Association (1979). Emergency Preparedness Project Final Report Washington D.C.: Government Printing Office.

National Governors' Association (1978). Emergency Preparedness Project - Final Report Washington D.C.: Government Printing Office.

National Hurricane Center (2005a). Hurricane Katrina discussion number 11. http://www.nhc.noaa.gov/ archive/2005/dis/al122005.discus.011.shtml [On-line]. Available: http://www.nhc.noaa.gov/

National Hurricane Center (2005b). Hurricane Katrina Forecast/Advisory Number 23. http://www.nhc.noaa.gov/ archive/2005/KATRINA.shtml [On-line]. Available: http://www.nhc.noaa.gov/

National Hurricane Center (2005c). Tropical Depression Twelve Forecast/Advisory Number 1. http://www.nhc. noaa.gov/archive/2005/KATRINA.shtml [On-line]. Available: http://www.nhc.noaa.gov/

National Weather Service (2005). Urgent Weather Message. http://www.srh.noaa.gov/data/warn_archive/ LIX/NPW/0828_155101.txt [On-line]. Available: http://www.nhc.noaa.gov/

Neal, D. M. (1997). Reconsidering the Phases of Disaster. International Journal of Mass Emergencies and Disasters, 15, 239-264.

Nelms, K. R. \& Porter, A. L. (1985). EFTE: An interactive Delphi method. Technological Forecasting and Social Change, 28, 43-61.

NERC Steering Group (2004). Technical Analysis of the August 14, 2003, Blackout: What Happened, Why, and What Did We Learn? Princeton, NJ: North American Electric Reliability Council.

Nohrstedt, D. (2013). Advocacy Coalitions in Crisis Resolution: Understanding Policy Dispute in the Volcanic Ash Cloud Crisis. Public Administration, 91, 964-979.

Norgaard, K. M. (2011). Living in denial: Climate change, emotions and everyday life. Cambridge, MA: MIT Press.

NYC Emergency Management (2014). NYC's Risk Landscape: A Guide to Hazard Mitigation. New York. 
O'Keefe, S. (2007). Looking Back, Moving Forward. Public Administration Review, Special supplement to volume 67, 5-6.

O'Rand, A. M. \& Krecker, M. L. (1990). Concepts of the Life Cycle: Their History, Meanings, and Uses in the Social Sciences. Annual Review of Sociology, 16, 241-262.

Obama, B. (2010). Election saps energy's motion. http://www.politico.com/news/stories/0610/38526_Page2. html\#ixzz0qtxjM1Zk [On-line].

OECD (1994). Guidelines for Aid Agencies on Disaster Mitigation. Paris: Organisation for Economic CoOperation and Development.

OECD (2003). Emerging Risks in the 21th century: an agenda for action. Paris: Organisation for Economic CoOperation and Development.

OECD (2011). Future Global Shocks: Improving Risk Governance. Paris: Organisation for Economic CoOperation and Development.

Osborn, A. F. (1963). Applied Imagination: Principles and Procedures of Creative Problem-Solving. New York, NY: Charles Scribner's Sons.

Pearce, C. L., Sims Jr., H. P., Cox, J. F., Ball, G., Schnell, E., Smith, K. A. et al. (2003). Transactors, transformers and beyond: A multi-method development of a theoretical typology of leadership. Journal of Management Development, 22, 273-307.

Pearce, L. D. R. (2000). An Integrated Approach for Community Hazard, Impact, Risk and Vulnerability analysis: HIRV. The University of British Columbia.

Pearson, C. M. \& Clair, J. A. (1998). Reframing crisis management. Academy of Management Review, 23, 5976.

Peek, L. A. \& Mileti, D. S. (2002). The History and Future of Disaster Research. In R.B. Bechtel \& A. Churchman (Eds.), Handbook of environmental psychology (pp. 511-524). New York: J. Wiley \& Sons.

Perrow C. (1984). Normal accidents: Living with High-risk Technologies. New York, NY: Basic Books.

Perrow, C. (1999a). Normal accidents: Living with High-risk Technologies. (Second ed.) Princeton: Princeton University Press.

Perrow, C. (1999b). Organizing to Reduce the Vulnerabilities of Complexity. Journal of Contingencies and Crisis Management, 7, 150-155.

Perry, R. W. (1989). Taxonomy, classification and theories of disaster phenomena. In G.A. Kreps (Ed.), Social structure and disaster (pp. 351-359). Newark, DE: University of Delaware Press.

Perry, R. W. (1998). Definitions and the development of a theoretical superstructure for disaster research. In E.L. Quarantelli (Ed.), What is a disaster? Perspectives on the question (pp. 197-215). New York, NY: Routledge.

Perry, R. W. (2007). What is a disaster? In H. Rodríguez, Quimby J., \& R.R. Dynes (Eds.), Handbook of disaster research (pp. 1-15). New York: Springer Science + Business Media LLC.

Perry, R. W. \& Lindell, M. K. (2003). Understanding Citizens Response to Disasters with Implications for Terrorism. Journal of Contingencies and Crisis Management, 11, 49-60.

Perry, R. W. \& Quarantelli, E. L. (2005). What is a disaster? New Answers to Old Questions. Philadelphia: Xlibris Corporation.

Pescaroli, G. \& Kelman, I. (2017). How Critical Infrastructure Orients International Relief in Cascading Disasters. Journal of Contingencies and Crisis Management, 25, 56-67.

Peterson, R. S. (1997). A Directive Leadership Style in Group Decision Making Can Be Both Virtue and Vice: Evidence from Elite and Experimental Groups. Journal of Personality and Social Psychology, 72, 11071121.

Phillips, B. D. (1991). Post-Disaster Sheltering and Housing of Hispanics, the Elderly and the Homeless. (Rep. No. Final Project Report to the National Science Foundation.). Dallas: Southern Methodist University, Department of Sociology.

Phillips, B. D. (2006). Research applications in the Classroom. In H. Rodríguez, E.L. Quarantelli, \& R.R. Dynes (Eds.), Handbook of Disaster Research (pp. 456-467). New York: Springer Science + Business Media LLC. 
Podsakoff, P. M., MacKenzie, S. B., Ahearne, M., \& Bommer, W. H. (1995). Searching for a needle in a haystack: Trying to identify the elusive moderators of leadership behavior. Journal of Management, 21, 422470.

Pollander, G. \& Rand, D. (1989). Analysis of medical needs in disasters caused by earthquakes: the need for a uniform injury reporting system. Disasters, 13, 365-369.

Porfiriev, B. N. (1995). Disaster and Disaster Areas: Methodological Issues of Definition and Delineation. International Journal of Mass Emergencies and Disasters, 13, 285-304.

Porfiriev, B. N. (1998). Issues in the definition and delineation of disasters and disaster areas. In E.L. Quarantelli (Ed.), What is a disaster? Perspectives on the question (pp. 56-72). New York, NY: Routledge.

Powell, J. W. (1954). An introduction to the National History of Disaster. Baltimore: University of Maryland Disaster Research Project.

Prince, S. H. (1920). Catastrophe and social change. New York: Columbia University, Department of Political Science.

Pugliese, R., Bortoluzzi, G., \& Zupic, I. (2016). Putting process on track: empirical research on start-ups' growth drivers. Management Decision, 54, 1633-1648.

Puglisi, M. (2001). The Study of the futures: an overview of futures studies methodologies. In D. Camarda \& L. Grassini (Eds.), Interdependency between agriculture and urbanization: Conflicts on sustainable use of soil and water. (pp. 439-463). Paris: Options Méditerranées.

Quarantelli, E. L. (1954). The Nature and Conditions of Panic. American Journal of Sociology, 60, 267-275.

Quarantelli, E. L. (1982a). Sheltering and Housing after Major Community Disasters: Case Studies and General Observations (Rep. No. 29). Columbus, Ohio: The Ohio State University.

Quarantelli, E. L. (1982b). What is a Disaster? An Agent Specific or an All Disaster Approach to SocioBehavioral Aspects of Earthquakes? In B. Jones \& M. Tomazevic (Eds.), Third International Conference on Social and Economic Aspects of Earthquakes (pp. 453-478). Skopje, Yugoslavia: Institute of Earthquake Engineering and Engineering Seismology, University "Kiril and Metodij".

Quarantelli, E. L. (1985). What is a Disaster? The Need for Clarification in Definition and Conceptualization in Research. In B.J. Snowder (Ed.), Disasters and Mental Health: Selected Contemporary Perspectives. (pp. 41-73). Rockville, MD: National Institute of Mental Health-Center for Mental Health Studies of Emergencies.

Quarantelli, E. L. (1987a). Disaster studies: An Analysis of the Social Historical Factors Affecting the Development of Research in the Area. International Journal of Mass Emergencies and Disasters, 5, 285-310.

Quarantelli, E. L. (1987b). What should we study? Questions and Suggestions for Researchers about the Concept of Disasters. (Rep. No. Article \#195a). Newark, DE: Disaster Research Center.

Quarantelli, E. L. (1988). Disaster Crisis Management: A Summary of Research Findings. Journal of Management Studies, 25, 373-385.

Quarantelli, E. L. (1993). The Environmental Disasters of the Future Will Be More and Worse but the Prospect is Not Hopeless. Disaster Prevention and Management, 2, 11-25.

Quarantelli, E. L. (1995). What Is a Disaster? (Editor's introduction). International Journal of Mass Emergencies and Disasters, 13, 221-229.

Quarantelli, E. L. (1996). The Future is Not the Past Repeated: Projecting Disasters in the 21st Century from Current Trends. Journal of Contingencies and Crisis Management, 4, 228-240.

Quarantelli, E. L. (1998). What is a disaster? Perspectives on the question. New York, NY: Routledge.

Quarantelli, E. L. (2001). Statistical and conceptual problems in the study of disasters. Disaster Prevention and Management, 10, 325-338.

Quarantelli, E. L. (2005). A Social Science Research Agenda for the Disasters of the 21st Century: Theoretical, Methodological and Empirical Issues and their Professional Implementation. In E.L. Quarantelli \& R.W. Perry (Eds.), What is a disaster? New Answers to Old Questions. (pp. 325-396). Philadelphia: Xlibris Corporation.

Quarantelli, E. L., Lagadec, P., \& Boin, A. (2006). A Heuristic Approach to Future Disasters and Crises: New, Old and In-Between types. In H. Rodríguez, E.L. Quarantelli, \& R.R. Dynes (Eds.), Handbook of Disaster Research (pp. 16-41). New York: Springer Science \& Business Media LLC. 
Raab, J., Soeters, J., van Fenema, P. C., \& de Waard, E. J. (2009). Structure in temporary organization. In P. Kenis, M. Janowicz-Panjaitan, \& B. Cambré (Eds.), Temporary Organizations. Prevalence, Logic and Effectiveness. (pp. 171-200). Cheltenham, UK: Edward Elgar Publishing Limited.

Raggatt, P., Butterworth, E., \& Morrissey, S. (1993). Issues in Natural Disaster Management: Community Response to the Threat of Tropical Cyclones in Australia. Disaster Prevention and Management, 2, $12-21$.

Rasmussen, J. \& Batstone, R. (1989). Why do Complex Organizational Systems Fail? World Bank Environmental Working Paper, 20.

Revell, S. M. H. (2013). Making Meaning in Qualitative Research with Conversational Partnerships: A Methodological Discussion. Advances in Nursing Science, 36, 54-65.

Rhinard, M. (2009). European Cooperation on Future Crises: Toward a Public Good? Review of Policy Research, 26, 439-455.

Richardson, B. K. (2005). The Phases of Disaster as a Relationship Between Structure and Meaning: A Narrative Analysis of the 1947 Texas City Explosion. International Journal of Mass Emergencies and Disasters, 23, 27-54.

Riolli-Saltzman, L. \& Luthans, F. (2001). After the bubble burst: How small high-tech firms can keep in front of the wave. Academy of Management Perspectives, 15, 114-124.

Ripley, A. (2008). The Unthinkable: Who Survives When Disaster Strikes - and Why. New York: Crown Publisher.

Robert, B. \& Lajtha, C. (2002). A New Approach to Crisis Management. Journal of Contingencies and Crisis Management, 10, 181-191.

Roberts, P. S. (2013). Disasters and the American State: How Politicians, Bureaucrats, and the public Prepare for the Unexpected. New York: Cambridge University.

Rodríguez, H., Quarantelli, E. L., \& Dynes, R. R. (2006). Handbook of Disaster Research. (vols. Springer Science+Business Media, LLC) New York, NY.

Rosenthal, U. (1998). Future disasters, future definitions. In E.L. Quarantelli (Ed.), What is a disaster? Perspectives on the question (pp. 146-159). New York, NY: Routledge.

Rosenthal, U. (2009). 21st Century Mega-crises: New Challenges to Crisis Management. Magazine for National Safety \& Security and Crisis Management, 4-6.

Rosenthal, U., 't Hart, P., Van Duin, M. J., Boin, A., Kroon, M. B. R., Otten, M. H. P. et al. (1994). Complexity in Urban Crisis Management: Amsterdam's Response to the Bijlmer Air Disaster. London: James \& James.

Rosenthal, U., Boin, A., \& Comfort, L. K. (2001). The Changing World of Crises and Crises Management. In U. Rosenthal, A. Boin, \& L.K. Comfort (Eds.), Managing crises: threats, dilemmas, opportunities (pp. 5-27). Springfield Illinois: Charles C Thomas Publisher Ltd.

Rossman, E. J. (1993). Public involvement in environmental restoration: Disaster research and sociological practice in Superfund community relations plans. International Journal of Mass Emergencies and Disasters, 11, 123-133.

Rotanz, R. A. (2006). From Research to Praxis: The Relevance of Disaster Research for Emergency Management. In H. Rodríguez, E.L. Quarantelli, \& R.R. Dynes (Eds.), Handbook of Disaster Research (pp. 468475). New York: Springer Science + Business Media LLC.

Rubin, H. J. \& Rubin, I. S. (2005). Qualitative Interviewing: The Art of Hearing Data. (second ed.) London: SAGE Publications, Inc.

Sakai, T. (2011). Japan Report. International Hospital Federation Newsletter, 10, 1-3.

Sapirstein, G. (2006). Social resilience: the forgotten dimension of disaster risk reduction. Journal of Disaster Risk Studies, 1, 54-63.

Scanlon, J. (1992). Disaster Preparedness: Some Myths and Misconceptions. Easingwold: Home Office Emergency Planning College.

Scanlon, T. J. (1988). Disaster's little known pioneer: Canada's Samuel Henry Prince. International Journal of Mass Emergencies and Disasters, 6, 213-232.

Schraagen, J. M. \& van de Ven, J. G. M. (2008). Improving Decision Making in Crisis Response Through Critical Thinking Support. Journal of Cognitive Engineering and Decision Making, 2, 311-327.

Schwenk, C. \& Cosier, R. (1993). Effects of consensus and devil's advocacy on strategic decision-making. Journal of Applied Social Psychology, 23, 126-139. 
Sears, D. O. (1986). College sophomores in the laboratory: Influences of a narrow data base on social psychology's view of human nature. Journal of Personality and Social Psychology, 51, 515-530.

Senauth, F. (2007). Hurricane Katrina: The worst storm to hit the Gulf. Denver, Colorado: Outskirst Press Ltd.

Shaluf, I. M., Ahmadun, F., \& Said, A. M (2003). A review of disaster and crisis. Disaster Prevention and Management, 12, 24-32.

Sharma, P. N. \& Kirkman, B. L. (2015). Leveraging Leaders: A Literature Review and Future Lines of Inquiry for Empowering Leadership Research. Group \& Organization Management, 40, 193-237.

Simon, H. A. (1955). A Behavioral model of Rational Choice. The Quarterly Journal of Economics, 69, 99-118.

Simpson, J., Fougere, G., \& McGee, R. (2013). A Wicked Problem: Early Childhood Safety in the Dynamic, Interactive Environment of Home. International Journal of Environmental Research and Public Health, 10, 1647-1664.

Sims Jr., H. P., Faraj, S., \& Yun, S. (2009). When should a leader be directive or empowering? How to develop your own situational theory of leadership. Business Horizons, 52, 149-158.

Smith, D. (2005). In the Eyes of the Beholder? Making Sense of the System(s) of Disaster(s). In E.L. Quarantelli \& R.W. Perry (Eds.), What is a disaster? New Answers to Old Questions. (pp. 201-236). Philadelphia: Xlibris Corporation.

Soave, O. \& de Maupeau, M. (2016). Managing cascading effects. Crisis Response Journal, 12, 38-39.

Sommer, A. \& Pearson, C. M. (2007). Antecedents of creative decision making in organizational crisis: A teambased simulation. Technological Forecasting and Social Change, 74, 1234-1251.

Song, Y. T., Fukumori, I., Shum, C. K., \& Yi, Y. (2012). Merging Tsunamis of the 2011 Tohoku-Oki Earthquake Detected over the Open Ocean. Geophysical Research Letters, 39, 1-6.

Srivastava, A., Bartol, K. M., \& Locke, E. A. (2006). Empowering leadership in management teams: Effects on knowledge sharing, efficacy and performance. Academy of Management Journal, 49, 1239-1251.

Stallings, R. A. (2005). Disaster, Crisis, Collective Stress, and Mass Deprivation. In E.L. Quarantelli \& R.W. Perry (Eds.), What is a disaster? New Answers to Old Questions. (pp. 237-274). Philadelphia: Xlibris Corporation.

Stark, A. (2014). Bureaucratic Values and Resilience: An Exploration of Crisis Management Adaptation. Public Administration, 3, 692-706.

Steiger, E. (2008). L'ouragan Katrina: les leçons d'un échec. Les faiblesses du dispositif de sécurité intérieure des Etats-Unis Paris: Diploweb.com.

Stoddard, E. R. (1968). Conceptual Models of Human Behavior in Disaster. El Paso: Texas Western Press.

Tenner, E. (1996). Why things bite back: technology and the revenge of unintended consequences. New York, NY: Alfred A. Knopf, Inc.

Tetlock, P. E., Peterson, R. S., McGuire, C., Chang, S., \& Feld, P. (1992). Assessing political group dynamics: A test of the group think model. Journal of Personality and Social Psychology, 63, 403-425.

Thompson, G. \& Vecchio, R. P. (2009). Situational leadership theory: A test of three versions. The Leadership Quarterly, 20, 837-848.

Tierney, K. (2014). The Social Roots of Risk: Producing Disasters, Promoting Resilience. Stanford, CA: Stanford University Press.

Townsend, F. F. (2006). The Federal Response to Hurricane Katrina - Lessons Learned. Washington, DC: U.S. Executive Office of the President.

Uitdewilligen, S. \& Waller, M. J. (2012). Adaptation in Multiteam Systems: The Role of Temporal Semistructures. In S.J. Zaccaro, M.A. Marks, \& L.A. DeChurch (Eds.), Multiteam Systems. An Organization Form for Dynamic and Complex Environments (pp. 365-394). New York: Routledge.

UN/ISDR (2002). Living with risk: a global review of disaster reduction initiatives, Preliminary version prepared as an interagency effort coordinated by the ISDR Secretariat Geneva.

United Nations Development Programme (2004). Reducing disaster risk: A challenge for development. New York: UNDP Bureau for Crisis Prevention and Recovery.

United Nations Development Programme (2013). A comparative review of country-level and regional disaster loss and damage databases. New York: UNDP Bureau for Crisis Prevention and Recovery.

van Aalst, M. K. (2006). The impacts of climate change on the risk of natural disasters. Disasters, 30, 5-18. 
Van de Ven, A. H., Delbecq, A. L., \& Koenig, R. (1976). Determinants of Coordination Modes within Organizations. American Sociological Review, 41, 322-338.

Van Heerden, I. (2006). The Storm: What went wrong and why during Hurricane Katrina - the inside story from one Louisiana scientist. New York: Penguin Group (USA) Inc.

Van Heerden, I. (2007). The Failure of the New Orleans Levee System Following Hurricane Katrina and the Pathway Forward. Public Administration Review, Special supplement to Volume 67, 24-35.

von Lubitz, D. K. J. E., Beakley, J. E., \& Patricelli, F. (2008). 'All hazards approach' to disaster management: the role of information and knowledge management, Boud's OODA Loop, and network-centricity. Disasters, 32, 561-585.

Vroom, V. H. (2003). Educating managers for decision making and leadership. Management Decision, 41, 968978.

Vroom, V. H. \& Yetton, P. W. (1973). Leadership and Decision Making. Pittsburgh, PA: University of Pittsburg Press.

Wack, P. (1985). Scenarios: Uncharted Waters Ahead. Harvard Business Review, 63, 72-89.

Waller, M. J. (1999). The timing of adaptive group responses to nonroutine events. Academy of Management Journal, 42, 127-137.

Wang, Y., Gray, P. H., \& Meister, D. B. (2014). Task-driven learning: The antecedents and outcomes of internal and external sourcing. Information \& Management, 51, 939-951.

Waring, A. \& Glendon, A. I. (1998). Managing Risk. Critical issues for survival and success into the 21st century. London: Thomson.

Waugh, Jr. W. L. (2006). Terrorism as Disaster. In H. Rodríguez, E.L. Quarantelli, \& R.R. Dynes (Eds.), Handbook of Disaster Research (pp. 388-404). New York: Springer Science \& Business Media LLC.

Weber, M. (1947). The theory of Social and Economic Organization (translated by A. M. Henderson and Talcott Parsons). New York: Free Press.

Wegner, D. M. (1986). Transactive memory: A contemporary analysis of the group mind. In B. Mullen \& G.R. Goethals (Eds.), Theories of group behavior. (pp. 185-205). New York: Springer-Verlag.

Weichselgartner, J. (2001). Disaster mitigation: the concept of vulnerability revisited. Disaster Prevention and Management, 10, 85-94.

Weick, K. E. (1985). Cosmos vs. chaos: Sense and nonsense in electronic contexts. Organizational Dynamics, 14, 50-64.

Weick, K. E. (1993). The collapse of sensemaking in organizations: The Mann Gulch disaster. Administrative Science Quarterly, 38, 628-652.

Wildavsky, A. B. (1988). Searching for Safety. New Brunswick: Transaction Publishers.

Wisner, B., Blaikie, P., \& Davis, I. (2004). At Risk. Natural hazards, people's vulnerability and disasters. Routledge, Taylor \& Francis Group.

Woods, D. D. (1993). Process-Tracing Methods for the Study of Cognition Outside of the Experimental Psychology Laboratory. In G.A. Klein, J. Orasanu, R. Calderwood, \& C.E. Zsambock (Eds.), Decision Making in Action: Models and Methods. (pp. 228-251). Norwood, NJ: Ablex Publishing Corporation.

Wooten, L. P. \& James, E. H. (2008). Linking Crisis Management and Leadership Competencies: The Role of Human Resource Development. Advances in Developing Human Resources, 10, 352-379.

Yang, M. C. (2010). Consensus and single leader decision-making in teams using structured design methods. Design Studies, 31, 345-362.

Yukl, G. (2010). Leadership in organizations. (7th ed.) Upper Saddle River, NJ: Prentice Hall.

Yun, S., Faraj, S., \& Sims Jr., H. P. (2005). Contingent Leadership and Effectiveness of Trauma Resuscitation Teams. Journal of Applied Psychology, 90, 1288-1296.

Zaccaro, S. J., Marks, M. A., \& DeChurch, L. A. (2012). Multiteam Systems: An Introduction. In S.J. Zaccaro, M.A. Marks, \& L.A. DeChurch (Eds.), Multiteam Systems. An Organization Form for Dynamic and Complex Environments (pp. 3-32). New York: Routledge.

Zaccaro, S. J., Rittman, A. L., \& Marks, M. A. (2001). Team leadership. The Leadership Quarterly, 12, 451-483. 
Valorization Addendum 

'Whenever science makes a discovery, the devil grabs it while the angels are debating the best way to use it

A. Valentine

The present dissertation investigates the issue of the mutating disaster landscape and its key objective is to facilitate a better understanding of the main consequences of those changes. However, the results of the empirical studies described in the dissertation are not only relevant to the scientific community. They also have practical implications. This valorization addendum discusses the empirical findings in a broader societal context. First the relevance of the research and the potential target groups are highlighted. Next, the implications of the findings and their innovative character are emphasized. The addendum concludes with a brief overview of the knowledge dissemination.

\section{Relevance of the Research}

Since the time people got organized in sedentary societies, they became more vulnerable to natural phenomena, as the choice of where to settle was essentially directed by their needs (Coppola, 2011). People needed water, food, fertile soil and easy access to commerce, so many societies were located in hazard-prone areas such as deltas, coastlines, rich soils on the slopes of volcanoes, etc. As human societies progressively evolved, additional types of hazards emerged (Quarantelli et al., 2006) and by the year 2000 it was estimated that $75 \%$ of the world population lived in high-risk areas which periodically experience major disasters (United Nations Development Programme, 2004).

Disaster statistics indicate a general increase in the number of disasters per time frame since the second half of the last century, with more people affected in either a direct or an indirect way, and with a significant increase of economic losses (Coppola, 2011; International Federation of Red Cross and Red Crescent Societies, 2015). Though over the years, the world has witnessed numerous disasters, people have reasonable well succeeded in developing means and procedures to cope with and survive these events based on lessons learned (Kirschenbaum, 2004). However, since the end of the last century, researchers and disaster managers have been warning for a qualitative shift in the disaster landscape. They assume that there is a strong notion that several disasters we face today are structurally different from those we had to deal with in the past (e.g.: Boin \& Lagadec, 2000; Helsloot et al., 2012b; Leonard \& Howitt, 2007). If such an evolution is real, we can expect that societies will be more violently affected in the future and in particular that the work of the intervening units of emergency manage- 
ment organizations will be more challenged, notwithstanding the improved disaster knowledge and refined emergency management capacities and procedures.

When the context changes fundamentally, it is not enough to apply a "more of the same logic" (Lagadec, 2009a, p. 473) with more detailed plans and more powerful tools. Accordingly, if we want to avoid to be continually one disaster behind (Davis, 2006), we have to rethink the issue in a fundamental way, not "open additional boxes fixing the same models" (Lagadec, 2009a, p. 473). Hence there still remains much to learn about how to cope with modern disasters or disasters of the $21^{\text {st }}$ century. The aim of the dissertation is to facilitate a better understanding of the key consequences of the mutating disaster landscape and to provide academics and practitioners with a more comprehensive view of modern disaster management. As such, we produce knowledge that is of interest to the research community, but also provide insights for "science-based decision-making" (Rodríguez et al., 2006, p. vii) by disaster managers, emergency workers, and other practicing professionals. The results of the empirical studies elaborated in this dissertation thus are not only relevant to the scientific community; they also have larger practical implications that go beyond academic impact.

\section{Target Groups}

There are several target groups for the findings of this dissertation. At first, there is the research community. Recent disasters, such as the 9/11 attacks (2001), the Southeast Asian Tsunami (2004), Hurricane Katrina (2005), and the earthquakes in Kashmir (2005) and Haiti (2010) have demonstrated that the disaster context is changing in a significant way and above all that the dominant response theories and practices have become outdated. Therefore, they remind us of the importance of systematic scientific research in order to expand our understanding on how to cope with disasters of the $21^{\text {st }}$ century. The results of the empirical studies in this dissertation are also useful for managers, emergency workers and other practicing professionals. Emergency management relies on researchers to provide referents and reports offering recommendations (Rotanz, 2006). As such, the current findings also supply disaster planners and emergency practitioners with directions for what can be done to improve the means to cope with and survive future disasters. In 2011 UN Secretary-General Ban Ki-moon emphasizes that as vulnerability to catastrophes is growing faster than the world's capacity to strengthen resilience, disaster risk reduction should be a daily concern for everyone (Ki-moon, 2011). Disasters thus concern everybody, not only academics, disaster managers and emergency workers. For that reason, the knowledge gained from this dissertation may be also valuable to every citizen. Finally, disaster research is also needed to infuse the writings and materials in classrooms (Phillips, 2006). Therefore, the knowledge from this dissertation may also be valuable for educational purposes. University professors and lecturers can use the insights in their courses and class work. The results are especially 
relevant for specific academic education (e.g., Master in Disaster Medicine at the Free University of Brussels, Master of Disaster Management at the University of Copenhagen, etc.) and for emergency management training programs such as the Urban Flood Management and Disaster Risk Mitigation, Short Course (UNESCO IHE Institute for Water Education Delft, Netherlands).

\section{Activities and Services}

In this paragraph, the practical implications of the findings of the dissertation are discussed. The focus is on the main target groups, being researchers and practicing professionals such as disaster managers and emergency workers. The results of the first empirical study (Chapter 2) confirm the assumed evolution toward more disasters of the $21^{\text {st }}$ century which occur with greater intensity and are characterized by a greater complexity to manage. This implies that societies will be challenged to a greater extent with more people affected, and that the work of the intervening units of emergency management organizations will be more compromised. Consequently, the policy of adjusting the existing and known procedures and textbooks in accordance with lessons learned does not provide the necessary framework to manage the challenges posed by the new ballgame of modern disasters (De Smet et al., 2012). For that reason, the target groups should focus on rethinking the issue of modern disaster management profoundly if we want to be well prepared to deal with future events. Disaster managers at the policy level and emergency workers at the operational level should therefore pay more attention to creatively 'think about the unthinkable', or as LaPorte (2007, p. 62) emphasizes: "[They] must prepare to be very surprised and no longer rely exclusively on existing plans which aim mainly at avoiding surprise".

Well considered mitigation efforts and up-to-date preparation initiatives are insufficient to guard societies against disasters occurring. Disaster response therefore remains a vital aspect of disaster management and will even become more important in the future, taking into account the trend towards more disasters of the $21^{\text {st }}$ century. The results of the second empirical study of the dissertation (Chapter 3) demonstrate that the response phase of the disaster management life cycle evolves as a global process through three succeeding stages (paralysis, operational response and strategic response) encompassing important sub-processes such as the gradual buildup of capacities, the coordination process and the event assessment process. The findings offer disaster management practitioners a new angle to look at the response activities. The described event assessment process is of utmost importance for disaster managers and emergency workers when they face events which are not understandable in terms of past disasters (Gundel, 2005; Hills, 1998). In such case, they do not have readymade responses, so they must 'take' and 'make' time to assess the event and dare to call into question acquired paradigms. The leading authorities of disaster management decision 
teams must exhibit innovation and take initiative during extremely trying circumstances (Townsend, 2006) in order to make qualitative decisions aiming at stabilizing the situation, preventing further damage, and preparing recovery activities to bring things back to normal. Disaster decision-making thus is very intertwined with leadership.

Though leaders play a key role in facilitating the decision-making process (e.g. Durham et al., 1997; Zaccaro et al., 2001), it still remains unclear which leadership style yields the best team performance (e.g. Ensley et al., 2006; Lorinkova et al., 2013). Exercising leadership in managing disasters of the $21^{\text {st }}$ century, which are of significant novelty, differs considerably from leading in routine emergencies (Leonard \& Howitt, 2007; Leonard \& Howitt, 2012). The results of Chapter 4 of this dissertation offer valuable insights for decision-making authorities when managing disasters. The findings of an experimental setup reveal that decision-making teams led by a directive leader make more accurate decisions when confronted with routine decision-making tasks, whereas teams led by an empowering leader outperform directive leaders when a team engages in non-routine decision-making tasks. The findings also demonstrate that teams led by a directive leader make decisions faster than teams with empowering leaders, independently of whether the team engages in routine or non-routine decision-making tasks, but that they are particularly fast in routine situations as compared to those led by an empowering leader. Of particular interest is the consideration of decision performance as a combination of decision accuracy and decision speed. When a team engages in routine decision-making tasks, a directive leadership style is best suited for enhancing team decision-making (i.e. making accurate and fast decisions). When considering nonroutine situations, both directive and empowering leadership style can lead to high decision performance. Directive leadership results in fast but less accurate decisions, whereas empowering leadership guarantees accurate but slower decision-making. The determination of which leadership style is best suited depends on the weight of the constituent criteria of decision performance, accuracy or speed. These insights underline that decision-making authorities should easily move back and forth along the continuum of participation in decision-making, (i.e. from directive to empowering leadership and vice versa) in order to obtain the best decision performance.

\section{Innovation of the Research}

Prince's dissertation (1920) on the 1917 explosion in the Halifax harbor is considered to be the first methodical study of disaster (Scanlon, 1988). Since then, a lot of research has been done to develop innovative and more efficient means and procedures to decrease the adverse impact of disasters on societies. As such, our study complements existing disaster research and therefore is not necessary new and innovative.

However, the innovation of the research lies in the consideration of the qualitatively evolving disaster landscape. In the first instance, we found empirical confirmation of a 
trend towards more disasters of the $21^{\text {st }}$ century, which add to the traditional ones that have not disappeared. Many researchers emphasize that these disasters of the $21^{\text {st }}$ century take on new dimensions. They strike with greater intensity (Coppola, 2011; Lagadec \& Carli, 2005) and are of a much greater complexity to manage (Boin \& Lagadec, 2000), essentially characterized by a significant novelty (Leonard \& Howitt, 2012). When dealing with traditional disasters, lessons of the past still have their place and the developed toolkits and procedures remain meritorious (Lagadec, 2006). Though, when the context changes, accepted theories and practices become outmoded and need to be revisited entirely and therefore academics should above all focus on a new paradigm for disaster research (Quarantelli, 1998). The similar shift in mindset is required from disaster managers and emergency workers. Merely adjusting existing procedures and capacities no longer suffice to deal with disasters of the $21^{\text {st }}$ century. A new and different approach, including open questioning and thinking out of the box, is needed if we want to avoid being continually one disaster behind (Davis, 2006). Therefore, the findings of the dissertation provide some lines of thought of what can and should be done. At first, they shed some light on a new and fresh approach of the response phase of the disaster management life cycle which is considered as an unfolding global process of succeeding stages and sub-processes instead of the traditional enumeration of potential activities. Next, we offer insight for leaders of disaster decision making teams in emphasizing that exercising leadership in managing disasters of the $21^{\text {st }}$ century, which are of significant novelty, differs significantly from leading in routine emergencies (Leonard \& Howitt, 2007; Leonard \& Howitt, 2012).

\section{Knowledge Dissemination}

The empirical chapters of the dissertation are based on a self-contained research and the results have been, and will be, disseminated in several ways. First, the early versions of the articles have been presented at different national and international workshops and conferences, which were attended by both researchers and professionals from the disaster research community. The studies presented in the Chapters 2 and 3 have already been published in international journals. The study described in Chapter 4 has recently been finished and will be submitted to an international peer reviewed journal. Additionally, the findings of the research have been communicated through lectures given to researchers and students at Maastricht University, the Belgian Royal Military Academy, the Belgian Higher Institute for Emergency Planning, and the Universite de Mons, as well as through scientific poster presentations. 
Nederlandse Samenvatting

Nederlandse Samenvatting 
Van oudsher heeft de mensheid door het ontwikkelen van noodmaatregelen en procedures getracht om zich te beschermen tegen de impact van rampen. Telkens deze maatregelen niet afdoende bleken, werden ze bijgestuurd op basis van 'lessons learned' en geïmplementeerd in de bestaande nood- en interventieplannen (Boin \& Lagadec, 2000; Coppola, 2011; Kirschenbaum, 2004).

In de recente literatuur waarschuwen onderzoekers echter voor significante veranderingen binnen het 'disaster landscape'. Vooreerst wijzen deze wetenschappers op de toename van het aantal rampen sinds de tweede helft van de vorige eeuw (e.g. Eshghi \& Larson, 2008; Granot, 1998; Rasmussen \& Batstone, 1989). Anderzijds benadrukken ze dat parallel aan deze kwantitatieve evolutie rampen ook kwalitatief veranderen. Ze stellen dat verscheidene rampen waarmee we recentelijk geconfronteerd werden, de 'rampen van de $21^{\text {ste }}$ eeuw', structureel verschillen van de rampen uit het verleden (e.g. Boin \& Lagadec, 2000; Lagadec, 2009a; Rosenthal, 2009).

Recente gebeurtenissen zoals de aanslagen van 9/11 (2001), de SARS-epidemie (2003), de tsunami in Zuidoost-Azië (2004), de aardbevingen in Kasjmir (2005) en Haïti (2010), de Deepwater Horizon olieramp in de Golf van Mexico (2010), enz., maken deze kwalitatieve verandering van het 'disaster landscape' zeer geloofwaardig en tonen vooral aan dat de bestaande noodplanningsprocedures niet langer efficiënt en doeltreffend zijn. Deze evolutie stelt onderzoekers, beleidsverantwoordelijken, rampenmanagers en hulpverleners voor grote uitdagingen. We kunnen bijgevolg stellen dat de huidige theorieën en werkwijzen van rampenmanagement dringend aan een grondige herziening toe zijn, willen we vermijden om continu achter de feiten aan te Ipen.

Dit proefschrift behandelt de problematiek van het veranderende 'disaster landscape' met als doel een beter inzicht te verkrijgen in de gevolgen van deze veranderingen. We willen tevens onderzoekers en practici een beter inzicht verschaffen in de noden van een modern en aangepast rampenmanagement. Het proefschrift begint met de stand van zaken betreffende 'disaster research' teneinde de lezer toe te laten de empirische hoofdstukken te kaderen. Op basis van literatuuronderzoek worden de voornaamste begrippen en concepten van rampenmanagement samengevat en toegelicht. Vervolgens worden de huidige situatie, alsook de hieraan verbonden gevolgen en uitdagingen verduidelijkt en worden de onderzoeksvragen en -objectieven geformuleerd. Dit inleidend theoretisch hoofdstuk legt de basis voor de drie empirische studies die onderdeel uitmaken van het proefschrift.

Hoewel verschillende auteurs melding maken van een kwalitatieve verandering van het 'disaster landscape' werd in de literatuur geen enkele academische studie gevonden die dergelijke evolutie proefondervindelijk onderzoekt. De eerste empirische studie van dit proefschrift tracht deze leemte te vullen. Gebruik makend van recente literatuur werden twee algemene kenmerken van 'rampen van de $21^{\text {ste }}$ eeuw' geïdentificeerd impact en complexiteit-, en werd de notie 'disaster out of the box' gedefinieerd. Een ramp is 'out of the box' wanneer deze een organisationele crisis veroorzaakt bij de interveniërende eenheden van hulporganisaties waardoor die eenheden hun opdracht 
niet of niet goed kunnen uitvoeren. Het analytisch deel van de studie omvat twee fases. Tijdens de eerste fase werd het 'Disaster Impact \& Complexity Diagram' (DI\&C-diagram) ontwikkeld, een instrument dat toelaat om rampen doorheen de tijd te bestuderen teneinde kwalitatieve trends vast te stellen. In eerste instantie werden academici met ervaring in het domein van risico-, crisis- en rampenmanagement gevraagd om tijdens een brainstormsessie variabelen te identificeren die betrekking hebben op de twee algemene kenmerken van 'rampen van de $21^{\text {ste }}$ eeuw'. Vervolgens werden de geïdentificeerde variabelen verder gespecificeerd op basis van de 'estimate-feedback-talkestimate'-methode (Nelms \& Porter, 1985) en werd op basis hiervan het DI\&C-diagram ontwikkeld. In de tweede fase van de studie werd het DI\&C-diagram gebruikt voor de analyse van 100 rampen die zich hebben voorgedaan tijdens de periode 1900-2010. Er werden 5 tijdsintervallen beschouwd (1900-1924, 1925-1949, 1950-1974, 1975-1999, en 2000-2010) waarbinnen telkens twintig rampen 'at random' werden geselecteerd uit het Disaster Database Project (Green III, 2011). De resultaten tonen dat sedert de jaren 1950 rampen een aanzienlijk grotere impact hebben, terwijl vanaf het midden van de jaren 1970 rampen steeds complexer worden om te managen. Verdere analyse van de data bevestigt dat er inderdaad een trend bestaat naar meer 'rampen van de $21^{\text {ste }}$ eeuw' met een toenemend potentieel om te evolueren tot 'disasters out of the box'. Gezien deze evolutie van het 'disaster landscape' is het noodzakelijk dat rampenmanagers op het beleidsniveau en hulpverleners op het operationeel niveau voorbereid worden om creatief na te denken over ongekende aspecten van hedendaagse rampen, willen ze goed voorbereid blijven en hun legitimiteit en geloofwaardigheid niet verliezen (Ripley, 2008).

Recente studies met betrekking tot rampenmanagement focussen op de versterking van mitigatie en het creëren van een veerkrachtige maatschappij. Toch ontwrichten rampen op regelmatige tijdstippen de samenleving. Rampen-response blijft bijgevolg van cruciaal belang bij het managen van huidige en vooral van toekomstige rampen, gezien de trend naar meer rampen 'out of the box'. Door deze evolutie zal de maatschappij steeds harder getroffen worden en zal het werk van de interveniërende eenheden van hulporganisaties steeds moeilijker worden, niettegenstaande de voortdurend verbeterende noodplanningsprocedures en -capaciteiten. Daarom wordt tijdens de tweede empirische studie de response fase van de 'disaster management life cycle' geremodelleerd. De data voor deze kwalitatieve studie werden verzameld en geanalyseerd met de 'responsive interviewing approach' (Rubin \& Rubin, 2005). Om een beter inzicht te krijgen in de impact die 'rampen van de $21^{\text {ste }}$ eeuw' hebben op de response-activiteiten van de hulporganisaties, werden personen geselecteerd met een grote ervaring in noodplanning en rampenmanagement. De resultaten tonen dat de response fase meer is dan een aantal activiteiten om het aantal gewonden en doden te beperken, of schade aan eigendommen of het milieu in te dijken (National Governors' Association, 1978). De data tonen aan dat de response fase zich uitrolt als een proces dat bestaat uit drie opeenvolgende en elkaar soms deels overlappende stappen ('paral- 
ysis', 'operational response' en 'strategic response') en dat bestaat uit een aantal subprocessen: de trapsgewijze opbouw van capaciteiten in de rampenzone, het coördinatieproces en het proces van de beoordeling van de gebeurtenis. De resultaten tonen tevens dat bij het managen van 'rampen van de $21^{\text {ste }}$ eeuw', het sub-proces van de beoordeling van de gebeurtenis uitermate belangrijk is. Rampenmanagers en hulpverleners worden daarom verplicht af te stappen van hun traditionele denk- en handelswijzen waarbij kan teruggegrepen worden naar op voorhand ontwikkelde en gedocumenteerde scenario's. Ze moeten bij aanvang van de ramp tijd vrijmaken om de gebeurtenis grondig te analyseren en durven afstand nemen van de bestaande en gekende paradigma's of, zoals LaPorte (2007, p. 62) stelt "Leaders must prepare to be very surprised and no longer rely exclusively on existing plans".

De derde en laatste empirische studie bouwt verder op de resultaten van de twee eerste onderzoeken. Veel teams opereren in een dynamische en complexe omgeving waar heel snel beslissingen moeten worden genomen op basis van onvolledige informatie. Dikwijls staat in een dergelijke context veel op het spel en hebben teambeslissingen die te laat worden genomen vaak zware consequenties. Kwaliteitsvolle teambeslissingen moeten derhalve accuraat zijn en ook snel worden genomen. Wanneer een team geconfronteerd wordt met een herkenbare of routinematige situatie, kan het teruggrijpen naar eerder opgedane kennis en ervaring, wat toelaat om snel accurate beslissingen te nemen. In het geval van een niet-routinematige context (cfr. rampen 'out of the box') ontbreken de nodige herkenningspunten. Uit onderzoek is gebleken dat teamleiders een belangrijke rol spelen in het beslissingsproces, maar het blijft onduidelijk welke leiderschapskarakteristieken, directief of empowering, leiden tot de meest kwaliteitsvolle teambeslissingen. In de studie wordt een contingentie leiderschapsmodel voor multidisciplinaire teambeslissingen ontwikkeld. We suggereerden dat het effect van leiderschap op de kwaliteit van teambeslissingen afhangt van de context waarin het team opereert. Gebruik makend van een experimentele setup (216 respondenten onderverdeeld in 72 multidisciplinaire teams) testten we de hypothese dat directief leiderschap leidt tot meer kwaliteitsvolle teambeslissingen in routinematige situaties, terwijl empowering leiderschap beter is in niet-routine situaties. Een multilevel analyse van de experimentele data toont aan dat teams die geleid worden door een directieve leider meer accurate beslissingen nemen in routine situaties. In het geval van niet-routine situaties zijn teams die geleid worden door empowering leiders accurater. De resultaten laten ook zien dat teams onder leiding van een directieve leider sneller beslissingen nemen, vooral in routine situaties. In niet-routine situaties blijkt dat teams die geleid worden door directieve leiders nog steeds sneller tot beslissingen komen, maar relatief gezien aan snelheid inboeten ten opzichte van teams geleid door empowering leiders. Van particulier belang in de studie is het samen beschouwen van accuraatheid en snelheid als maat voor kwaliteitsvolle teambeslissingen. Uit de resultaten kan worden we afgeleid dat, wanneer een team geconfronteerd wordt met een routine situatie, directief leiderschap best geschikt is voor het nemen van kwaliteitsvolle 
teambeslissingen. Wanneer een team geconfronteerd wordt met een niet-routine situatie, kan zowel directief als empowering leiderschap leiden tot kwaliteitsvolle beslissingen. In dergelijk geval is het relatieve belang van de samenstellende criteria welke kwaliteitsvolle beslissingen uitmaken (accuraatheid of snelheid) bepalend. Gemiddeld kan gesteld worden dat wanneer de snelheid van de beslissing primeert op de accuraatheid, directief leiderschap leidt tot de meest kwaliteitsvolle teambeslissing. Omgekeerd, wanneer de accuraatheid van de beslissing van doorslaggevend belang is, is empowering leiderschap gemiddeld gezien het best geschikt.

Concluderend is te stellen dat het proefwerk een originele kijk biedt op de impact op het rampenmanagement van het veranderende 'disaster landscape'. De bestaande procedures steeds weer aanpassen op basis van 'lessons learned' uit het verleden is niet meer afdoende om 'disasters out of the box' te beheersen en doelmatig te managen. Van rampenmanagers en hulpverleners wordt verwacht dat ze de situatie snel kunnen beoordelen. Wanneer de situatie als routinematig herkend wordt, zijn de bestaande nood- en interventieplannen toepasbaar. Dit is niet het geval voor niet-routinematige of 'out of the box'-situaties. Pasklare antwoorden zijn dan niet voorhanden en de beslissingsnemers moeten voldoende creatief zijn om de gepaste antwoorden te vinden op de ongekende en onbekende aspecten van de situaties waarmee ze geconfronteerd worden. De 'disaster community' ziet zich bijgevolg geplaatst voor grote uitdagingen en verder onderzoek met betrekking tot 'disaster management en 'disaster leadership' is onontbeerlijk. Gelet op de karakteristieken van 'rampen van de $21^{\text {ste }}$ eeuw -impact en complexiteit- zal toekomstig rampenonderzoek in hoofdzaak holistisch van aard moeten zijn. In eerste instantie stellen we vast dat het managen van rampen steeds vaker grensoverschrijdend dient te gebeuren wat verder onderzoek naar internationale coöperatie en coördinatie noodzaakt. Vervolgens stellen we ook vast dat ondanks de steeds betere mitigatie- en preventiemaatregelen, de samenleving niet van rampen gevrijwaard blijft. Afdoende response- en wederopbouw-procedures blijven bijgevolg noodzakelijk om huidige en vooral toekomstige rampen op een efficiënte en doeltreffende manier te managen. In dit kader lijkt het ons opportuun om in verder onderzoek mitigatie, preventie, response en wederopbouw samen te beschouwen en de 'disaster management life cycle' op een procesmatige manier te bestuderen. Tenslotte dient ook verder onderzoek te gebeuren naar de werking van multidisciplinaire teams en de impact van leiderschapskarakteristieken op multidisciplinaire teambeslissingen in complexe omgevingen. 
Dankwoord

\section{Dankwoord}


"Het schrijven van een doctoraal proefschrift is best vergelijkbaar met het ondernemen van een lange en avontuurlijke tocht doorheen ongekend gebied." Van zodra de beslissing is genomen om de tocht te ondernemen, begint de avonturier vol enthousiasme te plannen. Hij staat te popelen om te vertrekken want het gebied waar hij doorheen zal trekken, lijkt uitermate uitdagend te zijn. De reisweg naar de eindbestemming wordt op kaart uitgestippeld en hij is klaar om te vertrekken. Aan het begin van de tocht blijkt de uitgestippelde weg behoorlijk te kloppen en de avonturier vordert begeesterd verder. Maar naarmate de tijd verstrijkt wordt de avonturier regelmatig geconfronteerd met onverhoedse problemen. De tocht wordt steeds vermoeiender en tijdens moeilijke momenten denkt hij vaak "Was ik er maar nooit aan begonnen."

Hoe clichématig zal de lezer denken, maar toch heb ik me tijdens mijn tocht vaak vereenzelvigd met de avonturier. Gelukkig heb ik aan den lijve ondervonden dat doctorandi hun tocht niet solitair afleggen. Integendeel hun tocht naar de realisatie van het doctoraal proefschrift steunt op de bijdrage allerhande van menig persoon. Nu mijn zoektocht naar de doctorstitel stilaan op zijn einde loopt, neem ik uitgebreid de tijd om even achteruit te kijken en te blijven stilstaan bij de vele mensen die me de afgelopen jaren hebben bijgestaan in de verwezenlijking van mijn droom. In de eerste plaats gaat mijn dank uit naar mijn beide promotoren Prof. dr. ir. Jan Leysen en Prof. dr. Mariëlle Heijltjes en vooral naar mijn begeleider dr. Bert Schreurs, de personen zonder wie ik de toch nooit tot een goed einde had gebracht.

Jan, herinner je je nog? Onze eerste beroepsmatige kennismaking dateert al van in de jaren negentig, de periode tijdens welke ik je assistent was. Na een drietal jaren scheidden onze professionele wegen zich echter, maar om een of andere redenen zag je blijkbaar potentieel in me. In 2005 overtuigde je me om militair docent te worden aan het Departement Economie, Management en Leiderschap van de Koninklijke Militaire School, en na een inwerkingsperiode suggereerde je mijn eigen tocht aan te vatten. De eerste plannen werden uitgewerkt en ik vertrok uitbundig op queeste naar die doctoraatstitel. Mijn tocht verliep vaak over mooie heuvels maar geregeld kwam ik ook terecht in diepe dalen en wanneer ik ronddoolde in een dal en de weg was kwijtgeraakt, kon ik steeds bij jou te rade. Over de ganse periode beschouwd, hebben we urenlang ideeën zitten uitwisselen en zijn we advies gaan vragen bij diverse personen om toch maar de beste weg naar de eindbestemming te kunnen bepalen. Bij momenten liepen onze discussies zelfs fel op en in 2012 besloten we samen om het roer om te gooien. We zaten op een dwaalspoor en moesten noodzakelijkerwijs van parcours veranderen, wilden we het eindpunt behalen. Jan, bedankt voor je onvoorwaardelijk vertrouwen en je altijd aanmoedigende feedback als 'in-house' promotor van dit werk. 
Ook wil ik ontzettend graag mijn tweede promotor, Prof. dr. Mariëlle Heijltjes bedanken. Mariëlle, van harte bedankt voor het aanvaarden van deze promotortaak. Hoewel we elkaar slechts sporadisch hebben ontmoet, is jouw bijdrage onontbeerlijk geweest voor het tot een goed einde brengen van deze scriptie.

Wanneer een avonturier op de dool is, moet hij op zoek naar een uitweg wil hij zijn tocht beëindigen. Dit brengt me bij mijn studiebegeleider (co-promotor). Bert, ik kwam met jou in contact op een eerder toevallige manier, maar je was onmiddellijk bereid om naar het verhaal van mijn 'unifinished adventure' te luisteren. Je vond mijn relaas boeiend en je wou me verder op mijn tocht begeleiden naar de finish. Je geloof in het bereiken van de eindbestemming was een onmisbare bron van motivatie. Bedankt voor je vertrouwen, maar ook voor je praktische en professionele ondersteuning, de kritische verbeteringen, de vele constructieve gesprekken, en vooral, bedankt om de lat hoog te leggen.

Je tiens également à exprimer mes plus vifs remerciements à mon directeur de thèse initial, le docteur d'État Patrick Lagadec, ancien directeur de recherche à l'École polytechnique, qui m'a initié dans le monde des crises hors cadres. Grâce à ses conceptions particulières de ce milieu instable et largement inconnu, l'idée de cette recherche a pris forme.

Ik wil ook heel graag een speciaal woord van dank richten aan dr. Sjir Uitdewilligen (Universiteit Maastricht). Sjir, je was onmiddellijk bereid de tool die je hebt ontwikkeld voor het bestuderen van team besluitvorming tijdens noodsituaties (Maastricht University Emergency Management Simulation - MUEMS) ter beschikking te stellen en aan te passen aan de specifieke context die ik tijdens mijn onderzoek heb gebruikt. Daarenboven stond je steeds klaar met goede raad bij de diverse vragen die ik je stelde aangaande team onderzoek. Bedankt voor je grote interesse in mijn onderzoek en je gouden bijdrage.

Vervolgens gaat mijn dank ook uit naar een hele resem personen bij wie ik te pas en te onpas terecht kon met vragen allerlei. In eerste instantie betreft het Prof. dr. ir. Christiaan Perneel (Koninklijke Militaire School). Chris, bedankt dat ik steeds bij jou terecht kon voor bijkomende statistische inzichten. Ik wil ook Prof. dr. ir. Derrick Gosselin en dr. ir. Geert Letens (beide van de Koninklijke Militaire School) bedanken voor de tijd die ze vrijmaakte om even over het onderzoek te praten. Tijdens deze amicale gesprekken heb ik vaak bruikbare tips ontvangen. I also would like to thank my friends of the Canadian Risk and Hazard Network (CRHNet). Thank you for your confidence, for your support and for your friendship. I have been left with very good memories of the times I was visiting the CRHNet conferences all over Canada. I would above all like to thank Prof. David Etkin from York University, for the editorial work of some of the parts of the dissertation, Prof. Brenda L. Murphy of Wilfrid Laurier University (Brantford Campus) for het clarifying remarks and Prof. Ron Kuban of the Northern Alberta Institute of Technology for his many advices. Verder gaat mijn dank ook uit naar: Prof. dr. Wil Foppen en zijn medewerkers (Universiteit Maastricht) voor hun bereidwillige 
hulp tijdens de experimentenfase van de derde empirische studie, dr. ir. Ben Lauwens en dr. ir. Filip Van Utterbeeck (beide van de Koninklijke Militaire School) voor de vele goede raadgevingen, alsook de studenten van de Koninklijke Militaire School en van de Universiteit Maastricht voor hun bereidwillige medewerking aan de experimenten. Ook een woord van dank aan dr. Melvyn Hamstra (Universiteit Maastricht) en aan Prof. dr. Jeroen Stouten (Katholieke Universiteit Leuven) voor hun bijzondere nuttige tips na een 'friendly review' van de derde empirische studie in deze scriptie. Ten slotte wil ik ook alle personen bedanken die de tijd hebben vrijgemaakt voor een uitvoerig interview. Hun input was van onschatbare waarde tijdens de realisatie van de tweede empirische studie. Als ik van één zaak zeker ben, is dat ik in bovenstaande lijst een aantal personen ben vergeten benoemen. Mijn oprechte excuses hiervoor, maar mijn dank is hierdoor niet minder groot.

Sommige mensen hebben ogenschijnlijk niets met je proefschrift te maken. Toch ben ik ervan overtuigd dat zij een eervolle vermelding verdienen in dit dankwoord. Zo gaat mijn grootste dank en appreciatie uit naar mijn gezin. Mieke, Arne en Haakon, bedankt voor jullie uithoudingsvermogen tijdens de periode dat pa weer eens iets zou ondernemen. Door jullie directe en indirecte steun hebben jullie me er van overtuigd te geloven in mezelf, en vooral om door te zetten na een heel intense fase in ons leven (en vooral dat van jullie) eind 2015. Van harte bedankt. Ik draag dit proefschrift dan ook graag aan jullie op! 
About the author

About the author 
Hans De Smet was born on March, 1965 in Deinze, Belgium where he graduated at Sint Hendrikscollege in 1983. Subsequently, he started his studies at the Belgian Royal Military Academy (RMA), where he was rewarded with the Sword of the King in 1986. In 1989 he graduated and obtained his M.Sc. (Magna cum laude, with felicitations of the Minister of Defense) in Social and Military Sciences. After his studies, he served in several infantry units as an Army Officer. From 1999 until 2009, he was appointed as an equerry to His Majesty King Albert II of Belgium. After obtaining his M.Sc. in Public and Military Administration in 2005, he became an Assistant Professor at the Department of Economics, Management and Leadership of the RMA. In 2008, Hans started his academic research at the research pool "Risk, Crisis, and Disaster Management" of the RMA. Research topics are: the changing disaster landscape and the impact on society and intervening emergency management organizations, collaboration during emergency management operations, leadership and decision-making, etc. In 2010, he is elected as a Member of the board of Directors of the Canadian Risk and Hazards Network and in 2012, he is appointed as a member to the scientific committee of the Belgian Higher Institute for Emergency Planning. 


\section{Publications}

De Smet, H., Leysen, J., \& Lagadec, P. (2011). The Response Phase of the Disaster Life Cycle Revisited. In IIE 61st Annual Conference and Expo, Take your Career to new Heights (pp. 1-7). Reno, Nevada: Institute of Industrial Engineers. (rewarded Best Paper Competition Finalist)

De Smet, H., Lagadec, P., \& Leysen, J. (2012). Disasters out of the Box: A a New Ballgame? Journal of Contingencies and Crisis Management, 20, 138-148.

De Smet H. \& Leysen J. (2012). A Significant Evolution of the Disaster Landscape. In Lim G. \& Herrmann J.W. (Eds.), 2012 Industrial and Systems Engineering Research Conference (pp. 1-10). Orlando, FL.

(rewarded Best Paper Competition Finalist)

De Smet, H., Schreurs, B., \& Leysen, J. (2014). Facing the actual disaster landscape. A trend towards more Disasters out of the Box? In Etkin D. \& Murphy B.L. (Eds.), Disaster and Emergency Management in Canada (pp. 1-31). Vancouver, CA: CRHNET.

De Smet, H., Schreurs, B., \& Leysen, J (2015). The response phase of the disaster management lifecycle revisited within the context of 'disasters out of the box'. Journal of Homeland Security and Emergency Management, 12, 319-350.

De Smet, H., Schreurs, B., Uitdewilligen, S. \& Leysen, J (under construction). Tightening the reins or letting go: The importance of contingent team leadership when dealing with routine or non-utine situations. 